\title{
GLUCOSE TOLERANCE AND INSULIN RELEASE \\ IN MALNOURISHED RATS
}

By

Cyril Weinkove

A thesis submitted for the degree of Doctor of Philosophy in the Faculty of Medicine, University of Cape Town. 
The copyright of this thesis vests in the author. No quotation from it or information derived from it is to be published without full acknowledgement of the source. The thesis is to be used for private study or noncommercial research purposes only.

Published by the University of Cape Town (UCT) in terms of the non-exclusive license granted to UCT by the author. 
To Iiza 


\section{Part I}

1. The purpose and significance of this study 5

2. Some basic definitions and concepts 7

$\begin{array}{cc}\text { 3. The relationship between blood glucose and } & \\ \text { plasma insulin concentrations } & 15\end{array}$

4. The interpretation of in vivo experiments 20

5. A summary of Part I 25

\section{Part II}

6. Some pathological features of human

protein-calorie malnutrition

7. Glucose tolerance and insulin release in human protein-calorie malnutrition

8. Glucose tolerance and insuzin release in experimental animal models of proteincalorie malnutrition

\section{Part III}

9. The rat model 48

10. Experimental design 50

11. Assessment of the nutritional state of the rat model

12. Fasting blood sugar and plasma insulin concentrations

13. Intravenous glucose tolerance test 66

14. Oral glucose tolerance test 74

15. Intravenous insulin tclerance test 80

16. Glucose absorption from the gut 85

17. Portal venous glucose and insulin concentrations after an oral glucose load 
18. A brief summary of glucose tolerance in the protein-calorie deficient rat

19. Intravenous tolbutamide test

20. Intravenous glucose and aminophylline test

21. A short summary of pancreatic $\beta$ cell function tests in malnourished rats

22. Plasma and tissue potassium concentrations in protein-calorie malnourished rats

23. Light microscopic examination of the pancreas

24. A preliminary report on the ultrastructural changes in the pancreatic islets of malnourished rats

25.

Appendix A - Methods

Appendix B - Tables of individual results. 
ACKNOWLEDGMENTS

In a fit of optimism, Professor B.L. Pimstone employed me as a research worker in the Department of Medicine. Assisted by a grant from the Association of Round Tables of Southern Africa, I embarked on a more ambitious project than the present one. During those many frustrating months (or was it years?), I learnt something of laboratory techniques, statistics, desk-top computers and the fallibility of scientists. During that gloomy period only the enthusiasm of my supervisor kept me from entirely abandoning medical research. If I acquire nothing else other than some of Professor Pimstone's ability to detect the relevance of a new finding, to spot the weakness of an argument, to accept fair criticism and still maintain a lively interest in any new research venture, then the time spent has not been wasted.

I was encouraged to seek the advice of others and became a general nuisance in the Medical School and on the University campus. In return for their patience I would like to acknowledge the advice and criticism of the following:

Professor M.C. Berman (Department of Chemical Pathology), Professor L.C. Isaacson (Department of Physiology), Professor E.B. Dowdle (Department of Clinical Science), Dr. D. Becker (Departments of Medicine and Child Health), Dr. H. Sacks (Department of Medicine), Dr. J. du Plessis (South African Medical Research Council) and Mr. C. Melzer (Department of Physiology). 
Dr. R. Stead (Department of Biochemistry), as well as providing the original rat model on which all the investigations were conducted, answered a host of impertinent questions.

Dr. R.H. Hewlett (Departments of Anatomy and Pathology) introduced me to the art of histology and the science of playing chamber music (I prefer the latter).

Mr. C.J. Gouveia (Department of Pathology) taught me how to use a microtome, and Mr. V.M. Wells (Department of Medicine) cheerfully made innumerable bits of apparatus.

Mr. M. Green (Department of Mathematical Statistics) taught me the significance of statistics, while Professor G.v.R. Marais (Department of Civil Engineering) told me all I ever wanted to know about normal curve paper but was afraid to ask.

Dr. L.B. Kahn (Department of Pathology) and Dr. G. Milner (Department of Physiology) provided independent but surprisingly identical reports on the pancreatic histology.

Mr. J.R.P. Dale (Department of Pathology) prepared some preliminary electron photomicrographs of the pancreas. This task was later ably completed by Mr. F. Kennedy (Department of Physiology) and all the electron photomicrographs were reported on by Dr. A.H. Timme (Department of Pathology).

The animals were bred and housed in the Department of Medicine under the care of Mr. M. Stofile, Mr. M.F. Parker and Mr. G. Pillay. 
The invaluable assistance of $\mathrm{Mr}$. A. Isaacs and his deputy, Mr. D.C. Petersen, in the handling of the animals during the experiments, was much appreciated.

Mrs. M.J. McBlain typed the rough drafts to the detriment of her family, while Mrs. J. Wicks completed the final typing in record time. Mrs. I. Behm typed the tables in the appendix and Mr. S. Hendricks took the photographs.

I must include all the girls of the Isotope, Endocrine and Liver Laboratories who listened to my tales of woe and made me comforting cups of tea. To all these many people and those, whom in haste I may have omitted, thank you.

In gratitude for her invaluable help in every aspect of the work presented here, this included the preparation of graphs and the reading of the manuscript, I have dedicated this thesis to my assistant, Liza, who has since become my wife. 


\section{PART 1}

General introduction: aims, definitions and concepts

"When I use a word", Humpty Dumpty said, in rather a scornful tone, "it means just what I choose it to mean - neither more nor less".

"The question is", said Alice, "whether you can make words mean so many different things". "The question 1s", said Humpty Dumpty, "which is to be master - that's all".

Lewis Carroll

Through the Looking Glass. 
CHAPTER I

THE PURPOSE AND SIGNIFICANCE OF THIS STUDY

"..... Research-workers tend to present their results as if they were the outcome of systematic and orderly

progression. This fosters the tendency to overestimate the importance of planning in scientific research. This same tendency exists in all fields of human activity, and in retrospect each of us is apt to regard his actions and thought processes as rational. We readily deceive ourselves that our convictions are the logical consequence of a continuous and reasonable train of thought."

Dr. N. Howard-Jones (1947)

The results; discussion and conclusion of this work will, I trust, be expressed in a systematic and orderly progression to ease the way for the reader.

I confess, however, in agreement with Dr. Howard-Jones, that the aims of this study only became apparent when all the results were analysed. These were:

1. to study the effects of a protein-calorie deficient diet on glucose tolerance in young rats,

2. to determine if there were any significant differences in the insulin responses of malnourished as compared to well-nourished animals, following the administration of glucose and other agents known to promote insulin release, 3. to evaluate, as far as is possible in an in vivo study, the mechanism of any abnormality or anomaly revealed. 
"Malnutrition has been identified as the world's number one health problem and is associated with more deaths and disease than the occasional famines"

\section{Alan Berg (1973)}

"Protein deficlency in man or monkey affects all cells and tissues of the body, but they are not all affected at the same time nor at the same rate..... Organs with a high protein or high cell turnover bear the brunt of the body response in the early stages of protein depletion; they show rapid and extensive alteration".

V. Ramalingaswami (1969)

This work ignores the global nature of the problem of protein-calorie malnutrition, but concentrates on one small aspect, viz. protein-calorie malnutrition and its effects on early insulin release and glucose tolerance.

The demonstration of impaired glucose tolerance and diminished early insulin release in the protein-calorie malnourished rat is not surprising, considering the protean effects of this abnormal condition. The significance of this work lies in the study of the mechanisms involved, the questions raised, and in the possibility of extrapolation to other pathological states. 


\section{CHAPTER 2}

SOME BASIC DEFINITIONS AND CONCEPTS

The terms malnutrition, glucose tolerance, and insulin release have already been introduced in the title of this work. Some of these definitions will appear too vague to the purist. Unfortunately this is the way in which they have been used by biologists. In fact, the imprecision of many of these terms will be stressed.

1. NUTRITION

Starvation is defined as a complete deprivation of food or a drastic reduction in food intake over a period of time leading to severe physiological, functional, behavioural and finally morphological disturbances. Malnutrition is the pathological state resulting from a relative or absolute deficiency or an excess in the diet of one or more essential nutrients. Most workers use this term synonymously with undernutrition, which is the pathological state caused by an inadequate diet over a prolonged period of time causing a reduction of body weight. Malnutrition, when referred to in this thesis, implies undernutrition and not overnutrition.

Two commonly used terms in the description of malnourished children are marasmus and kwashiorkor. McCance (1968) has defined marasmus as being due to an insufficiency of all food, and kwashiorkor as being caused by a diet deficient in protein but "potentially high in 
calories". Both are characterised by failure to gain weight with kwashiorkor including some or all of the following signs:

oedema, dermatosis, hepatomegaly, hair changes and mental apathy. Hypoproteinaemia and periportal fatty infiltration of the liver are regarded as characteristic of kwashiorkor. However, kwashiorkor and marasmus are but two ends of ' a broad spectrum of protein-calorie malnutrition (PCM) which includes marasmic kwashiorkor (or marasmus with oedema).

\section{GLUCOSE TOLERANCE}

In the fasted state the blood glucose concentration remains relatively constant, indicating that glucose production is equal to glucose utilisation. Many hormones are involved in glucose homeostasis, including insulin, glucagon, epinephrine, growth hormone and cortisol. In overt diabetes mellitus where glucose production exceeds utilisation, the diagnosis suspected on the history (weight loss, polyuria and polydypsia), is confirmed on demonstrating fasting hyperglycaemia with or without ketoacidosis. It would appear reasonable to assume that prior to this gross pathological state, there should exist phases where the individual is able to maintain a normal fasting blood sugar but yet be incapable of coping "normally" with a glucose load. This forms the basis of the glucose tolerance test.

Glucose intolerance may be defined as an impairment in the ability to dispose of a glucose load administered 
either orally or intravenously. Though the concept is simple, in practice it is difficult to define "normal glucose tolerance".

From a recent review by Duffy et al (1973), it appears that:

(i) borderline cases appear frequently,

(ii) because of this, there is as yet no single test that can clearly divide the general population into an abnormal and normal group,

(iii) the demonstration of an abnormal glucose tolerance test does not imply inevitable diabetes mellitus. This should not be surprising in view of the many factors involved in the maintenance of glucose homeostasis. The number of clinical states associated with glucose intolerance is becoming embarrassingly large. These include advancing age, liver disease, hyperthyroidism, myocardial infarction, azotemia, burns, starvation, obesity, in addition to protein-calorie malnutrition.

\section{INSULIN RELEASE}

Insulin release can only be defined in terms of the method used for its investigation. A sudden increase in plasma concentration of insulin following some stimulus is reported by the clinical research worker as insulin release. The laboratory worker determines insulin release by measuring the increase in insulin concentration in a medium containing pancreatic islet tissue. Degranulation of the beta cells of the pancreatic islets is the evidence of. insulin release used by the histologist. 
The results of all three methods of assessing insulin release, though often in agreement, may sometimes differ. To measure insulin release recent investigators have used the immunoassay technique of Yalow and Berson (1960) in place of the less specific bioassay methods employing the rat epididymal fat pad (Martin et al, 1958) or the rat diaphragm (Vallance-Owen and Wright, 1960).

A short survey of the different methods of investigating insulin release follows. 
A. METHODS OF INVESTIGATING INSULIN RELEASE

1. In vivo methods

(a) Measurementsof plasma insulin are taken at varying time intervals following a given stimulus. By measuring the "area under the curve" after plotting insulin concentration against time, an index of total insulin release is obtained. However no account is taken of hepatic degradation of insulin, tissue removal of insulin and the effects of dilution in the extracellular fluid.

(b) Measurement of portal insulin in man or animals avoids the problem of hepatic extraction and gives a better index of insulin release.

\section{In vitro techniques}

(i) Perfusion of the intact pancreas provides a useful method of testing the effects of various agents on the whole pancreas.

(ii) Incubation of pancreatic slices, which includes acinar tissue as well as the beta and alpha cells of the islets, is perhaps easier to perform. But, because of the presence of acinar tissue which contains degradative enzymes, one can not be certain that the insulin is not being broken down during the course of incubation.

(iii) Incubation of pancreatic islets avoids the lastmentioned problem since the system now contains only alpha and beta cells with no acinar tissue.

(iv) Incubation of cultured foetal pancreatic tissue which contains no alpha cells provides a system whereby one can test the effect of the stimulus on a pure beta 
cell preparation.

In all the incubation systems described under (ii), (iii) and (iv) above, there is the possibility that insulin released into the medium might inhibit further insulin release by the beta cells. To overcome this problem:

(v) perifusion of pancreatic islets has been used. In this system-isolated islets are placed in small chambers through which suitable buffers are allowed to run without recirculation.

The methods described above and the results obtained have been extensively reviewed by others (Mayhew et al, 1969; Martin, 1969). Some of the factors shown to influence insulin secretion will be discussed later with the results of the relevant investigations.

It may be pointed out now that glucose is still the major stimulus of insulin secretion in the mammalian pancreas and that various stimuli give different results depending upon the in vitro system used. Some stimuli require the presence of intact alpha cells or intact acinar tissue to be effective in provoking insulin release.

\section{B. MECHANISM OF INSULIN RELEASE}

1. A morphological description

The actual'mechanical mechanism of insulin release has been reviewed by Lacy (1970). As a result of electron microscopic studies, he proposed the following model:

(a) Intraceliular glucose metabolism signals the initiation of proinsulin synthesis in the endoplasmic reticulum. 
(b) Proinsulin is then transferred to the Golgi complex, where proinsulin is converted to insulin and beta granules formed.

(c) Mature beta granules are released into the cytoplasm and become attached to a microtubular system.

(d) Glucose metabolism initiates the entry of calcium into the cell which triggers a change in the physical conformation of the microtubules and results in displacement of the granules to the cell surface, where they are released by emiocytosis.

\section{A biochemical description}

Renold (1970) in his review has stressed the complexity of the mechanism of insulin biosynthesis and secretion. Biochemical evidence suggests that the stimulation of insulin release involves a multicomponent system including (i) cyclic 3'5'-AMP, (ii) alpha and beta autonomous nervous receptors, (iii) at least two types of substrate effects a general one, coming from any one of the three major body fuels (carbohydrates, fats and proteins), and a specific one, perhaps an intermediate of the direct oxidation of glucose-6-phosphate, (iv) a final common pathway requiring the presence of $\mathrm{Ca}^{++}$ions and modified by the relative concentration of other cations including $\mathrm{Na}^{+}$and $\mathrm{K}^{+}$.

\section{A kinetic description}

Porte (Porte and Pupo, 1969; Porte and Bagdade, 1970) has shown that a two-compartment model of insulin release could best explain the effects of glucose stimulation. Thus an "acute response pool" releases its insulin in 
response to a sudden change in glucose concentration, whereas a "chronic response pool" is the source of the sustained insulin release during prolonged glucose infusion.

Whether or not one believes that insulin is secreted from two or more distinct compartments is immaterial, but. the concept assists in understanding the relationship between glucose tolerance and insulin release. 
CHAPTER 3

THE RELATIONSHIP BETWEEN BLOOD GLUCOSE

AND PLASMA INSULIN CONCENTRATIONS

The central role played by insulin in glucose homeostasis has been reviewed by others (Levine and Haft, 1970; Cahill, 1971; Hetenyi, 1971) and the importance of glucose as a stimulus of insulin release stressed (Mayhew et al, 1969). It is not surprising therefore that a relationship was sought and found between the plasma glucose and the plasma insulin level (Metz, 1960).

During prolonged fasting and after intravenous glucose administration, Cahill and Soeldner (1969) were able to show a linear relationship between the immunoreactive insulin levels and the blood sugar levels in normal subjects. This relationship broke down however, during oral glucose administration. Computer models describing the relationship between these two parameters have been devised by many workers (Cerasi, 1967; Charette et al, 1969; Riggs, 1970), in an attempt to quantitate this relationship. If oral and intravenous glucose intolerance were always associated with diminished concentrations of plasma insulin, there would be no problem in the interpretation of the relationship between glucose tolerance and plasma insulin levels. With the discovery by Yalow and Berson (1960) that maturity onset diabetics (unlike juvenile diabetics) had normal or perhaps elevated fasting plasma insulin levels despite glucose intolerance, attempts to relate these two parameters have led to a great deal of 
confusion. Thus MCKiddie et al (1969), studying a large group of diabetics explained their findings of a significant inverse correlation between insulin response and the severity of carbohydrate intolerance by claiming that "the factor which appears to be most important in determining the height of the insulin response to glucose is the severity of the glucose intolerance."

Attempts to show that the higher than normal plasma insulin levels in maturity onset diabetics vere inappropriately low for the high level of blood sugar, have led to the use of a number of ratios between insulin and glucose concentrations. Perley and Kipnis (1966) divided plasma insulin concentration by the blood glucose concentration and found this I/G ratio to be lower in diabetics than normals. Seltzer et al (1967) used an empirical "insulinogenic index" obtained by dividing the increase in plasma insulin concentration above the fasting concentration, by the corresponding net increase of blood glucose concentration to show the same abnormality in diabetics. These ratios are of more than theoretical interest as a diminished ratio (insulinogenic index or $I / G$ ) has been used as evidence for diminished insulin release in diabetes.

The use of these ratios has been criticised by Peterson and Reaven (1971), who have shown that an increase in the oral glucose load results in a greater insulin release without a correspondingly large increase in plasma glucose concentration in normal subjects. Therefore, an 
increase in the glucose load resulted in an increase in the I/G ratio suggesting that it is glucose load, rather than the glucose concentration which determines the magnitude of the plasma insulin response.

olefsky et al (1973a) obtained similar results using constant glucose infusions in anaesthetised dogs to show that the glucose load rather than the plasma glucose concentration próduced changes in plasma insulin concentrations. Their results "suggested that the level of blood glucose may not be the primary determinant of the insulin response to glucose during the chronic phase of insulin secretion". To explain the high plasma insulin concentrations and glucose intolerance in the maturity onset diabetics, one must return to the original suggestions made by Yalow and Berson (1960). They proposed the following possibilities:

(1) abnormal tissues with a high threshold for the action of insulin,

(2) abnormal insulin that acts poorly with respect to hormonal activity in vivo, but reacts well immunologically in vitro,

(3) an abnormally rapid inactivation of hormonally active sites, but not of immunologically active sites on the insulin molecule and,

(4) the presence of insulin antagonists. It becomes necessary to define now a number of new terms. Insulin resistance and insulin sensitivity Insulin resistance implies a lower than normal rate 
of fall of the blood sugar level following the administration of exogenous insulin. The converse, insulin sensitivity, would be demonstrated by an increase in the rate of fall of blood sugar concentration during the insulin. tolerance test (Cerasi and Luft, 1969; Frohman et al, 1972).

It is generally accepted that insulin resistance as defined above is often associated with fasting hyperinsulinaemia (Berson and Yalow, 1965; Porte and Bagdade, 1970; Goldfine et al, 1973). High fasting concentrations of plasma insulin are often used as evidence for insulin resistance, although Frohman et al (1972) have questioned this concept.

Olefsky et al (1973b) assessed the degree of insulin resistance to exogenous insulin by measuring the steady state plasma glucose concentration, during the infusion of glucose plus insulin. with epinephrine and propranolol. The last two mentioned reagents inhibit the release of endogenous glucose and insulin. Thus similar circulating levels of exogenous insulin were achieved in all their subjects and the steady state plasma glucose concentration was used as a measure of resistance to insulin mediated glucose transport. They showed a highly significant $(p<0.0001)$ correlation between the fasting plasma insulin concentration and the degree of insulin resistance as they have defined it above.

In this thesis the rate of decline in the blood glucose concentration, after intravenous insulin administration, has been used as an index of insulin sensitivity. The 
demonstration of a high fasting plasma insulin concentration in the presence of a normal (or high) fasting blood glucose concentration has also been used as evidence of insulin resistance.

Other workers (Heard and Henry, 1969a; Alleyne et al, 1972) have used the rate of fall of blood glucose concentration following the administration of glucose plus insulin $(\mathrm{Kg}+1)$ as their index of insulin resistance. However, $\mathrm{Kg}+\mathrm{i}$ has not been substantiated as an index of insulin resistance and its use has produced some anomalous results.

Much of the confusion about insulin resistance arose from the failure of investigators to demonstrate a relationship between insulin release and intravenous glucose tolerance. This may have been due to a delay in taking samples for the determination of plasma insulin concentrations, or due to attempts to relate glucose tolerance to the total insulin response.

Lerner and Porte (1971) have shown that it is the acute insulin response (the insulin peak 3 - 5 minutes after an intravenous glucose load), which correlated best with $\mathrm{Kg}$ (the glucose disappearance rate). The total insulin response measured, throughout the intravenous glucose tolerance test correlated poorly with $\mathrm{Kg}$. 
THE INTERPRETATION OF ' IN VIVO ' EXPERTMENTS

At a time when everyone else perfuses isolated organs, incubates bits of tissue, or assays enzymes in submicroscopic particles, no apology will be offered for the fact that most of these studies were performed in the intact animal. On the simple principle that the whole is often more (or different) to the sum of its individual parts, an in vivo study is still the final testing ground of the relevance of more sophisticated experimentation.

There are, however, certain problems, peculiar to the interpretation of in vivo studies of insulin release. These are dealt with below.

In comparing the response of different groups of animals to various stimuli, peripheral plasma insulin levels have been used as an index of insulin secretion from the pancreas. However, as has been pointed out by others (Mayhew et al, 1969; Wright, 1972), changes in the peripheral insulin values depend on:

(1) The volume of distribution of insulin,

(2) The rate of removal of insulin by the liver and other tissues,

(3) The rate of insulin secretion by the beta cells of the islets.

It is, therefore, necessary to show that factors (1) and (2) above are similar in all groups of animals before ascribing changes in peripheral plasma insulin levels to the rate of insulin secretion by the pancreas. 
1. The volume of distribution of insulin

The volume of distribution of a substance (S) is

defined by Riggs (1963) as the volume of solution which, if it had a uniform concentration would contain the same total amount of $S$ as is distributed about the entire system at equilibrium, i.e. when there is no net transfer of $S$ between compartments.

It has been shown that both in the rat (Rasio et al, 1965) and in man (Rasio et al, 1967), both immunoreactive insulin and glucose equilibrate rapidly with the interstitial fluid. In man the mean volume of insulin distribution was found to approximate $26 \%$ of body weight for an inulin space of $23 \%$, while the glucose space was found to be $34 \%$ of body weight (Rasio et al, 1967).

The glucose space measured with a constant infusion technique in normal and diabetic dogs (Searle et al, 1954), was found to be of the order of $30 \%$ of the dog's weight, in accord with the assumption that glucose was distributed over the extracellular space. Injection of insulin into diabetic dogs did not affect glucose space in these studies.

From the above one may conclude that glucose and insulin equilibrate rapidly with the extracellular space, and that it is reasonable to use the glucose space as an index of the extraceliular space.

Berson and Yalow (1965) have also reported that insulin has a volume of distribution similar to the extracellular fluid volume. 
2. The rate of disappearance of insulin from the plasma

Samols and Marks (1966) measured the disappearance rate of endogenous insulin in humans after prolonged intravenous infusion of glucose plus glucagon, and obtained results that were close to those of Ørskov and Christensen (1966) who measured the half life of exogenous human insulin. Rasio et al (1967) obtained similar results using the endogenous insulin disappearance rate after intravenous glucose administration.

Although giving no information as to which tissue is predominantly responsible for insulin removal, this simple method does give some indication of the total removal rate of insulin from the extracellular compartment. In this study, the endogenous insulin disappearance rate after intravenous glucose has been compared in two different groups of animals, and assumed to be a measure of insulin degradation.

Do peripheral plasma insulin levels reflect portal insulin concentrations?

Blackard and Nelson (1970) catheterised the portal vein in humans and found a significant positive correlation between portal vein and peripheral vein plasma insulin concentrations in response to glucose infusion. This positive correlation was also found in diabetics (Blackard and Nelson, 1971).

Erwald et al, (1973) have shown that in patients with pancreatitis, a low increase in the peripheral venous plasma insulin concentration after oral glucose loading, was not invariably accompanied by a poor insulin concen- 
tration in the portal blood. The fractional reduction of insulin concentrations between the portal and the peripheral venous blood was not constant, but tended to be higher at a high than at a low portal insulin concentration.

Portal vein insulin concentrations, after oral glucose, have been measured in this work and show that the peripheral insulin concentrations do reflect pancreatic vein insulin concentrations.

However, because of the reported fluctuations in the hepatic insulin extraction rate, it was felt inadvisable to calculate total insulin release from peripheral plasma insulin concentrations, but limit the study to the early insulin release.

\section{$\underline{\text { Summary }}$}

Experimental evidence is quoted to indicate

(1) that insulin and glucose equilibrate rapidly (within 10 minutes) with interstitial fluid and

(2) both appear to have similar volumes of distribution equivalent to the volume of the extracellular fluid compartment.

(3) Peripheral plasma insulin levels parallel the changes in portal insulin concentrations after intravenous glucose loading in both normal and diabetic humans.

(4) However, after an oral glucose load, at least in pancreatitics, the fraction of insulin extracted by the liver is not constant.

It would thus appear reasonable to assume that early 
changes in peripheral plasma insulin concentrations reflect changes in the rate of insulin secretion from the pancreas, but that total insulin release could not be calculated from peripheral plasma insulin concentrations because of possible variations in hepatic extraction of insulin. 


\section{CHAPTER 5}

A ' SUMMARY OF PART I

The aims and significance of this study have been stated and some terms and concepts defined. It should immediately be obvious that there is ample scope for confusion

(a) in defining the types of malnutrition that exist,

(b) in defining glucose tolerance,

(c) in defining and measuring insulin release, and

(d) in attempting to relate glucose tolerance to insulin release.

The following decisions were made on the basis of information provided in this Introduction.

(1) To avoid confusion, one group of animals would be arbitrarily designated as having normal glucose tolerance and insulin release. All other groups would be compared to this group.

(2) Since plasma insulin and blood glucose concentrations would be compared directly, and since all stimuli would be given in a dose related to body weight, it would be necessary to demonstrate similarity of

(a) total body water content and

(b) extracellular fluid volume

in these animals.

(3) Since insulin release may be provoked by many drugs, hormones and metabolites, and since they may act via different biochemical mechanisms, it was decided to use 
more than one stimulus of insulin release.

(4) Since the early change in insulin concentration was most important in determining glucose tolerance, early sampling would be necessary after oral and intravenous glucose.

(5) Since the beta cell of the pancreas is the final pathway of insulin release, it becomes important to assess their number and integrity in the groups of animals to be investigated. 


\begin{abstract}
PART II
Protein-calorie malnutrition: A review of the literature

"I don't think they play at all fairly", Alice began, in rather a complaining tone, "and they all quarrel so dreadfully one can't hear oneself speak - and they don't seem to have any rules in particular; at least, if there are, nobody attends to them - and you've no idea how confusing it is all the things being alive".
\end{abstract}

Lewis Carroll Alice's Adventures in Wonderland. 
CHAPTER 6

$\frac{\text { SOME PATHOLOGICAL FEATURES OF HUMAN }}{\text { PROTEIN-CALORIE MALNUTRITION }}$

No attempt will be made to give an account of all the pathological features of human protein-calorie malnutrition, since these have been adequately reviewed by others (Trowell et al, 1954a; Jelliffe, 1959). Instead changes in two organs, the pancreas and the liver, are described and their possible relationship discussed. The Liver

Waterlow (1948) and Davies (1948) have described fatty infiltration of the liver in human malnutrition. In severe cases, fat may be found in nearly every hepatocyte and fat may constitute as much as $50 \%$ of the wet liver weight (Waterlow, 1948). In less severe cases fatty infiltration of the liver is believed to begin with the accumulation of small aroplets in the cells at the periphery of the lobule, and then spread to involve cells in the centrilobular region. So characteristic is the lesion, that Davies (1948) would suspect a complicating illness if fatty infiltration of the liver was found to be predominantly centrilobular in distribution. Although round cell infiltration of the portal tract has been described (Campbell, 1956); it is uncertain whether fatty infiltration does eventually lead to cirrhosis (Trowell et al, 1954b).

The Pancreas

Normet (1926) is reported in a recent review 
(Pitchumoni, 1973) to be the first to note pancreatic atrophy in children dying of kwashiorkor. Changes in the exocrine pancreas were also observed by Waterlow (1948) in the British West Indies, by Davies (1948) in Uganda, Véghelyi et al (1950a) in Hungary and Campbell (1956) in South Africa. These changes are reported to progress from simple atrophy of the acinar cells to hyaline changes and tubular dilatation, and to end eventually in extensive loss of acinar tissue with pancreatic fibrosis (Davies, 1948). Numerous reports of diminished pancreatic exocrine function in malnutrition, as reviewed by Pitchumoni (1973), appear to corroborate the pathological changes described in the exocrine pancreas.

$\underline{\text { Pancreatic Islets }}$

While most workers have agreed that the acinar tissue is abnormal in human protein-calorie malnutrition, reports on the pancreatic islet tissue have been scanty or conflicting. Davies (1948) reported islet hypertrophy and possibly hyperplasia in the early stages, with disappearance of pancreatic islets later. Camain and Pierchon (1954) reported a true increase in the size of the islets with a decrease in the number of alpha cells and an increase in the number of beta cells. Campbell (1956) and Véghelyi (1950a) reported that islet tissue was not affected, while others (Bras et al, 1956; Ramalingaswami, 1969) have made no comment on the pancreatic islet tissue at all. Trowell et al (1954c) commenting on some of the earlier work which had suggested either islet atrophy or islet hypertrophy, said 
that the "islets do not seem to have actually been measured and no cytologic changes have been mentioned".

What is the relationship between the pancreatic and hepatic changes in protein-calorie malnutrition?

Davies (1948) pointed out that while acute kwashiorkor was associated with fatty infiltration of the liver, in the later stages of the disease this pathology was not obvious. Recalling that fatty infiltration of the liver had been described in pancreatectomised dogs kept alive with diet and insulin, he felt that it was the loss of the exocrine pancreatic tissue that caused the fatty changes in the liver. Bras et al (1956) did a careful statistical analysis of the relationship between hepatic fatty infiltration, pancreatic pathology, renal pathology and clinical malnutrition. They concluded that there was a positive association between the presence of malnutrition and pancreatic pathology, irrespective of the presence or absence of fatty change of the liver. It would appear from the above that the pancreas was more sensitive to the effects of malnutrition than the liver.

A possible mechanism relating pancreatic damage to fatty infiltration of the liver

Since the pancreatic damage described in malnutrition preceded fatty infiltration of the liver, a causal relationship between the two was sought. Gillman and co-workers (Gillman and Gilbert, 1958; Gillman et al, 1962) have demonstrated a massive increase in hepatic fatty infiltration of the liver within 48 hours of discontinuing insulin treatment in pancreatectomised dogs. They suggested that 
diminished pancreatic endocrine function caused fatty infiltration of the liver. By changing the endocrine environment e.g. by hypophysectomy, or administration of cortisol and thyroxine, they were able to alter the degree of fatty infiltration in the liver after discontinuing insulin therapy in pancreatectomised baboons (Gillman et al, 1962). This would suggest that endocrine function in general, and pancreatic beta cell function in particular, play some role in the pathogenesis of fatty infiltration of the liver.

\section{A possible relationship between the pancreatic} exocrine and endocrine function

The acinar tissue, rather than the islet tissue of the pancreas, appears to bear the brunt of the pathological changes found in protein-calorie malnutrition. However, diminished pancreatic islet function has been suggested as the cause of the fatty liver of malnutrition. It may be argued that the islets, though histologically normal, are functioning poorly, and that healthy exocrine pancreatic tissue is necessary for normal pancreatic endocrine function. In fact it has been shown that patients with known exocrine pancreatic dysfunction did not have a normal insulin response to oral glucose, although their insulin response to intravenous glucose was normal (Raptis et al, 1971). Since oral glucose has been shown to stimulate the release of gut hormones and these hormones stimulate insulin release (Youngs, 1972), Raptis and co-workers (1971) suggested that healthy exocrine pancreatic tissue appeared to be 
necessary for the normal insulin response to these gut hormones. Experimentally induced pancreatic exocrine insufficiency in rats impaired theirinsulin response to secretin without affecting their insulin response to pancreozymin and glucose (Goberna et al, 1971). It may be concluded from this experiment that at least one intestinal hormone, secretin, requires the presence of intact exocrine tissue to produce its effect on insulin secretin.

\section{Infection in protein-calorie malnutrition}

Campbell (1956) found from his necropsy experience that infections played a predominant role in precipitating the malnourished child into serious illness and eventual death. In 31 of the 40 children he examined, the lungs showed microscopical evidence of pyaemic abscesses or bronchopneumonia with or without abscess formation and pleurisy. Pyaemic abscesses were found in the kidneys of 3 children. Since clinical evidence of infection was not apparent in many of these cases, antibiotic administration has since become part of the routine treatment of children with severe protein-calorie malnutrition in Cape Town (Hansen, 1968). Infection may also play an important part in the pathology of human protein-calorie malnutrition, since toxins have been shown to induce pancreatic and hepatic damage in well-nourished animals (Vêghelyi et al, 1950b). 


\section{SUMMARY}

I. Fatty infiltration of the liver and acinar atrophy of the pancreas occur frequently in human protein-calorie malnutrition.

2. 'There is some evidence to suggest that the pancreatic pathology precedes the hepatic damage and may even cause it. 3. Abnormal pancreatic endocrine function has been implicated in the pathogenesis of fatty infiltration of the liver.

4. Reports on pancreatic islet pathology are sometimes conflicting but most often negative.

5. Infection has been reported to occur frequently in human protein-calorie malnutrition and may contribute to both the hepatic and pancreatic pathology described. 


\section{CHAPTER 7}

GLUCOSE TOLERANCE AND INSULIN RELEASE 'IN HUMAN PROTEIN-CALORIE : MALNUTRITION

While there appears to be general agreement that protein-calorie malnutrition is associated with glucose intolerance and diminished insulin release (Milner, 1972), conflicting reports do however appear in the literature. It is the intention in this short review to draw attention to the differences either in the results or in the conclusions of some workers in order to:

1. Stress the problems of interpreting glucose tolerance and insulin release in human malnutrition.

2. Indicate the necessity for animal experimentation.

\section{A. Differences in the patients selected for study}

Some investigators have confined their study to patients with either marasmus (Tisdall et al, 1925a; Brown, 1925; Oxman et al, 1968) or kwashiorkor (Slone et al, 1961; Baig and Edozien, 1965).. In some studies children with marasmus and kwashiorkor are included and distinctions drawn between the results (Bowie, 1964; Hadden, 1967), while in other investigations the two groups are combined and no distinction made in reporting results (Alleyne and Scullard, 1969; Milner, 1971a; Milner, 1971b; Becker et al, 1971; Alleyne et al, 1972).

B. Differences due to the nature and interpretation of the tolerance test used

Glucose tolerance tests have been used in studies in human malnutrition for a number of reasons: 
1. As a test of glucose absorption from the gut (Brown, 1925; Tisdall, 1925a).

2. As an index of liver function (Holmes and Trowell, 1948; Niemeyer and Meneghello, 1950).

3. As an index of pancreatic beta cell function (James and Coore, 1970a; Becker et al, 1971; Milner, 1971a). Since many extrapancreatic factors influence oral glucose tolerance it is not surprising that results are difficult to interpret. Oral glucose tolerance has been described as either normal (Brown, 1925; Tisdall, 1925a), flat (Bose et al, 1946; Chaudhuri, 1948), persistently abnormal (James and Coore, 1970a), or variable (Baig and Edozien, 1965; Becker et al, 1972) in malnourished patients.

In view of the variability of oral glucose tolerance between individuals even in one study (Baig and Edozien, 1965), and the reported malabsorption of glucose in malnutrition (James,1968), the intravenous glucose tolerance test has been used most commonly. (Slone et al, 1961; Bowie, 1964; Hadden, 1967; Oxman et al, 1968; Milner, 1971a; Alleyne et al, 1972). Becker et al (1971) performed oral and intravenous glucose tolerance tests in malnourished children. They calculated I/G ratios in an attempt to relate the insulin response to the glycaemic. stimulus (see Chapter 3).

C. Differences in the selection of control patients

Both the oral and intravenous glucose tolerance tests must be interpreted in terms of some "normal" standard. Some investigators have used patients as their 
own controls comparing glucose tolerance or insulin responses before and after treatment (Milner, 1971a; Becker et al, 1971), while others have compared their malnourished subjects with a different group of children, previously malnourished but now recovered (Alleyne and Scullard, 1969; Milner, 1971b; Alleyne et al, 1972). Other investigators have compared their malnourished children with well-nourished subjects from the same general population (Bowie, 1964; Cook, 1967; Oxman et al, 1968; James and Coore, 1970a). Differences in the selection of control patients account for some of the differences in results.

D. The problem of intercurrent illness

Infection is a common complication of malnutrition (see Chapter 6) and has been shown to have an effect on glucose tolerance (Tisdall, 1925b). Improvement in glucose tolerance and insulin release after treatment in hospital may reflect the efficacy of antibiotic treatment, often given routinely (Hansen, 1968; Alleyne and Scullard, 1969), rather than the improvement in nutritional status. Becker et al (1971) excluded patients with overt infection. However postmortem' material from the same hospital (Campbell 1956) has shown that infective processes may not be obvious clinically.

E. Problems caused by indirect methods of study

Ethical considerations limit the number and nature of tests that may be performed on young children. Thus indirect methods have been devised which are often difficult to interpret. The use of the oral glucose tolerance 
test as an index of glucose absorption has already been mentioned and the intravenous glucose tolerance test has been used as an index of liver function (Niemeyer and Meneghello, 1950).

A comparison of the glucose disappearance rate after the administration of glucose alone $(\mathrm{Kg})$, and after the administration of glucose plus insulin ( $\mathrm{Kg}+\mathrm{i}$ ) has been used as an indexof insulin sensitivity. Bowie (1964) found that $\mathrm{Kg}$ was equal to $\mathrm{Kg}+\mathrm{i}$ in kwashiorkor. Since additional insulin did not increase the glucose disappearance rate, he deduced that the impairment of intravenous glucose tolerance was not due to insulin lack but rather reflected insulin resistance. In his study however, $\mathrm{Kg}+\mathrm{i}$ values were not determined in the control paijents. Alleyne et al (1972) found that $\mathrm{Kg}+\mathrm{i}$ was greater than $\mathrm{Kg}$ in both control and malnourished children, but since the $\mathrm{Kg}+\mathrm{i}$ of the latter was lower than the $\mathrm{Kg}+\mathrm{i}$ of the controls, he assumed that malnourished children were insulin resistant.

Insulin resistance (Chapter 3) has been defined as the rate of fall of blood glucose concentration following insulin alone. The biological significance of the glucose disappearance rate following the administration of glucose plus insulin hasnot yet been determined and should not be used as a test of insulin resistance. Nor is insulin resistance compatible with the low fasting blood sugar in the malnourished children reported in the same paper (Alleyne et al, 1972) and the low fasting plasma 
insulin concentrations found in malnourished children from the same unit (James and Coore, 1970bl.

F. Other causes of conflicting reports

Regional genetic and dietetic factors may account for some of the reported differences in glucose tolerance and insulin release. The differences in methodology also play a part. Thus Baig and Edozien (1965) measured plasma insulin levels 15 minutes after intravenous glucose, at a time when the plasma insulin level had already fallen. Hadden (1967) measured only fasting plasma insulin concentrations, but this is a poor index of beta cell function. Discrepancies within the same unit, will not be discussed (see glycaemic response to glucagon - Alleyne and Scullard (1969) and Milner (1971a).

A summary of some of the effects of protein-calorie malnutrition on glucose tolerance and insulin release

1. Differences between patients with marasmus and kwashiorkor

Where intravenous glucose tolerance tests have been compared directly in patients with marasmus and kwashiorkor (Bowie, 1964; Hadden, 1967) glucose intolerance was found only in the latter group. In the paper by Hadden (1967) it appears that children with marasmus had a significantly lower age and weight than those with kwashiorkor. Oxman et al (1968) found marasmic children to have impaired intravenous glucose tolerance. Since the clinical and biochemical differences between these groups are not always clear, recent investigators have combined their cases of 
kwashiorkor and marasmus.

2. Insulin release

When adequately performed, tests of insulin release have been shown to be impaired in protein-calorie malnutrition (James and Coore, 1970a; Milner, 1971a; Becker et al, 1972; Milner, 1972). James and Coore (1970a) regarded the impairment of insulin release as being a permanent one, Becker et al (1971) reported that most patients improved within 3 months. They demonstrated that "healthy" patients, who had been admitted to hospital for malnutrition 10 years previously, had normal insulin release when compared with their siblings. However, both the previously malnourished group and their siblings were below "normal" weight.

\section{Insulin resistance}

Evidence of insulin resistance in protein-calorie malnutrition is poor being based either on indirect evidence (Bowie, 1964; Alleyne et al, 1972) or on selected cases from a large group (Becker et al, 1972).

\section{Conclusion}

It may be generally accepted that glucose intolerance and diminished insulin release occur commonly in patients with protein-calorie malnutrition. However, these studies do not reveal the cause of the glucose intolerance since other factors such as an intercurrent illness may be responsible for the glucose intolerance and diminished insulin release. 
Different workers vary in the type of patients they select for study and for use as controls. This, as well as regional, genetic or dietetic factors may account for some of the discrepancies in the literature. Differences in experimental methodology, and the use of indirect methods for the determination of glucose absorption or insulin resistance, have only added to the confusion.

Consideration of all these problems must lead one to conclude that investigations on experimental animal models of protein-calorie malnutrition are fundamental to our understanding of the relationship between glucose tolerance, insulin release and nutritional status. 


\section{CHAPTER 8}

$\frac{\text { GLUCOSE TOLERANCE AND INSULIN RELEASE }}{\text { IN : EXPERTMENTAL : ANIMAL MODELS OF PROTEIN- }}$

There are limitations both as to the number and nature of investigations that may be conducted in malnourished humans. Furthermore, human protein-calorie malnutrition is often complicated by infections and these alone may produce glucose intolerance. The duration of malnutrition and the nature of the diet of the individual children is often uncertain. These constitute the main indications for the use of experimental animal models of proteincalorie malnutrition, the advantages of which are summarised below:

1. A homogeneous population may be studied,

2. The composition of the diet is known,

3. The age at onset and duration of the dietary deficiency is known,

4. Potentially hazardous investigations may be performed on animals,

5. Animals may be killed in order to analyse body constituents.

Despite these advantages many of the inherent defects of human studies have not been corrected in animal investigations. Two possible reasons for this are:

1. Attempts on the part of the investigator to produce all the clinical, biochemical and pathological features of protein-calorie malnutrition in experimental animals, 
2. The use of indirect methods of investigation.

1. Attempts to reproduce all the features of human protein-calorie malnutrition in experimental animals

Investigators have gone to extraordinary lengths to convince the clinician that their animal models are valid facsimiles of human protein-calorie malnutrition.

The clinical investigator, understandably, will refer to that experimental animal work which is in accord with his own findings. Research workers abandon animal models that do not conform to the results of the clinical investigators. This situation, though satisfying to both groups fails to improve understanding or add to knowledge. While clinicians continue to argue about the clinical, biochemical or pathological features which may be used to distinguish different types of dietary deficiency, it would be naive to expect the animal research worker to provide an ideal animal model of protein-calorie malnutrition. Instead many models have been produced (Kirsch et al, 1968b), confusing both to the reviewer and the research workers themselves.

Investigations into the effects of protein-calorie malnutrition on glucose tolerance and insulin release provide a good example. One group of workers (Platt, Heard and Stewart, 1964a) have:

1. Investigated more than one species, pigs, dogs and rats (Platt et al, 1964a).

2. These animals have been placed on different diets of varying protein and carbohydrate content (Platt et al, 1964b). 
3. Animals were investigated following various periods of dietary deficiency. (Heard, 1966).

This has resulted in:

1. a small number of animals being used in each test, making statistical evaluations of the results impossible. 2. anomalies, illustrated by a comparison in insulin response between severe protein-calorie deficiency in pigs and marginal deficiency in dogs (Heard and Turner, 1967, fig. 8, p. 104).

3. problems of interpretation, as shown by the fact that glucose tolerance in malnourished animals may be declared better or worse than normal, depending on the age at which these animals were studied: (Heard and Turner, 1967).

\section{Indirect methiods of study}

Despite the opportunity for direct investigation offered by the use of experimental animals, inferences have been made from indirect evidence. Three examples are quoted below:

(1) An impairment of glucose absorption in malnourished pigs has been based on:

(a) the finding of normal glucose tolerance in the presence of impaired intravenous glucose tolerance (Platt et al, 1964d), and

(b) the presence of pathological changes in the gut epithelium (Platt et al, 1964c). Glucose absorption has not been measured directly. 
(ii) Evidence for absolute deficiency of insulin in severe protelin-calorie deficiency has been derived from histological evidence (Heard, $1966, \mathrm{p} .86 \mathrm{l}$.

(iii) The evidence for insulin resistance as the cause of the impaired glucose tolerance in protein-calorie malnutrition has been based on glucose disappearance rate following administration of glucose plus insulin $(\mathrm{Kg}+\mathrm{i})$ (Heard and Henry, 1969a). See the discussion in chapters 3 and 7 .

Effect of protein-calorie malnutrition on glucose tolerance and insulin release in malnourished animals Despite the criticisms outlined above, some valuable information may be obtained from these workers. 1. Glucose tolerance does appear to improve with age in normal animals (Heard and Turner, 1967; Heard, 1966; Heard and Henry, i969a).

2. Severe protein-calorie deficiency in pigs (Heard, 1966) resulted in impaired glucose tolerance. 3. Infections (e.g. toxocara canis in dogs) may temporarily impair glucose tolerance in both wellnourished and malnourished animals (Heard and Turner, 1967). 4. There is marked variation in glucose tolerance not only between species but between litters of the same species (Heard and Henry, 1969b).

5. When plasma insulin-like activity was measured in dogs on diets of suboptimal protein value, insulin release after 
intravenous glucose was found to be extremely variable. The results depended on the biological assay method used (Heard and Turner, 1967).: Measurement of immunoreactive insulin revealed no difference in peak insulin concentrations following intravenous glucose in dogs on diets of different protein value provided that the intake was sufficient to prevent marasmus (Heard and Henry, 1969b).

6. The workers quoted above have ascribed the glucose intolerance in normal young, and older protein-calorie deficient animals to insulin resistance on the basis of (a) normal plasma insulin concentrations or (b) an impairment in glucose disappearance rate after administration of insulin (Ki) or more commonly after administration of glucose plus insulin $(\mathrm{Kg}+\mathrm{i})$.

\section{Conclusion}

Glucose intolerance has been described in proteincalorie malnourished animals and this has been said to be due to insulin resistance rather than diminished insulin release.

Deficiencies in the work of others, either in experimental methodology or in the interpretation of results allows room for yet another investigation into the effects of protein-calorie malnutrition on glucose tolerance and insulin release in an experimental animal.

This investigation would have to be limited to one species, on one diet, investigated after a fixed period on a protein-calorie deficient diet, in order to provide sufficient data for statistical analysis. 
Wherever possible, direct evidence would have to be found for either insulin resistance, impaired insulin release or impaired glucose absorption. Since other workers have demonstrated that glucose tolerance in normal animals varies with age, age-matched controls would have to be used. 


\title{
PART III
}

Experiments : Results : Conclusions

\author{
"Consider your verdict", the King said to the \\ jury. "Not yet, not yet!" the Rabbit hastily \\ interrupted. \\ "There's a great deal to come \\ before that!"
}

Lewis Carroll

Alice's Adventures in Wonderland. 


\section{CHAPTER 9}

\section{THE RAT MODEL}

Cholce of experimental animal model of proteincalorie malnutrition

The rat was chosen as the experimental animal model for purely practical reasons. These were:

1. The ease of breeding, housing and feeding rats made it possible to use many animals to provide enough data for statistical analysis.

2. A suitable rat model of protein-calorie malnutrition had been developed in the Department of Medicine (Stead and Brock, 1972).

The rat model

Unsexed, weanling rats of the Wistar strain, weighing approximately 30 grams and approximately 21 days old were placed on one of two isocaloric diets.

One diet contained $20 \%$ protein (casein) and the other contained $4 \%$ protein (casein) supplemented with methionine。 Details of the diet are shown in Table 9.1.

Six weanling rats from the same litter were randomly allocated to one of the two diets. Animals were housed, three per stainless-steel cage; in an air-conditioned room $\left(21-22^{\circ} \mathrm{C}\right)$ equipped with artificial lighting. Animals were allowed free access to food and water for three weeks. 
Table 9.1

\section{COMPOSITION OF DIETS}

\section{Casein \\ Dextrin}

Mineral mixture

Vitamin mixture

Maize oil

cod-liver oil

Choline chloride

DI-Methionine

Composition of vitamin mixture $\mathrm{mg} / 100 \mathrm{~g}$ mixt.

$\begin{array}{lr}\text { Thiamine HCl } & 50.0 \\ \text { Riboflavin } & 50.0 \\ \text { Nicotinic acid } & 250.0 \\ \text { Ca Pantothenate } & 200.0 \\ \text { Pyridoxine-HCl } & 25.0 \\ \text { Vitamin K3 } & \\ \quad \text { (Heterozeen) } & 2.5 \\ \text { Biotin } & 1.0 \\ \text { Folic acid } & 2.0 \\ \text { Cyanocobalamin B.P. } & 400.0 \\ \text { (equivalent to } & \\ \text { 200 pg pure } & \\ \text { vitamin Bl2) } & \\ \text { Inositol } & 1000.0 \\ \text { Ascorbic acid } & 500.0 \\ \text { Dextrin } & 97520.0\end{array}$

2.5

1.0 $\frac{208 \text { protein }}{9 / 100 \mathrm{~g}}$ diet $\frac{4 \% \text { protein }}{\text { et }}$ 20.0

4.0

69.7

85.5

4.0

4.0

1.0

1.0

4.0

4.0

1.0

1.0

0.3

0.3

0.2

Composition of mineral mixture $\mathrm{g} / 100 \mathrm{~g}$ mixt.

$\mathrm{CaCO}_{3}$ 29.29

$\mathrm{CaHPO}_{4} \cdot 2 \mathrm{H}_{2} \mathrm{O}$

0.43

$\mathrm{KH}_{2} \mathrm{PO}_{4}$

34.31

$\mathrm{NaCl}$

25.06

$\mathrm{MgSO}_{4} \cdot 7 \mathrm{H}_{2} \mathrm{O}$

9.98

Fe $\left(\mathrm{C}_{6} \mathrm{H}_{5} \mathrm{O}_{7}\right) \cdot 6 \mathrm{H}_{2} \mathrm{O}$

0.623

$\mathrm{CuSO}_{4} \cdot 5 \mathrm{H}_{2} \mathrm{O}$

0.156

. $0 \mathrm{MnSO}_{4} \cdot 4 \mathrm{H}_{2} \mathrm{O}$

0.16

0.02

$\mathrm{ZnCl}_{2}$

0.0005

KI

0.0025 
CHAPTER 10

\section{EXPERIMENTAL DESIGN}

In order to avoid repetition this section fulfils three functions:

1. To define some of the frequently occurring terms and their abbreviations used in the text, figures and tables that follow,

2. To describe the general experimental techniques and principles employed where these apply to more than one investigation,

3. To state the criteria used for assigning significance to any differences in mean values reported in the results of any investigation, and to define "normal responses" when comparisons are drawn between the groups of animals in the discussion of the results.

\section{Experimental animals}

Three groups of rats were used in this study:

(i) Weanling rats: These were unsexed weanling rats of the Wistar strain, approximately 21 days old and weighing approximately $30 \mathrm{~g}$. In the tables and figures, results from this group appear under the heading "Weanling".

(ii) 20\% protein-fed rats: This term refers to weanling rats (as described above) which had been maintained for 3 weeks on a 20\% protein diet as described in Chapter 9. These animals were approximately 42 days old at the time of investigation. In the figures and tables this group has been designated "20\% protein". 


\section{(iii) $4 \%$ protein-fed rats: This term refers to weanling}

rats (as described above) investigated after they had been allowed free access for three weeks to a $4 \%$ protein diet as described in chapter 9: At the time of investigation these animals were approximately 42 days old and are referred to in the figures and tables as "4\% protein". As will be shown in Chapter 11, weanling rats although younger did not differ significantly in weight from the older $4 \%$ protein-fed rats. Weanling rats, therefore, were used as weight-matched controls. Rats on the $4 \%$ protein diet, designed to produce protein-calorie deficiency, are referred to frequently as the protein-calorie deficient rats (or animals) and occasionally as the malnourished rats (or animals).

The $20 \%$ protein-fed rats were well-nourished and were the same age as the $4 \%$ protein-fed rats. They form the main standard of comparison for the investigations that follow.

Some general points important in the experimental protocol

The housing and feeding of the animals have been described and this section deals only with the preparation of the animals for investigation, the handing of the animals during the tests, and the method of collecting blood samples. Specialised techniques of sample collection or investigation are described in the appropriate chapter. 1. Fasted rats

Food was removed from the cages of the $20 \%$ protein and $4 \%$ protein arimals at $5 \mathrm{p} . \mathrm{m}$. on the day preceding the 
investigation. Weanling rats were removed from their mothers and litter mates, and kept in groups of three in cages similar to those used for the other two groups, while fasting. AIl animals were allowed free access to water during their period of fasting.

2. All investigations were done in the morning following the overnight fast.

3. All animals were killed after the experiments were completed. No animal was used for more than one experiment involving the collection of blood samples. 4. Whenever possible, anaesthesia was avoided in view of reports of the effects of anaesthesia on glucose tolerance and insulin release (Davidson, 1971; Aynsley-Green et al, 1973). In some tests e.g. the measurement of portal insulin and glucose levels and the measurement of serum potassium from cardiac blood samples, rapid ether anaesthesia prior to sample collection was used and the animals then killed.

5. Unless otherwise stated, all samples were collected from a tail vein in the unanaesthetised rat, after warming the animal for at least 5 minutes in front of a fan heater. Where frequent blood samples were required, animals were kept warm in front of the heater throughout the test which never lasted longer than 30 minutes. In those tests that were prolonged beyond 30 minutes, the animals were kept away from the heater until 5 minutes prior to sample collection.

6. Unless otherwise stated, tail vein blood samples were 
used for the estimation of plasma insulin and blood glucose concentrations. The animals were held by an experienced laboratory technician while the tip of the tail was amputated and blood collected into heparinised capillary tubes. Repeated blood samples on the small $4 \%$ proteinfed and weanling rats were made possible by the development of micro methods for the determination of plasma insulin and blood glucose concentrations (described in Appendix A). Only $50 \mu l$ of whole blood was taken per sample and this did not appear to have any adverse effect on the smaller animals.

7. Oral and intravenous glucose as well as other intravenous stimuli to insulin release were given in a dose related to body weight. Every animal received $1 \mathrm{ml} / \mathrm{lo} \mathrm{g}$ body weight of the appropriately diluted drug or substance. 8. All intravenous injections were given into a tail vein using a 26 gauge needle attached to a $1 \mathrm{ml}$ graduated disposable syringe. Prior to injection the animal's tail was warmed for 2 minutes in water $\left(50^{\circ} \mathrm{C}\right)$. Where the intravenous injection failed, as shown by swelling of the tissues or difficulty in completing intravenous injection within 15 seconds, the test was abandoned. Determination of blood glucose and plasma insulin concentrations

Blood glucose concentration was estimated on $5 \mu 1$ of whole blood using a glucose oxidase method fully described in Appendix A. This method measures true glucose and not reducing substances.

The plasma insulin concentration was determined using 
a double antibody radioimmunoassay technique, suitably modified for a $5 \mu \mathrm{l}$ or $10 \mu \mathrm{I}$ sample volume. (The details of the method are given in Appendix Al. This technique measures only immunoreactive insulin (IRI) and may not be a reflection of biologically active insulin. However, the close correspondence in most of these studies between the peak plasma insulin concentration attained and the ability to dispose of a glucose load suggests that IRI is a reliable measure of biologically active insulin.

\section{Method of reporting results} 1. Individual results of the tests are'recorded in Appendix B, with the weight of the animal on the morning of the investigation (i.e. the fasted weight).

2. In all tables of results the mean and the standard error of the mean (SEM) appear as defined in Appendix A. 3. In all the figures and tables which show the changes in blood sugar or plasma insulin concentration with time the following points should be noted:

(a) Time ' $O$ ' refers to a basal blood sample, taken after an overnight fast and before any provocative stimulus.

(b) Other time intervals recorded graphically or referred to in the text are a measure of time that has elapsed after completion of this stimulus.

(c) The mean blood sugar level is recorded with vertical bars indicating the SEM.

(d) Only median values for the plasma insulin concentrations are given, since these are not normally distributed (see Statistics, Apperidix A). 


\section{Interpretiation of Results}

The student's $t$ test was used for assessing significance of differences between means, where the data was found to be normally distributed (see statistics, Appendix Al. The Mann-Whitney $U$ test was used where data was found not to have a normal distribution.

For both these tests, p values greater than 0:05 ( $p>0.05$ ) are reported as being not significant. Unless otherwise recorded, significant differences have $p$ values less than $0.05(p<0.05)$. Where differences between means or medians are small but nevertheless statistically significant, they are reported in the results but are not necessarily discussed, unless felt to be of biological significance.

\section{Normal or Abnormal?}

To facilitate discussion of the differences between the three groups of animals, the results of the $20 \%$ proteinfed rats have been arbitrarily designated as "normal". Where terms require some standard of reference (e.g. glucose tolerance, diminished insulin release, or insulin resistance), the results reported for the $20 \%$ protein-fed rats have been used as that reference. 
CHAPTER 11

ASSESSMENT : OF: THE : NUTRITIONAL; :STATE : OF: THE : RAT MODEL

Stead and Brock (1972) have already demonstrated that the young rats used in their study rapidly developed signs of protein deficiency when fed a low protein diet. Since many of the tests in their study were not performed after the animals had been on the diet for 21 days, it was felt advisable to measure some of those parameters commonly used as evidence of protein-calorie malnutrition in humans.

\section{Investigations}

1. Animal weight Animals were weighed once a week.

2. Serum albumin and total serum protein estimations These were done on blood samples from the tail vein of fasted rats. Serum albumin was measured using the method of Doumas et al (1971) and total serum protein was estimated by the method of Lowry et al (1951).

3. Liver fat was estimated in fasted rats by weighing the dry tissue before and after extraction with petroleum ether.

4. Total body water was determined by dilution studies using tritiated water.

Methods

Details of the methods used in the determination of 2,3 and 4 above appear in Appendix A. 


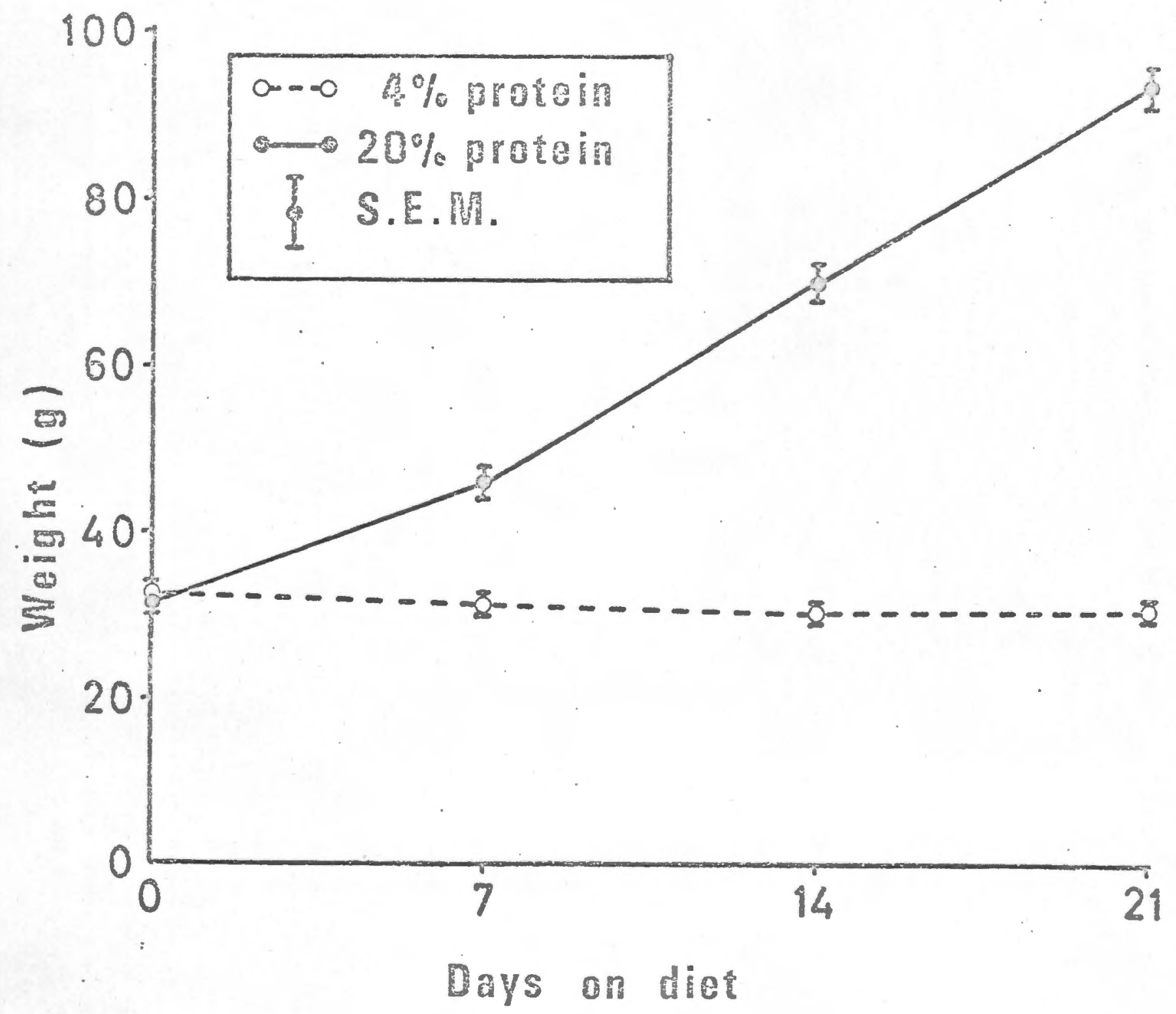

Fig.11.1. Comparison of body weights of $4 \%$ protein-fed and $20 \%$ protein-fed rats. 


\section{Results}

The change in body weight with time is recorded in fig.1l.l and individual results in the determination of liver fat and total body water appear in Appendix B. (B23, B24, B25, B2). A summary of all these results appear in Table 11.1

Table 11:1

\begin{tabular}{|c|c|c|c|}
\hline & $20 \%$ Protein & $4 \%$ Protein & Weanling \\
\hline $\begin{array}{l}\text { Weight } \\
\text { (g) }\end{array}$ & $93.1 \pm 2.4$ & $30.8 \pm 1.2$ & $32.3 \pm 0.6$ \\
\hline $\begin{array}{l}\text { Total body water } \\
\text { (\% body weight) }\end{array}$ & $77.6 \pm \frac{18}{(8)} 0.7$ & $77.9 \pm 1.1$ & $75.6 \pm 0.7$ \\
\hline $\begin{array}{l}\text { Serum albumin } \\
(\mathrm{g} / 100 \mathrm{ml})\end{array}$ & $\begin{array}{l}3.26 \pm 0.06 \\
(12)\end{array}$ & $\begin{array}{l}2.12 \pm 0.08 \\
(12)\end{array}$ & $\begin{array}{l}3.04 \pm 0.05 \\
(13)\end{array}$ \\
\hline $\begin{array}{l}\text { Total serum protein } \\
(\mathrm{g} / 100 \mathrm{ml})\end{array}$ & $\begin{array}{l}6.04 \pm 0.16 \\
(12)\end{array}$ & $\begin{array}{l}3.98 \pm 0.14 \\
(12)\end{array}$ & $\begin{array}{l}5.38 \pm 0.09 \\
.(12)\end{array}$ \\
\hline $\begin{array}{l}\text { Liver fat } \\
\text { (\% dry liver weight) }\end{array}$ & $4.5 \pm 0.6$ & $9.7 \underset{(8)}{ \pm}$ & $2.4 \pm 0.3$ \\
\hline
\end{tabular}

Values represent Means $\pm \mathrm{SEM}$. Numbers. in parentheses represent $n$, the number of animals.

1. Animal weight. It is apparent from fig.11.1 that rats on the $4 \%$ protein diet failed to gain weight. Examination of Table 11.1 reveals a slight reduction in the body weight of the malnourished animals when compared to the weanling rats but this difference is not statistically significant.

2. Serum albumin and total serum protein.

(a) Serum albumin and total serum protein was significantly lower in malnourished rats than both the $20 \%$ protein-fed animals and the weanling rats ( $p<0.001)$. 
(b) Weanling rats had significantly lower serum albumin and total serum protein concentrations than $20 \%$ proteinfed rats ( $p<0.01$ and $p<0.005$ respectively). The magnitude of this difference was not as great as the difference between the $4 \%$ protein and $20 \%$ protein-fed rats.

3. Liver fat.

(a) The $4 \%$ protein-fed rats had significantly higher concentrations of petroleum ether extractable lipids than both the $20 \%$ protein-fed rats $(p<0.02)$ and the weanling rats $(p<0.005)$.

(b) Of all three groups, weanling rats had the lowest concentration of liver "fat" being significantly less than the $20 \%$ protein-fed rats $(p<0.01)$.

Frozen sections of the rat livers stained with sudan 3 showed that the increase in chemically extractable lipid in the malnourished animals was associated with a mild to moderate degree of periportal fatty infiltration. However, both histologically and chemically the amount of fat present in the $4 \%$ protein-fed rats showed a great deal of individual variation.

4. The mean total body water content expressed as a percentage of body weight was similar in all three groups of animals. No statistically significant differences could be demonstrated. 


\section{Discussion}

Young rats, after 3 weeks on a low protein diet, have been shown to develop many of the signs attributed to protein-calorie deficiency in humans. These are:

1. Failure to gain weight,

2. Significant hypoalbuminaemia,

3. An increased concentration of Iiver fat.

There are, however, some differences in this rat model from other models of protein-calorie malnutrition, as well as differences between the model described above and certain forms of human protein-calorie malnutrition. These are discussed below.

\section{A. Oedema}

There was no clinical evidence of oedema in these malnourished rats, but others have noted the difficulty of producing oedema in protein depleted rats (Ramalingaswami and Deo, 1968; Widdowson and McCance, 1957). Where clinical oedema has been reported in rats (Alexander and Sauberlich, 1957; Kirsch et al 1968a; Enwonwu and Sreebny, 1970), this has not been substantiated by the measurement of total body water.

Schnieden et al (1958) reported an increase in the total body water of rats maintained on an exclusive cassava diet. It required 15 weeks on the abnormal diet, associated with marked loss of weight and a decrease in the serum albumin from $4.2 \mathrm{~g} \%$ to $1.2 \mathrm{~g} \%$ to produce an increase. in total body water from $69.9 \%$ to $77.4 \%$. 
It has been shown that a deficiency of lipotropic factors. (Alexander and Sauberlich, 1957) contributes to the development of clinical oedema, which could be prevented by adding methyl compounds to the protein deficient diet. Thus two factors (a) the addition of methionine to the protein deficiency diet and (b) the short duration of protein-calorie deficiency may explain the absence of oedema in the rat model of Stead and Brock (1972). Total body water estimation in these animals indicates that there was no occult fluid accumulation. This negative finding had some value in that corrections did not have to be made for differences in total body water in calculating the dose of drugs or glucose to be given to the three groups of animals.

B. Dietary intake

Dietary intake was not estimated during this study, but Stead and Brock (1972) have shown in their paper that animals on the $4 \%$ protein diet had a reduced caloric intake. Since it is widely believed that in humans fatty liver and kwashiorkor are associated with a high caloric intake (McCance, 1968), it may be argued that these animals do not have kwashiorkor. However, since the purpose of this study was to investigate the effects of protein-calorie malnutrition on glucose tolerance and insulin release, it is immaterial whether these animals may or may not be labelled as suffering from kwashiorkor. A more cogent objection raised by Dr. du Plessis (1973) evolves around the difference in food intake of rats on high protein diet 
as compared to those of a low protein diet. As well as a reduction in calories and proteins, there might also be a concomitant reduction in other nutrients present in the diet, such as minerals and vitamins. Thus any differences shown between these two groups of animals may not be attributed solely to protein-calorie deficiency but might be the result of other deficiencies caused by their reduced intake.

From the unpublished data of Mr. C. Melzer (1974) it appears that weanling rats placed on diets deficient in any one major constituent e.g. protein-free diets, vitaminfree diets or mineral-free diets, all eat significantly less than control rats, fail to grow and die within 30 - 40 days. Even diets deficient in a single constituent such as an amino acid (Sidransky and Farber, 1958) or a single mineral such as potassium (Mondon et al, 1968) result in a reduced intake. Unless one resorted to unphysiological procedures such as force-feeding (Platt et al, 1962) there appears to be no way to demonstrate that the abnormalities found in the malnourished rat are due to either the protein, carbohydrate, mineral or vitamin deficiency. However it is important to note that rats fed ad lib either a protein-free diet (Platt et al, 1962) or a diet deficient in a single amino acid (Sidransky and Farber, 1958). did not show the pathological changes of kwashiorkor found in rats force-fed the same diets. Despite their reduced intake of food, the rat model of stead and Brock (1972) did, however, show some of the features of protein-calorie malnutrition and 
kwashiorkor.

C. Individual variation

During the course of this study it became apparent that some animals on a. low protein diet lost weight and died. It should also be noted that some of the control animals on the high protein diet also fared badly in that they did not reach their expected weight after 3 weeks. Stead and Brock (1972) commented that the "response was unrelated to food intake and appeared to represent a difference in metabolic adaptation of individual animals to dietary protein deficiency". This individual variation was also reflected by pronounced differences in liver lipid concentrations between individual animals. In the investigations still to be reported, it was therefore decided to exclude those animals that did not adapt to their diet. The rats on a $20 \%$ protein diet that failed to reach their expected weight at the end of 3 weeks, and those $4 \%$ protein-fed animals that continued to lose weight throughout the 3 week period have been excluded from further investigation.

Because of a wide degree of individual variation results from individual animals are not discussed. (This data is available in Appendix B). Only the differences in the means (or medians) of data from different groups of animals have been compared. 


\section{FASTITNG : BLOOD : SUGAR: AND : PLASMA : INSULIN CONCENTRATIONS}

This investigation was done to determine whether all three groups of animals were able to maintain the same fasting blood glucose concentration. High fasting plasma insulin concentrations might also be used as an index of insulin resistance (See Chapter 3).

Methods. (See Experimental Design, Chapter 10). After an overnight fast, the rats were heated for 5 minutes in front of a fan heater. Tail vein blood was collected into heparinised capillary tubes. Plasma insulin concentrations were measured on $10 \mu 1$ samples of plasma (See Appendix A).

Results (See Table B3 for individual results). Table 12.1 shows the mean fasting blood glucose concentrations ( $₫ S E M$ ) and the medians of the fasting insulin concentrations (with the range). Numbers in parentheses refer to $n$, the number of animals. 
Table 12.1

$$
\frac{\text { Glucose }}{(\mathrm{mg} / 100 \mathrm{ml})}
$$

$20 \%$ Protein diet

4\% Protein diet

Weanling
$94 \pm 4$

(12)

$101 \pm 9$

(10)

$92 \pm 3$

(5)
Insulin

( $\mathrm{ng} / \mathrm{ml}$ )

$0.99(0.50-2.87)$

(12)

$0.28(0.02-0.85)$

(10)

$0.79(0.17-2.12)$

(II)

There was no statistically significant difference in the mean blood glucose levels between any two of the three groups of rats studied.

Rats on the $20 \%$ protein diet had fasting plasma insulin concentrations which were statistically higher than both the $4 \%$ protein-fed and weanling rats $(p<0.002$ and $\mathrm{p}<0.05)$ respectively. Although the weanling rats had a higher median fasting plasma insulin concentration than the 4\% protein-fed animals, this difference was not statistically significant $(0.05<p<0.10)$.

Conclusion

Weanling and $4 \%$ protein-fed rats, despite fasting plasma insulin levels which were statistically significantly lower than those of the $20 \%$ protein-fed rats, were still able to maintain normal fasting blood sugar concentrations. This may be cited as evidence against the presence of insulin resistance in either the younger weanling rats or the protein-calorie deficient animals, since insulin resistance would have been characterised by higher fasting plasma insulin concentrations. 


\section{INTRAVENOUS : GLUCOSE · TOLERANCE ' TEST}

\section{Aims}

1. The determination of the glucose disappearance rate (Kg).

2. Estimation of early insulin release following intravenous glucose administration.

3. Calculation of the glucose space (used as an estimate of extracellular fluid volume).

4. Estimation of the half disappearance time of endogenous insulin.

Method

After basal blood samples were taken, $1 \mathrm{ml} / 100 \mathrm{~g}$ body weight of a $12.5 \%$ dextrose solution (125 mg/100g body weight) was injected into the tail vein of the rats. The animals were kept warm in front of the heater and blood samples taken at $3,6,10,15,20,25$ and 30 minutes after completion of the injection. Any delay in collecting the blood samples was noted and appear in the tables of individual results given on pages B4, B5 and B6. Blood glucose and plasma insulin concentrations were estimated on all samples.

Calculation of $\mathrm{Kg}$

The glucose disappearance rate $(\mathrm{Kg})$ was calculated by using the method of least mean squares (see Appendix A) to find the slope of the line relating the logarithm of the absolute blood glucose concentration to time in minutes. The slope of this line X 100 was recorded as $\mathrm{Kg} i . e$. the 
percentage fall in blood glucose concentration per minute. Calculation of the glucose space

The glucose volume (or spacel, Vg, was calculated as described by Franckson et al (1962) from the following equation:

$$
V g=\frac{Q}{A-C O}
$$

$Q=$ quantity of glucose injected

$A=$ the theoretical concentration of glucose at time zero, as calculated from $\mathrm{Kg}$

Co = the initial (fasting) blood glucose concentration

\section{Results}

These are shown in Table 13.1 and in figure 13.1. The individual results are presented on pages $B 4, B 5$ and $B 6$.

\section{Table 13.1}

\begin{tabular}{|c|c|c|c|}
\hline & $20 \%$ Protein & $4 \%$ Protein & Weanling \\
\hline Meain $\mathrm{Kg}( \pm S E M)$ & $7.44 \pm 0.42$ & $5.29 \pm 0.57$ & $5.23 \pm 0.30$ \\
\hline Peak insulin ( $\mathrm{ng} / \mathrm{ml})$ & 10.9 & 3.5 & 2.8 \\
\hline (Range ) & $(3.3-40)$ & $(0.9-11.4)$ & $(1.2-7.5)$ \\
\hline Glucose space $\left( \pm_{S E M}\right)$ & $35 \pm 1$ & $34 \pm 2$ & $41 \pm 1$ \\
\hline (\% body weight) & & & \\
\hline $\mathrm{n}$ & 10 & 10 & 12 \\
\hline
\end{tabular}




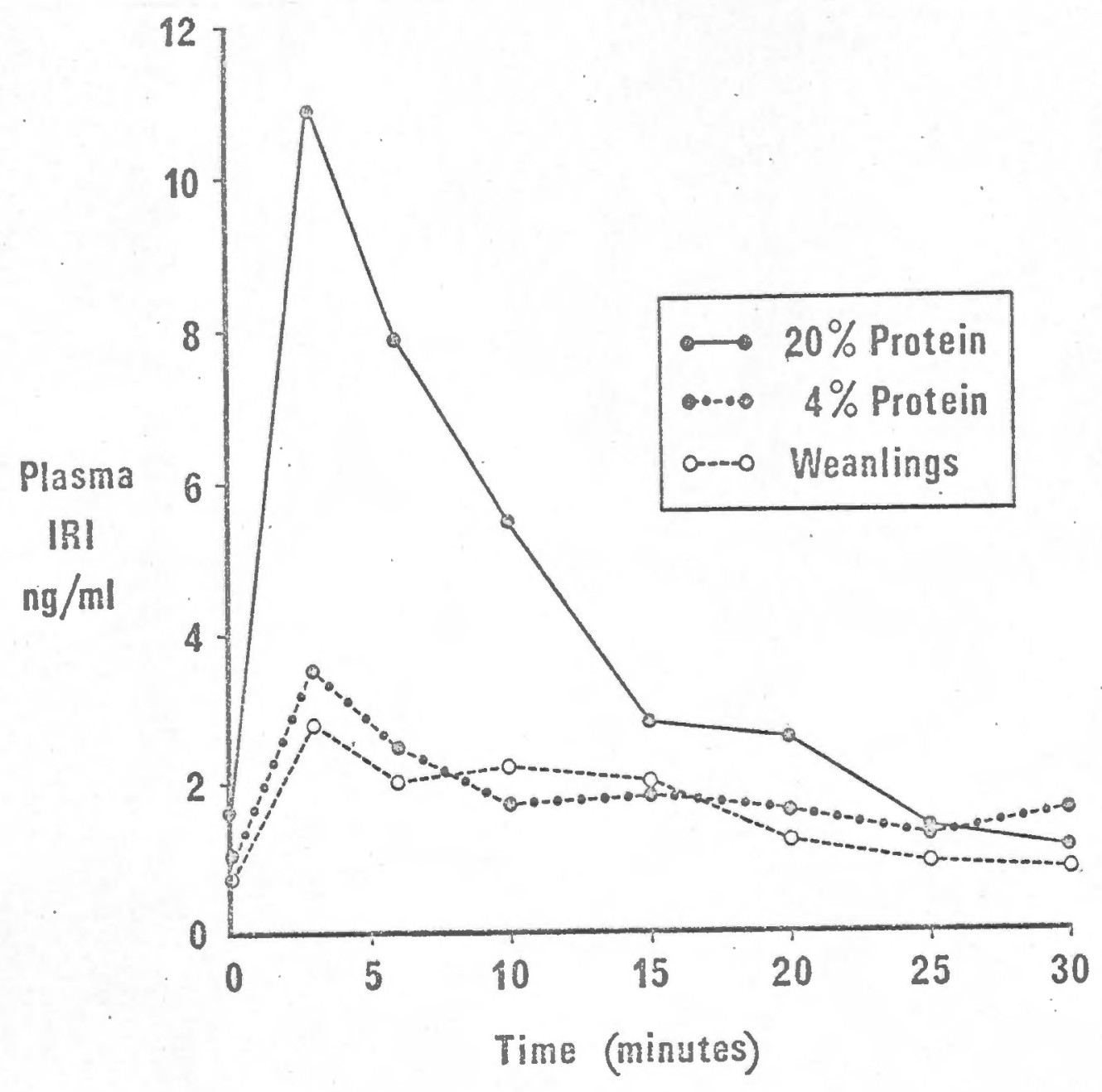

Fig. 13.1 Insulin concentrations following intravenous glucose. 
1. Intravenous glucose tolerance tests showed that the $20 \%$ protein-fed animals had $\mathrm{Kg}$ values significantly higher than both the $4 \%$ protelin-fed rats and the weanling controls $(p<0,01$ and $p<0.001$ respectively).

2. Plasma insulin concentrations were significantly higher in the $20 \%$ protein-fed animals than both the $4 \%$ and weanling rats at $3,6,10$ minutes $(p<0.02)$.

3. There were no statistically significant differences in the $\mathrm{Kg}$ values and peak insulin concentrations after intravenous glucose administration between the weanling and $4 \%$ protein-fed animals.

4. Insulin concentrations in all three groups of animals attained their peak value at the same time (3 minutes). There was no delay in insulin secretion in either the weanling or malnourished rats.

5. There was no statistically significant difference in the glucose spaces of the $20 \%$ protein and $4 \%$ protein-fed animals. Weanling rats however showed a significantly larger glucose space than both the $20 \%$ protein-fed and the $4 \%$ protein-fed rats, $(p<0.001$ and $p<0.01$ respectively).

6. The mean half disappearance time ( $\left.t \frac{1}{2}\right)$ of endogenous insulin, determined from fig.13.1, was approximately 8 minutes in both the $20 \%$ protein-fed and $4 \%$ protein-fed rats. Because of their low peak insulin concentration,

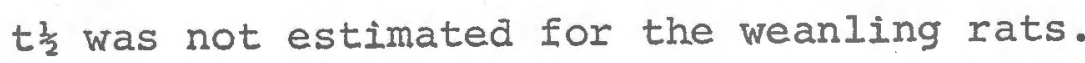

\section{Conclusion}

Intravenous glucose tolerance is impaired in rats fed on a $4 \%$ protein diet and in weanling rats, when compared to the 
$20 \%$ protein-fed controls. This impairment in glucose tolerance is associated with a diminished insulin response in both the $4 \%$ protein-fed rats and the weanling rats. Discussion

Method of calculating $\mathrm{Kg}$

There is general agreement that the fall in blood glucose concentration after intravenous loading may be described by an exponential equation. Controversy still exists, however, as to whether one should calculate $\mathrm{Kg}$ from the log of the absolute glucose concentration (Dyck and Moorhouse, 1966; Ikkos and Luft, 1957) or use the log of the glucose excess (the concentration of glucose in excess of the fasting blood sugar concentration) as originally advised by Amatuzio et al (1953) and Duncan (1956).

Butterfield et al (1971) found that the latter (incremental $\mathrm{K}$ values) did not discriminate between normal and diabetic subjects, whereas the absolute $K$ values did. Korec (1973) found that the incremental $K$ values could be used as a better discriminator between the mild and moderate diabetics.

In this study "absolute $K$ values" were used. What does $\mathrm{Kg}$ mean?

It is generally assumed that after allowing a suitable time interval for equilibration, the rate of change of glucose concentration with time is a measure of glucose uptake by the tissues. There are, however, many factors affecting the rate of fall of blood glucose concentration 
and these are summarised below:

1. Urinary losses of glucose.

2. Equilibration of glucose within the extracellular fluid compartment.

3. Irreversible loss of glucose to the tissues.

4. Gluconeogenesis.

Ikkos and Luft (1957) have shown that in non-diabetic subjects urinary losses of glucose constituted only $4 \%$ of the administered dose and could for all practical purposes be neglected. Chernick and Scow (1958) using the same intravenous glucose load as was used for this study (125 mg/loog body weight), found that only $2-3 \%$ of the administered glucose was lost in the urine of rats. Thus urinary losses of glucose have not been taken into account in the calculation of either $\mathrm{Kg}$ or the glucose space in the present work.

Franckson et al (1962) found that glucose equilibrated with the extracellular space by 15 minutes in humans, a result similar to that of Rasio et al (1967). It would appear reasonable to assume a much shorter time for equilibration of glucose with the extracellular fluid in rats than man in view of their small size and rapid circulation time.

Some workers (Chernick and Scow, 1958; Mondon et al, 1968; Penhos et al, 1971; De Santis, 1973) have taken their first blood sample 10 or 15 minutes after the intravenous glucose load, presumably to allow for the equilibration of glucose with the extracellular fluid. 
It was found in this study, however, that the plot of the logarithm of the absolute glucose concentration against time gave a straight line from 3 - 20 minutes in all cases, and in most animals this Iinearity was maintained up to 30 minutes. Aynsley-Green and Alberti (1973) have also used blood sugar values between 2.5 and 20 minutes to calculate $\mathrm{Kg}$. After 30 minutes, blood glucose concentration no longer fell exponentially. This was presumably due to homeostatic mechanisms correcting the blood glucose concentration as it approached the fasting concentration. The correlation coefficient of the line relating the logarithm of the blood sugar concentration to time was greater than 0.96 in all the animals studied. The significance of $\mathrm{Kg}$ value and its relation to insulin release

Lerner and Porte (1971) have shown that the $\mathrm{Kg}$ value correlated with the acute insulin response (3-5 minutes), whereas total insulin output correlated with the size of the glucose load. The importance of this acute insulin response is substantiated by the findings of Vranic et al (1971). They used fasted pancreatectomised dogs maintained on an intraportal insulin infusion sufficient to maintain glucose turnover and plasma concentrations of glucose, insulin and free fatty acids. These animals nevertheless showed a $50 \%$ reduction in their $\mathrm{Kg}$ values when compared to controls. This reduction in the $\mathrm{kg}$ value was due to failure of inhibition of glucose production by the liver which is normally caused by acute 
insulin release.

Thus early insulin release after intravenous glucose loading inhibits glucose production by the liver and is an important factor affecting the rate of fall of glucose concentration in the blood.

Glucose space

Franckson et al (1962) found. no statistical difference between the glucose space and sodium thiocyanate space using the method described above. In this study glucose space has been expressed as a percentage of body weight and may be regarded as an estimate of the extracellular fluid volume. The larger glucose space in the weanling rats, as compared to the other two groups, does not entirely account for. their lower insulin concentrations after intravenous glucose administration.

Half disappearance time $\left(t \frac{1}{2}\right)$ of endogenous insulin

This may be used as an index of insulin degradation and removal by the tissues (See Chapters 4 and 15). The $20 \%$ and $4 \%$ protein-fed animals showed no difference in their mean $t \frac{1}{2}$ values. 
CHAPTER 14

\section{THE : ORAI GLUCOSE TOLERANCE TEST}

The insulin response to an oral glucose load has been reported to be greater than the insulin response to the same intravenous glucose load (McIntyre et al, 1964). This enhancement of the insulin response to oral glucose has been attributed to the release of intestinal hormones or factors which act presumably by 'priming the $\beta$ cells' and making them more responsive to the glycaemic stimulus (Creutzfeldt et al, 1970a; Youngs, 1972).

Both the weanling and $4 \%$ protein-fed rats showed a diminished insulin response to an intravenous glucose load. It was important to discover if oral glucose administration would improve their insulin response or reveal differences between these two groups. Method

Unanaesthetised fasted rats were given $1 \mathrm{ml} / 100 \mathrm{~g}$ body weight of a $50 \%$ dextrose solution $1500 \mathrm{mg} / 100 \mathrm{~g}$ body weight) via an intragastric tube (a polythene catheter attached to the end of a 15 gauge needle). In administering the glucose load, care was taken to correct for the dead space occupied by the catheter and needle. Blood samples were taken at 5, 10, 15, 30, 45, 60 and 90 minutes after the glucose load from the tail vein of the animal. Blood, glucose and plasma insulin concentrations were determined as described in Appendix A. 


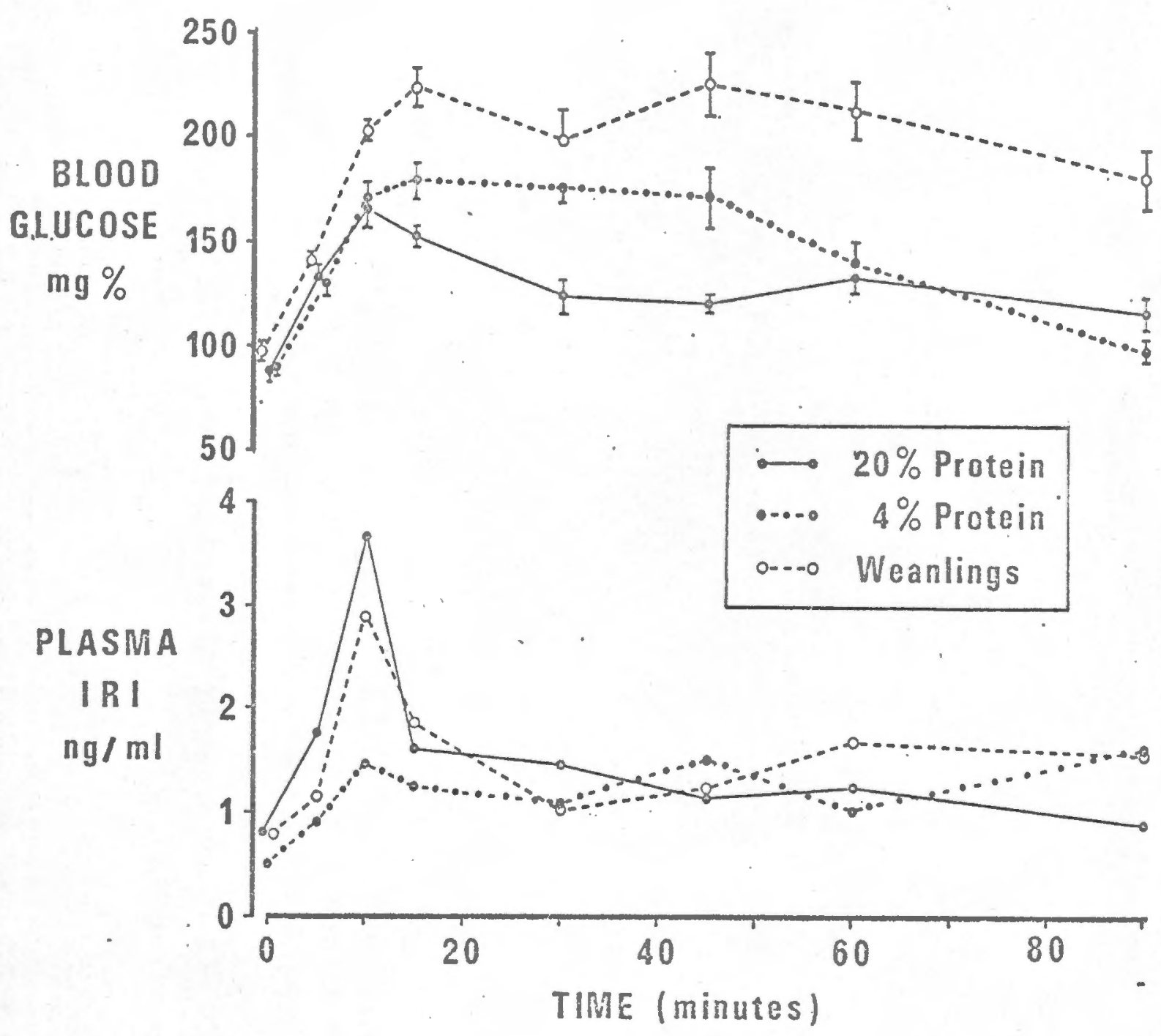

Fig. 14.1 Plasma insulin and blood glucose concentrations following an oral glucose load. 
Resuilts

The mean blood sugar concentrations with their SEM and the median plasma insulin concentrations are shown in fig.14.1. The individual results appear in Tables B7, $\mathrm{B} 8$ and $\mathrm{B9}$.

A. Plasma insulin responses to oral glucose

1. The peak insulin response following an oral glucose load occurred at 10 minutes. This applied to the median values of all three groups of animals studied.

2. No statistically significant differences between the median insulin values of the $20 \%$ protein and weanling rats could be demonstrated except at 90 minutes when the weanling rats showed a higher plasma insulin concentration than the $20 \%$ protein-fed animal ( $1.6 \mathrm{ng} / \mathrm{ml}$ vs $0.9 \mathrm{ng} / \mathrm{ml} \mathrm{p}<0.02)$. 3. The $4 \%$ protein-fed rats had plasma insulin responses which were significantly lower than the $20 \%$ protein-fed animals at 5 and 10 minutes $(p<0.05$ and $p<0.02$ respectively). At 90 minutes however the plasma insulin concentration was higher in the $4 \%$ protein-fed rats than the $20 \%$ protein-fed controls $(p<0.05)$.

4. Although it would appear from the plot of median insulin concentrations (fig.14.1) that weanling rats had a greater early. insulin response than the $4 \%$ protein-fed animals, no statistical significance could be found in the difference between these insulin concentrations. This was due to the large degree of overlap between individual plasma insulin concentrations. 


\section{B. Oral glucose tolerance}

If one accepts the oral glucose tolerance curve of the 20\% protein-fed rats as being "normal" (See Chapter 10), a number of conclusions may be drawn.

1. Weanling rats show the greatest degree of glucose intolerance. Their blood glucose concentrations were significantly higher than the $20 \%$ protein-fed rat at and after 10 minutes following the glucose load ( $p<0.005$ in all cases).

2. The $4 \%$ protein-fed rats showed relatively mild glucose intolerance with blood glucose concentrations significantly higher than the $20 \%$ protein-fed animals at 15 and 30 minutes only ( $p<0.05$ and $p<0.001$ respectively.)

3. The fact that weanling rats were more glucose intolerant than the $4 \%$ protein-fed animals is shown by the fact that their blood sugar concentrations are significantly higher than the latter at $10,15,45,60$ and 90 minutes after oral glucose loading $(p<0.05$ at 45 minutes, in all other cases $\mathrm{p}<0.001$ ).

\section{Conclusions}

With the results of blood glucose and plasma insulin concentrations from the $20 \%$ protein-fed animals as the standard, the following conclusions may be drawn:

1. The 4\% protein-fed animals showed glucose intolerance.

2. Glucose intolerance was more marked in weanling rats.

3. The 4\% protein-fed animals showed a diminished early insulin response to an oral glucose load. 
4. Weanling rats had a normal insulin response during this same early period.

It should be noted that the difference in early insulin response between weanling and $4 \%$ protein-fed rats was not statistically significant. Thus the insulin response in weanling rats appears to fall between the responses of the $20 \%$ protein-fed and the malnourished rats. Depending on which group one chose as the reference standard their insulin response might be described as either normal or diminished. However, since it was decided earlier (Chapter 10) to use the $20 \%$ protein animal as the control and reference animal, the insulin response of the weanling rats will be regarded as "normal" for the benefit of this discussion.

5. This study shows that oral glucose loading in rats produces a peak insulin response at 10 minutes and not at 20 minutes as reported by Grey et al (1970) or 30 minutes as reported by Penhos et al (1971). These latter workers may have missed an early glucose peak at 15 minutes in their normal controls, which was reported by Donly (1961), as well as missing an early insulin peak at 10 minutes, which has also been found by Turner and Young (1973). Inferences and Interpretation

It would appear from this study that oral glucose administration had improved the insulin response of weanling rats while producing no changes in the insulin response of the $4 \%$ protein-fed rats, both these groups of animals have been previously shown (Chapter 13) to have a diminished 
insulin response to intravenous glucose. This would suggest that weanling rats require the additional stimulus of some gut factor to "normalise" their insulin response to glucose. This gut factor or factors may be postulated as being either absent or ineffective in improving insulin release in malnourished animals, but this question has not been pursied in the present work.

The $4 \%$ protein-fed animals despite their poor insulin response to an oral glucose load showed a relatively mild degree of glucose intolerance, as compared to the glucose intolerance of the weanling rats which have shown an apparently normal insulin release. This difference in glucose tolerance after an oral load, which was not apparent following an intravenous glucose load, prompted a number of further studies. The first was an investigation into insulin tolerance and the second was a test of the ability of these animals to absorb glucose. 
CHAPTER 15

\section{INTRAVENOUS : INSULIN : TOLERANCE · TEST}

\section{Indications}

Himsworth (1939l showed that the glucose intolerance caused by a carbohydrate deficient diet in man was accompanied by increased resistance to the action of exogenous insulin. Bowie (1964) reported that the intravenous glucose tolerance of children with kwashiorkor was not improved when insulin was given with the glucose intravenously. Some studies in glucose tolerance in malnutrition both in children (Alleyne et al, 1972) and in animals (Heard and Henry, 1969a) have indicated that insulin resistance is the important factor responsible for the glucose intolerance associated with malnutrition. However the investigation of insulin tolerance in the malnourished rats was prompted by the fact that weanling rats showed a more marked oral glucose intolerance than did the $4 \%$ protein-fed rats. In fact these results suggested that the weanling rats were either insulin resistant or that the malnourished rats were markedly insulin sensitive.

The blood sugar concentration depends not only on the action of insulin which tends to lower it, but also on the action of other hormones which tend to elevate the blood sugar. The action of these latter hormones could be assessed during an intravenous insulin tolerance test. The aims of the study were therefore twofold: 1. To determine whether weanling or $4 \%$ protein rats showed any difference in their sensitivity to the hypo- 
glycaemic action of exogenous insulin.

2. To assess the ability of these animals to correct the insulin-induced hypoglycaemia.

Method

Fasted rats were given an intravenous injection of soluble beef insulin (Insulin B.P. Burroughs Wellcome (Pty) Ltd.) diluted in saline to provide a dose of $0.2 \mathrm{U} / \mathrm{Kg}$ body weight. Blood glucose levels were measured before and $10,20,30,45,60,90$ and 120 minutes after injection of the insulin.

Results

Results are plotted in figure 15.1 with individual results appearing in Tables $\mathrm{BlO}, \mathrm{B} 1 \mathrm{I}$ and $\mathrm{Bl} 2$.

1. There were no statistically significant differences between the mean blood glucose concentrations in the 3 groups of animals at 0,10 and 20 minutes.

2. The $4 \%$ protein-fed rats showed significantly lower blood glucose concentrations $(p<0.02)$ at all time intervals after 20 minutes, when compared to $20 \%$ protein-fed rats. 3. Weanling rats had blood glucose concentrations which were not significantly different from the $20 \%$ protein-fed controls at any of the times tested. 4. Weanling rats had significantly higher blood glucose levels than the $4 \%$ protein-fed rats at 60,90 and 120 minutes following intravenous insulin administration $(p<0.05, p<0.02 ; p<0.01$ respectively).

5. One-third of the $4 \%$ proteinmfed rats originally tested did not survive the insulin tolerance test. 


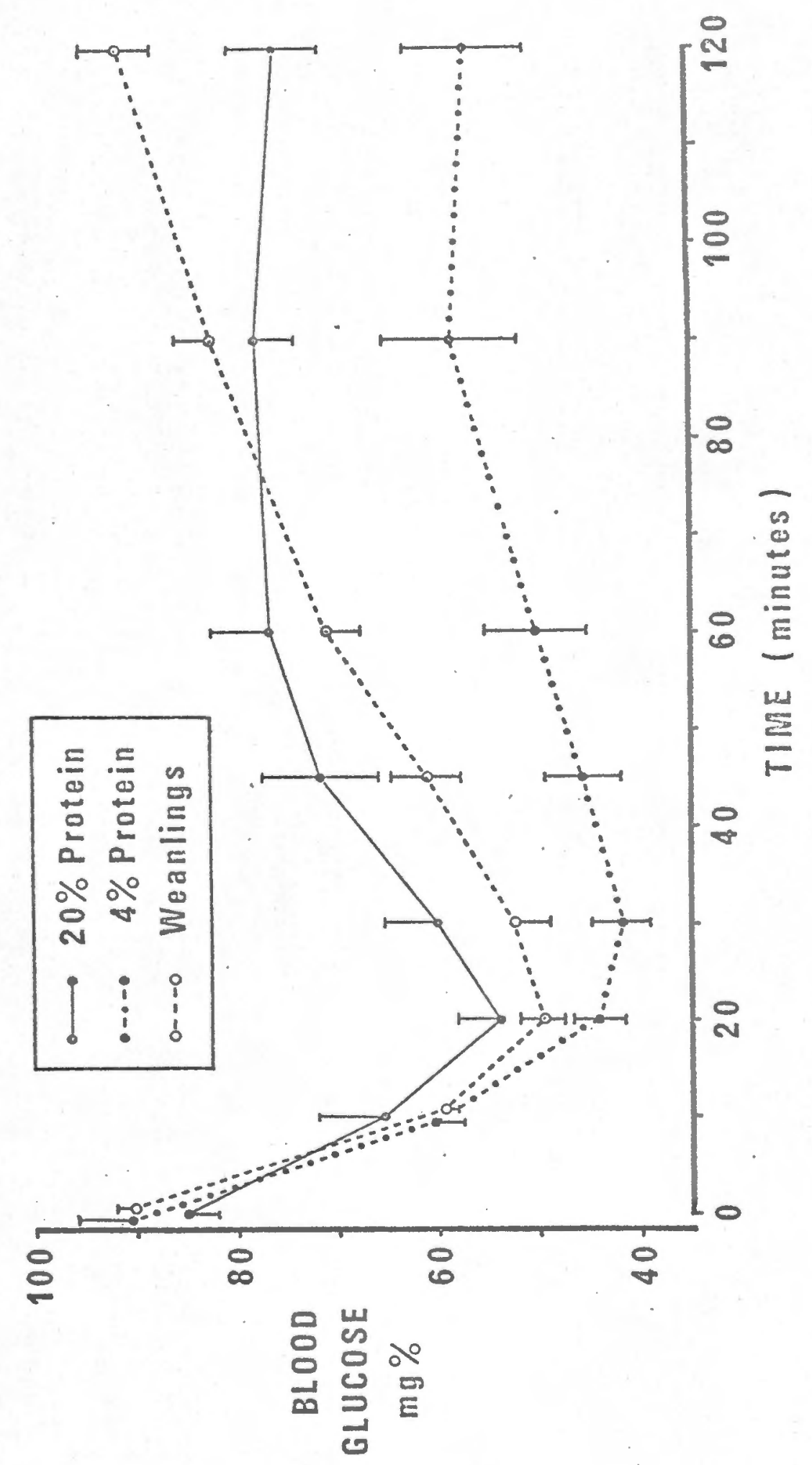

ב

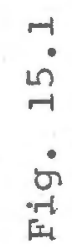




\section{Conclusion}

1. If one uses the rate of fall of blood glucose in the first 20 minutes following insulin administration as an index of insulin sensitivity (see Chapter 31, then all 3 groups studied appear to be equally sensitive to exogenous insulin. It is possible that a smaller dose of insulin might have shown differences in insulin sensitivity between the groups of rats.

2. The malnourished ( $4 \%$ protein-fed) rats were unable to correct the insulin-induced hypoglycaemia.

3. Weanling rats (the weight-matched controls) were however able to correct the insulin-induced hypoglycaemia. Discussion

Insulin resistance as defined earlier (Chapter 3) does not appear to be the explanation of the glucose intolerance with normal insulin release found in weanling rats, after an oral glucose load (Chapter 14). Nor does increased insulin sensitivity account for the comparatively mild glucose intolerance despite poor insulin release found in the $4 \%$ protein-fed rats, after a similar glucose load. The failure of the $4 \%$ protein-fed rats to correct the insulin induced hypoglycaemia may have three possible explanations:

1. An impairment in the degradation of insulin causing a prolonged insulin action, 2. An impairment of the release of hormones which promote gluconeogenesis, such as glucagon and epinephrine, 3. The failure of the liver to respond to these hormones. 
The half disappearance time of endogenous insulin may be calculated from the median insulin levels after an intravenous glucose load (Chapter 13). This showed that the $20 \%$ protein and $4 \%$ protein-fed rats have similar half-disappearance times (approximately 8 minutes). Sacks (1974) from preliminary work in this Department found no difference in the ability of the isolated perfused livers of $4 \%$ protein and weanling rats to dispose of exogenous insulin. For these reasons an abnormality in insulin degradation rate is thought not to be the cause of the prolonged hypoglycaemia in malnourished animals.

Heard (1966) has also reported prolonged hypoglycaemia in malnourished pigs following intravenous insulin administration. In the fasting state, however, these animals responded to adrenalin with immediate hyperglycaemia, which was greater both in degree and duration than that of control pigs.

Alleyne and Scullard (1969) showed an increase in the hepatic levels of one of the key gluconeogenic enzyries glucose-6-phosphatase in malnourished children. Liver phosphorylase concentrations were normal in malnourished children and they had a normal hyperglycaemic response to glucagon.

For the above reasons, the writer suspects a deficiency of glucagon, or rather an impairment of glucagon release in malnourishea rats as the possible cause of their inability to correct the insulin-induced hypoglycaemia. This has however, not been investigated in the present study. 
Summary

There is no difference in insulin resistance or sensitivity between the three groups of animals studied. Malnourished rats showed an inability to correct insulininduced hypoglycaemia and glucagon deficiency has been suggested as a possible cause.

Since this investigation did not provide an explanation for the relatively mild oral glucose intolerance demonstrated in the insulinopaenic $4 \%$ protein-fed animals, previously shown to have marked intravenous glucose intolerance, an investigation into glucose absorption was indicated. 


\section{GLUCOSE : ABSORPTION : FROM THE GUT}

The malnourished animals in these experiments have shown marked glucose intolerance following an intravenous load with only mild glucose intolerance following an oral load, despite the fact that insulin release was significantly impaired in both cases. The relatively mild impairment of oral glucose tolerance is not a unique finding. Thus Platt et al (1964d) reported that oral glucose tolerance testing in malnourished pigs appeared to indicate "an abnormally high tolerance for glucose" whereas intravenous glucose administration revealed markedly impaired glucose tolerance. They attributed this difference in response to impaired glucose absorption, since their malnourished pigs also showed abnormalities in the gut epithelium (Platt et al, 1964c). Thus many workers have chosen the intravenous glucose tolerance test to assess glucose tolerance in malnourished animals "to avoid (the) complications arising from malabsorption which commonly occurs in protein-calorie deficiency" (Heard and Henry, 1969b, page 382). Since the evidence for impaired glucose absorption appeared circumstantial rather than direct, it was felt necessary to investigate glucose absorption in the malnourished rat model. Methods

Many techniques for the investigation of intestinal absorption in vivo have been described (Smyth,1961). However, the technique used here was the simple one devised 
by Cori (1925) since this method avoided anaesthesia and measured glucose disappearance from the whole of the gut instead of sections of bowel.

overnight fasted rats were given an oral glucose load ( $50 \%$ dextrose $1 \mathrm{ml} / 100 \mathrm{~g}$ body welght as described for the oral glucose tolerance test except that no blood samples were taken. Animals were killed by stunning 15 or 30 minutes after the glucose load. The abdominal cavity was opened, ligatures tied round the oesophagus and rectum, and the entire gut was removed and placed in a petri dish. The bowel was slit open and the contents washed with distilled water through a cottonwool filter into a $100 \mathrm{ml}$ volumetric flask. A standard solution was prepared from the same solution of $50 \%$ dextrose as was given to the animals orally. The: glucose concentration was measured in standard and samples using the glucose oxidase method described in Appendix A.

\section{Calculation}

The amount of glucose absorbed from the gut lumen was calculated from the difference between the total amount of glucose given orally and the amount of glucose recovered from the bowel washings. During preliminary trials, during which animals were killed immediately after receiving the glucose load, this method was found to give a glucose recovery rate of approximately $80 \%$ which is in agreement with that found by scow and cornfield (1954). 


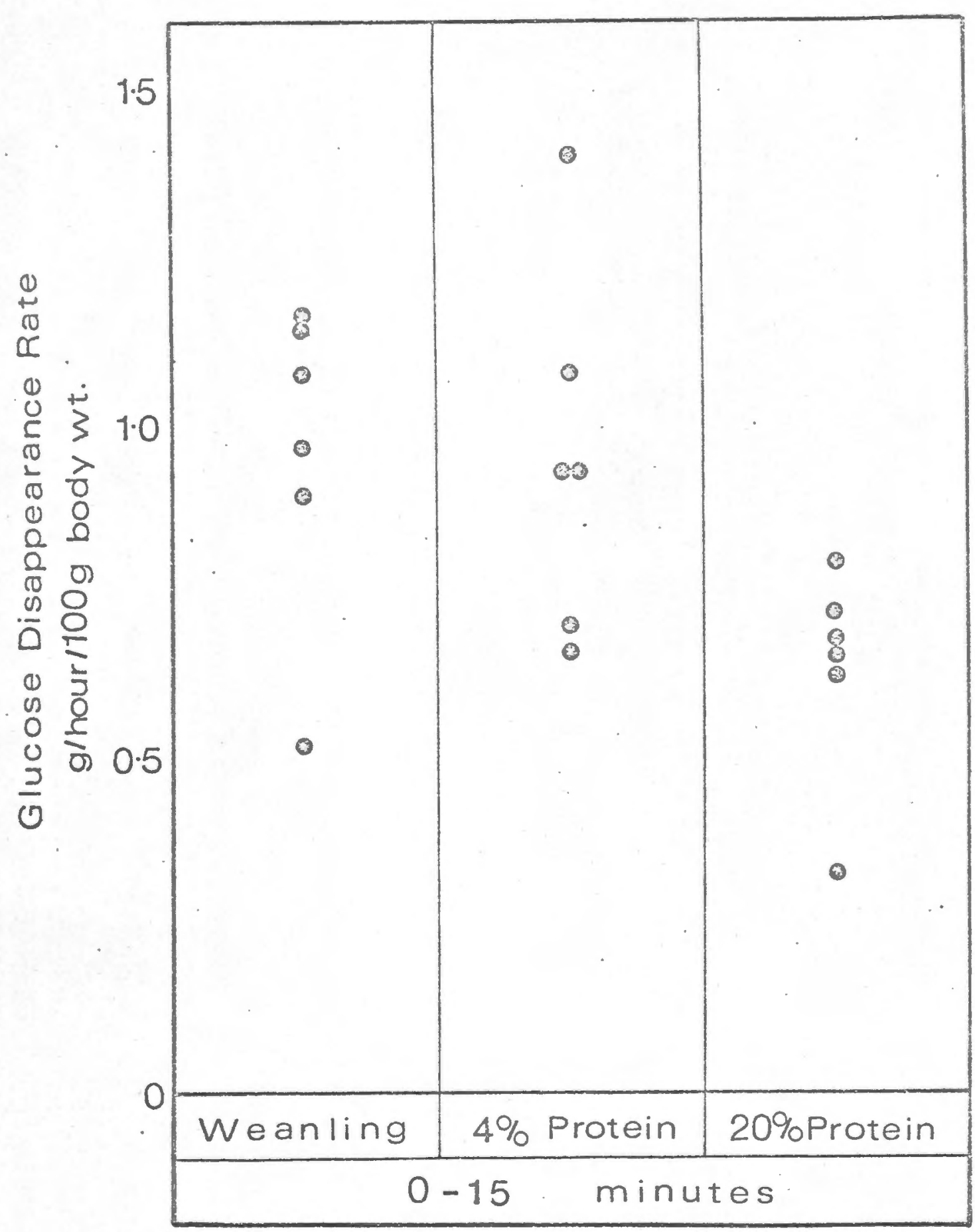

Fig. 16.1 Glucose absorption from the gut Iumen calculated over the first 15 minutes. 


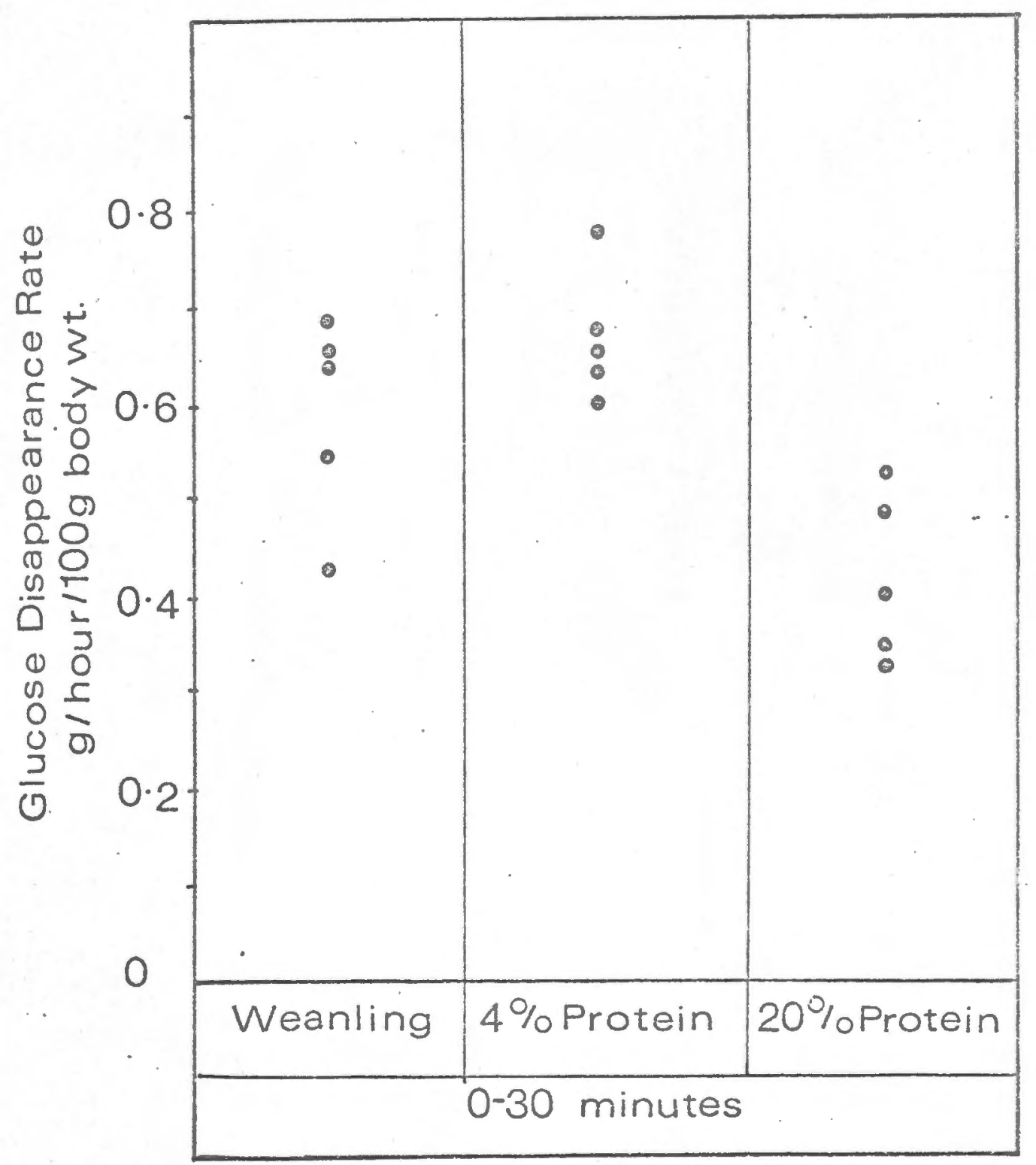

Fig. 16.2 Glucose absorption from the gut lumen, calculated over 30 minutes. 
Resuilt.s

Results are expressed as grams of glucose absorbed per hour per $100 \mathrm{~g}$ body weight and appear in figures 16.1 and 16.2, with individual results in Table $\mathrm{B} 13$, 1. There was no significant difference between the mean disappearance rate of glucose from the gut between the $4 \%$ protein-fed rats and weight-matched weanling controls, during the 0 to 15 and 0 to 30 minute intervals.

2. The $4 \%$ protein-fed rats had significantly higher glucose disappearance rates than the $20 \%$ protein-fed controls as measured over the 0 to 15 minute period $(p<0.05)$ and the 0 to 30 minute period $(p<0.001)$.

3. Weanling rats showed significantly higher glucose disappearance rates than $20 \%$ protein-fed controls when this was measured over the 0 to 15 minute period $(p<0.025)$. There was no statistical significance in the difference between the mean values of glucose disappearance rates, measured over the 0 to 30 minute period, between these two groups.

\section{Conclusions}

The rate of glucose absorption from the gut lumen is greater in $4 \%$ protein-fed than $20 \%$ protein-fed rats. There was nosignificant difference between the rate of glucose absorption from the gut lumen between weanling and $4 \%$ protein-fed rats.

\section{Discussion}

The relatively mild glucose intolerance following an oral load in malnourished rats cannot be attributed to a 
diminished rate of absorption of glucose from the gut lumen. In fact the glucose absorption rate in malnourished rats is greater than that of the $20 \%$ protein-fed controls and does not differ significantly from the weight-matched controls.

These results would seem to be at variance with the reports of impaired glucose absorption in malnourished children (James, 1968) and the report by Heard and Henry (1969b) of glucose malabsorption occurring commonly in protein-calorie deficiency. In malnourished rats lifshitz et al (1972) found an increased absorption of carbohydrates, while Kirsch et al (1968c) found amino acid uptake to be normal in protein-calorie deficient rats and increased in rats on a protein-free diet.

Since there was no difference in the rate of glucose absorption from the gut lumen to account for the difference in glucose tolerance between weanling and $4 \%$ protein-fed rats, two other possibilities were considered:

1. An increased hepatic glucose extraction in $4 \%$ proteinfed animals as compared to the weanling rats. However, since insulin is known to be one of the most important factors affecting glucose uptake by the liver, and since the malnourished rats have been shown to have consistently low plasma insulin concentrations both before and after oral or intravenous glucose, this seemed an unlikely possibility. 2. Glucose, though rapidly disappearing from the gut lumen was not being transported into the portal circulation due to either a block in the transport mechanism or due to excessive utilisation by the gut wall itself. 
To investigate this second possibility, portal glucose concentrations were measured in rats following an oral glucose load. 
CHAPTER ' 17

PORTAI VENOUS GLUCOSE AND INSULIN CONCENTRATIONS

AFTER AN : ORAL GLUCOSE : LOAD

Aim

This experiment fulfilled two functions:

1. To determine whether the high rate of glucose

disappearance from the gut lumen of the $4 \%$ protein-fed and weanling rats was accompanied by high concentrations of glucose in the portal vein following an oral glucose load. Since glucose disappeared from the gut of these animals at equal rates (see Chapter 16) any difference in their portal venous blood glucose concentrations might indicate increased utilisation of glucose by the gut lumen, or a block in the glucose transport mechanism in one of these groups.

2. To determine whether the low peripheral insulin concentrations encountered in the malnourished rats following an oral glucose load was a true reflection of portal vein insulin concentrations.

Methods

Basal blood samples were taken from the tail vein of fasted rats which were then given an oral glucose load (50\% Dextrose, $1 \mathrm{ml} / 100 \mathrm{~g}$ body weight) as described in Chapter 14. Portal vein samples were taken at either 5, 10 or 15 minutes after the glucose load. Two minutes prior to sample collection the rat was rapidy anaesthetised with ether, the abdomen opened and blood taken directly from the portal vein with a 26 gauge needle attached to the 
end of a heparinised capillary tube. Only one sample was taken from each rat, the animal being killed immediately thereafter. Blood glucose and plasma insulin concentrations were determined on each sample as described in Appendix A. Results

The mean blood sugar concentrations with their SEM are shown in fig.17.I with the median plasma insulin levels plotted in fig.17.2. In both these graphs the mean peripheral blood glucose and median insulin concentrations were recorded from data obtained from fig.14.1. Individual results are recorded in Tables $\mathrm{B} 14, \mathrm{~B} 15$ and $\mathrm{B} 16$, in which also appear the animal weights and their fasting blood glucose and insulin concentrations.

There are fewer results reported in this study than in that following the conventional oral glucose tolerance test, since animals had to be sacrificed at varying time intervals. Nevertheless a statistical evaluation of the results is reported.

A. Blood glucose

1. Weanling rats show significantly higher portal blood glucose concentrations at 5 and 10 minutes when compared with the $20 \%$ protein-fed controls $(p<0.05)$.

2. Malnourished animals showed a significantly higher blood glucose level at 15 minutes than the $20 \%$ protein-fed rats $(p<0.05)$.

3. Weanling rats had significantly higher blood glucose levels than the malnourished animals at 5 minutes $(p<0.025)$. 

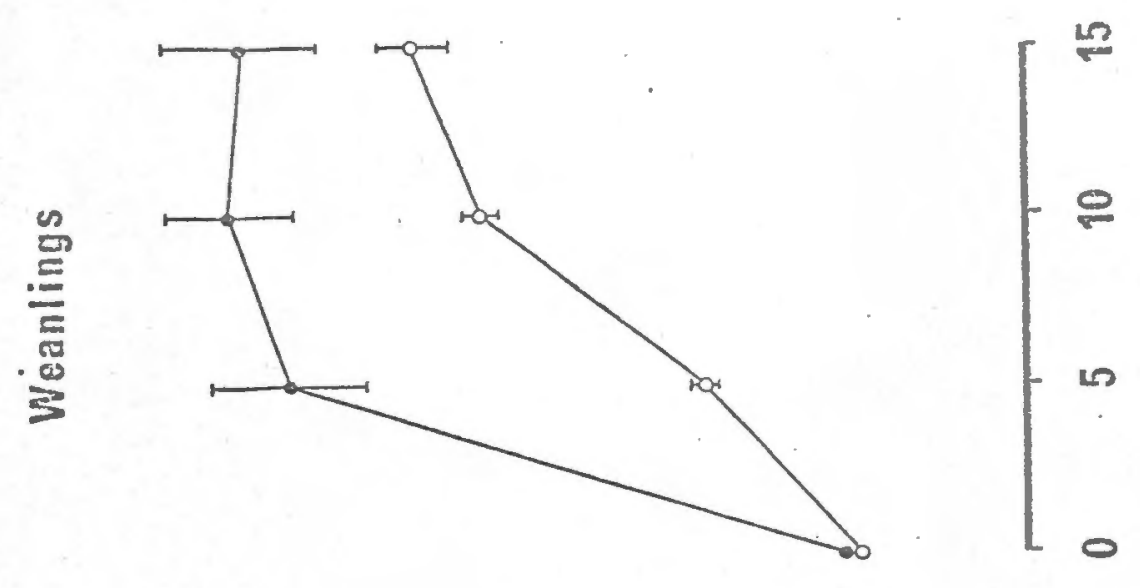

0
0
0
-1
+1
0
4
4
0
0
0
0
0
0
0
0
0
0
5
0
0
0
0
0
0
-1
0
0

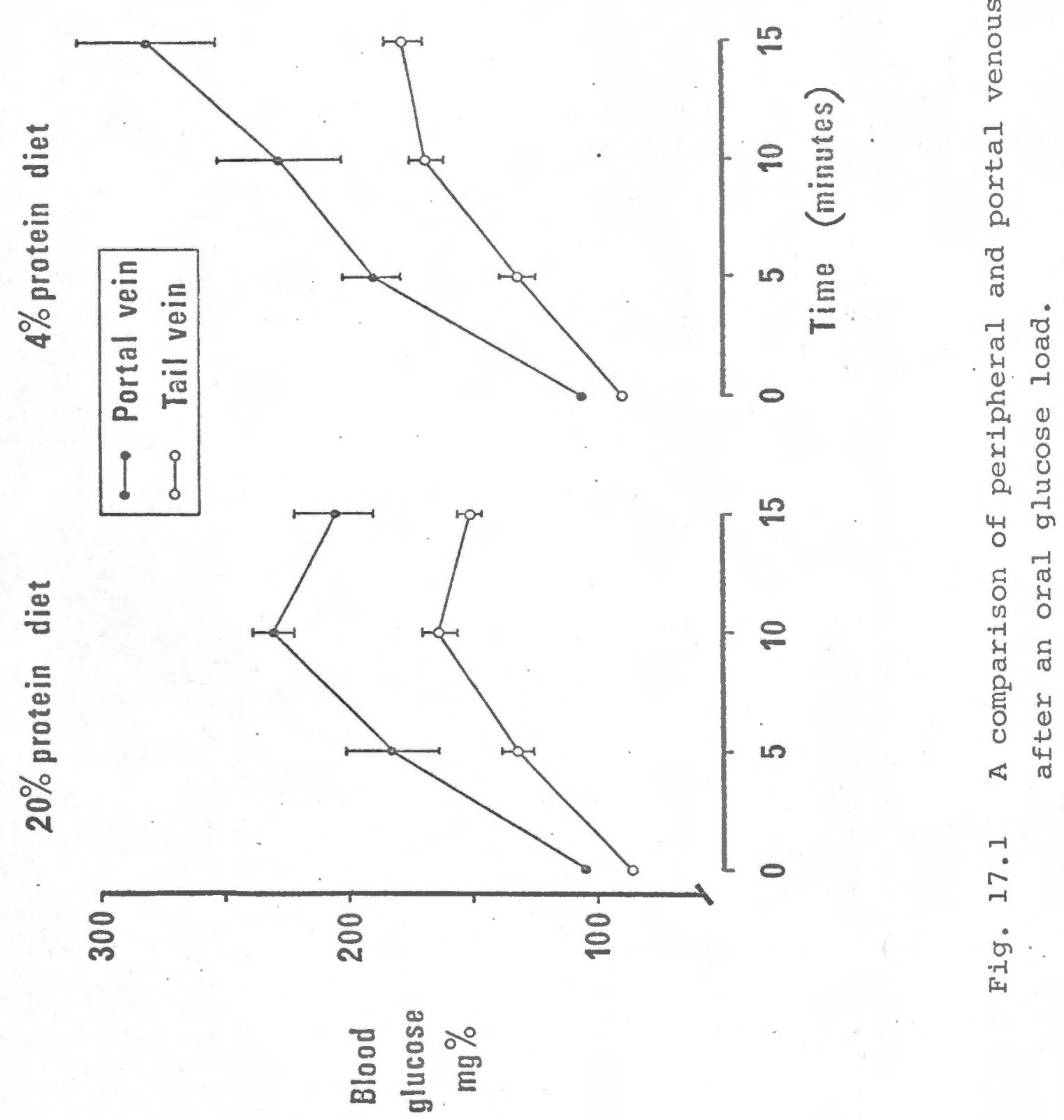



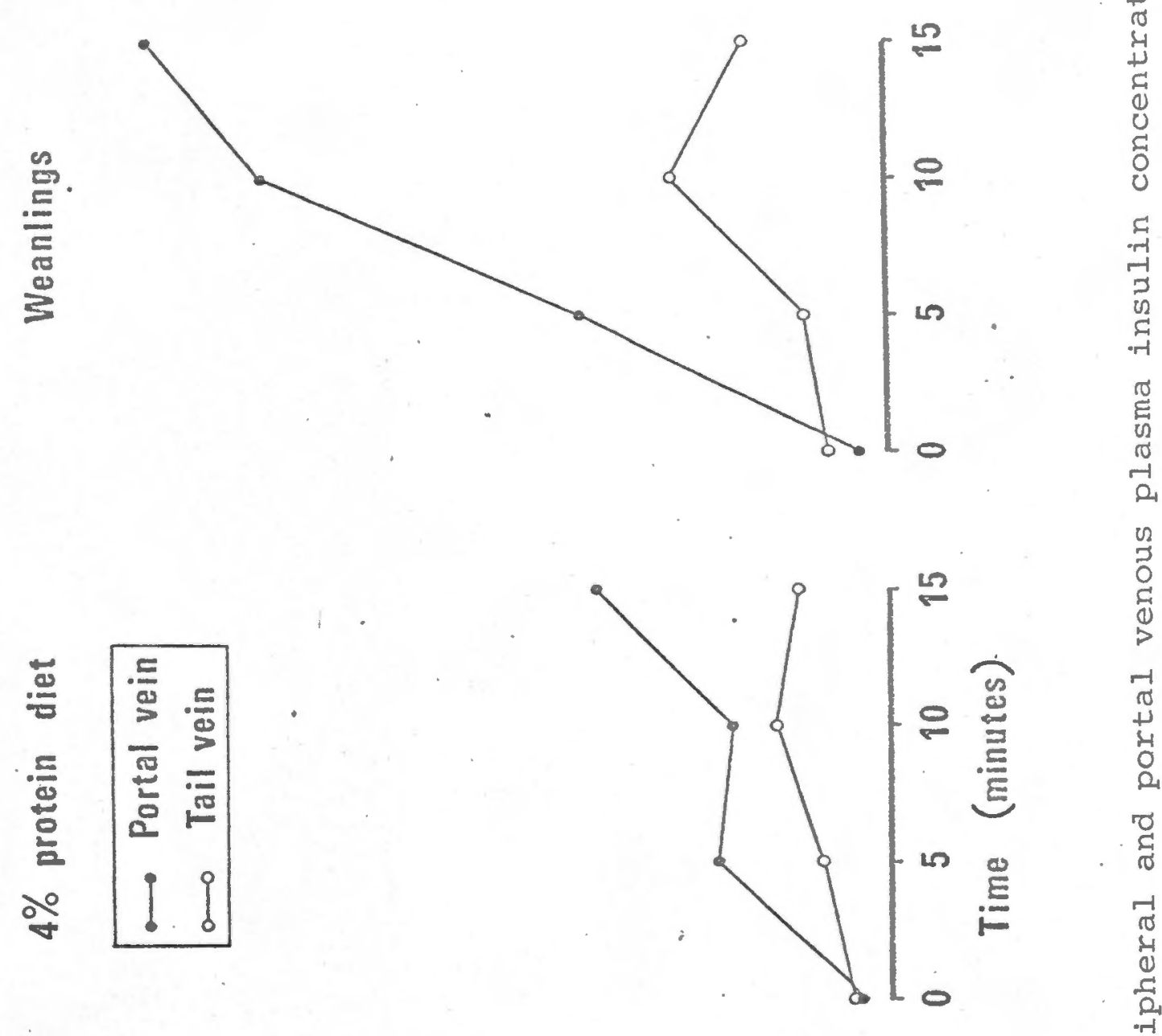

ป

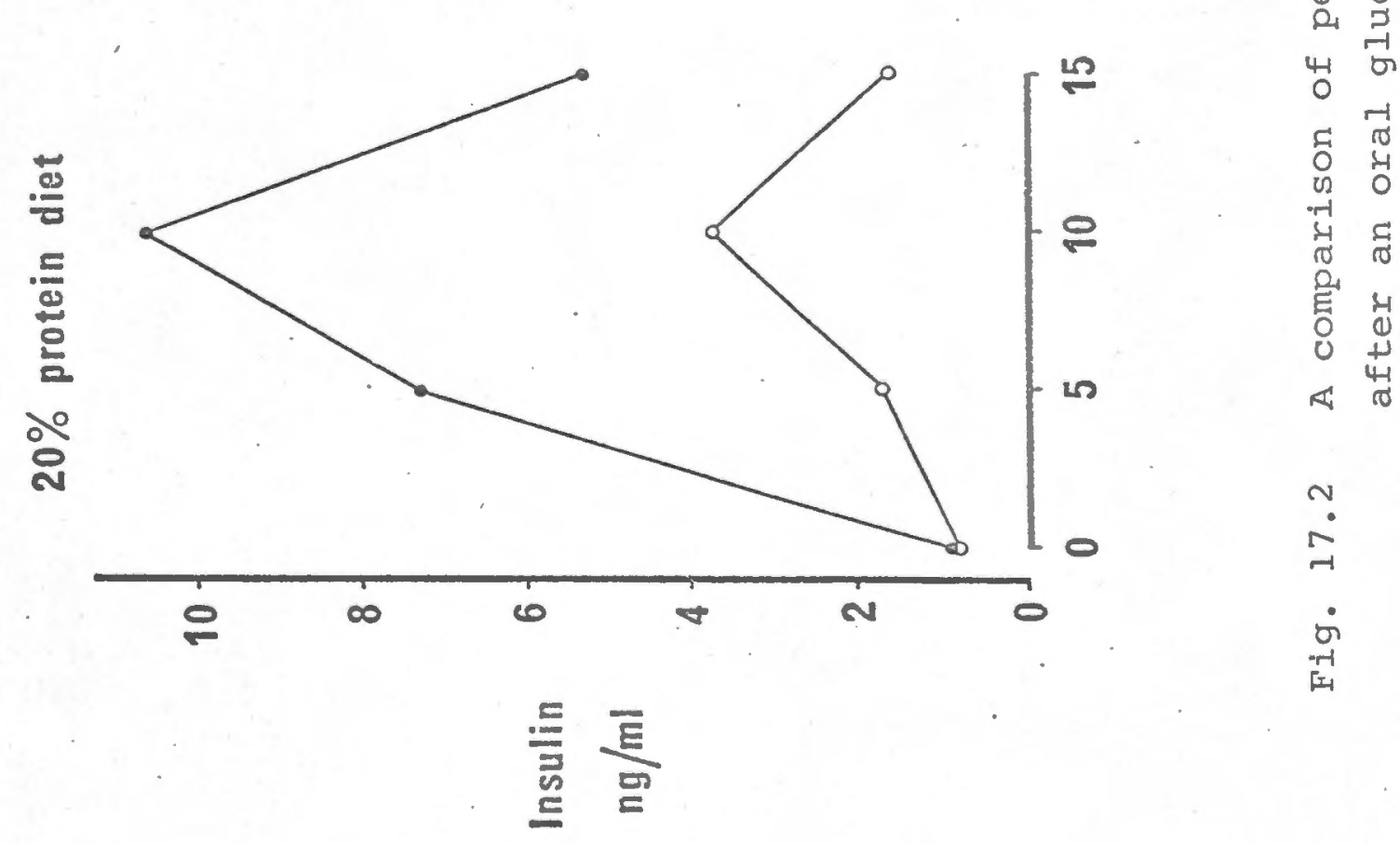

 


\section{B. Plasma insulin responses}

1.

There were no significant differences between the portal vein plasma insulin concentrations of weanling and $20 \%$ protein-fed rats during the test.

2. Weanling rats had portal plasma insulin concentrations that were significantly higher than the $4 \%$ protein-fed animals at 10 minutes $(p<0.01)$ and at 15 minutes $(p<0.05)$.

3. The portal plasma insulin concentrations of the malnourished rats were significantly lower at 10 minutes $(p<0.005)$ than the $20 \%$ protein-fed animals.

\section{Conclusions}

Assuming that there were no differences in portal blood flow between the groups of animals studied, one would expect greater rates of glucose absorption from the gut lumen to be reflected in higher portal blood glucose concentrations. It is not surprising therefore to find that weanling rats, previously shown to have a greater rate of glucose absorption from the gut lumen, have significantly higher portal blood glucose concentrations at 5 and 10 minutes than the $20 \%$ protein-fed rats.

When the portal blood glucose concentrations of the $20 \%$ protein-fed rats were compared to those of the $4 . \%$ protein-fed animals, there were no significant differences at the 5 and 10 minute intervals, despite the fact that the 4\% protein-fed rats had glucose disappearance rates from the gut lumen which were significantly higher than that. of the $20 \%$ protein-fed rats. This finding has been interpreted as indicating that glucose, although disappearing ranidly 
from the gut lumen of malnourished rats, had not crossed the gut wall into the portal circulation or had been rapialy metabolised by the gut epithelium itself.

The measurement of portal insulin concentrations in this study has shown that the low peripheral plasma insulin concentrations obtained in the malnourished animals after an oral glucose load, was not due to increased hepatic degradation of insulin in these animals.

This study also revealed a significant difference in the 10 minute portal insulin concentrations between the weanling and 4 \% protein-fed rats $(8.7 \mathrm{ng} / \mathrm{ml} \mathrm{vs} 2.1 \mathrm{ng} / \mathrm{ml}$, $p<0.01)$, a significance not shown in the peripheral plasma insulin concentrations $(2.9 \mathrm{ng} / \mathrm{ml}$ vs $1.5 \mathrm{ng} / \mathrm{ml}, \mathrm{p}>0.05)$. Discussion

Although the mean disappearance rate of glucose from the gut lumen was of the same magnitude in weanling and 4\% protein-fed rats, the former showed a more rapid rise in portal glucose concentrations than the latter. Assuming equal flow rates in these two groups one may conclude that not all the glucose disappearing from the gut in the malnourished animal reached the portal circulation. These results are in accord with those of lifshitz et al (1972) who measured the absorption of carbohydrate in malnourished rats by the perfusion of intestinal segments in vivo. They reported a temporary increase in the transport of glucose, sodium and water in these animals with an increased utilisation of glucose by the intestine. Kershaw et al (1960) reported that semi-starvation 
in rats enhanced the rate of disappearance of both glucose and I-histidine from the small intestine in vivo, and they demonstrated increased transport of these substances in vitro.

Kirsch et al (1968c) found an increased amino acid uptake by gut segments of rat maintained on a proteinfree diet. These animals however showed no increase in amino acid transport across the intestine.

Increased glucose utilisation by the intestine of malnourished animals may in part explain their relatively mild glucose intolerance despite very low plasma insulin concentrations.

Portal insulin concentrations after an oral glucose load have been shown to correspond with peripheral plasma insulin concentrations, as has been reported in humans (Blackard and Nelson, 1970, 1971). However the fractional reduction of insulin concentration between portal and peripheral venous blood was not constant, with the difference between the two being greater at higher than at lower portal insulin concentrations (fig.17.2). This is in agreement with the findings of Erwald et al (1973) in human pancreatitics. 


\section{A BRIEF SUMMARY OF GLUCOSE TOLERANCE IN THE PROTEIN-CALORIE DEFICIENT :RAT}

1. The malnourished rats had fasting normoglycaemia with low peripheral plasma insulin concentrations. 2. Malnourished rats have diminished early insulin release following both oral and intravenous glucose loading. 3. In malnourished rats intravenous glucose intolerance was marked, whereas oral glucose intolerance was relatively mild.

4. The mild oral glucose tolerance was not due to a diminished rate of absorption of glucose from the gut lumen, but was felt to be partially explained on the basis of increased utilisation of glucose by the gut wall. 5. Malnourished rats do not show increased insulin resistance as measured by the rate of fall of blood glucose in the first 20 minutes following insulin administration. 6. Malnourished rats did, however, show an impairment in their ability to correct insulin-induced hypoglycaemia. 7. There was no impairment of hepatic degradation of insulin to account for the prolonged hypoglycaemia following insulin administration. From evidence in the literature, it is suggested that these animals might have an impaired ability to release glucagon, which may account for their prolonged hypoglycaemia after the administration of insulin. 
CHAPTER 19

\section{INTRAVENOUS TOLBUTAMIDE - TEST}

\section{Introduction}

Rats on a $4 \%$ protein diet have been shown in the preceding chapters to have a diminished insulin response to both an oral and an intravenous glucose load. If this was due to a defect in some "glucoreceptor" it was hoped that some other agent acting in a different way might provoke a normal insulin response. Since tolbutamide has been shown to have a direct stimulatory action on the $\beta$ cell of the islets of Langerhans (Basabe et al, 1971), and since this drug had an action on the early release of insulin which was independent of blood glucose concentration and unaffected by mannoheptulose (Loubatières-Mariani et al, 1973), it was chosen for this test.

Method

Tolbutamide (Rastinon, Farbwerke Hoechst AG), $12.5 \mathrm{mg} / 100 \mathrm{~g}$ body weight diluted with normal saline, was injected into the tail vein of fasted rats. Blood samples were taken before and $3,6,10,15,30,45$ and 60 minutes after completion of injection. Blood glucose and plasma insulin concentrations were measured on all samples (see Appendix A).

Resuilts

(a) Changes in blood glucose concentration following intravenous tolbutamide. (See fig. 19.1 and Tables $B 17, B 18$ and $B 19)$. 


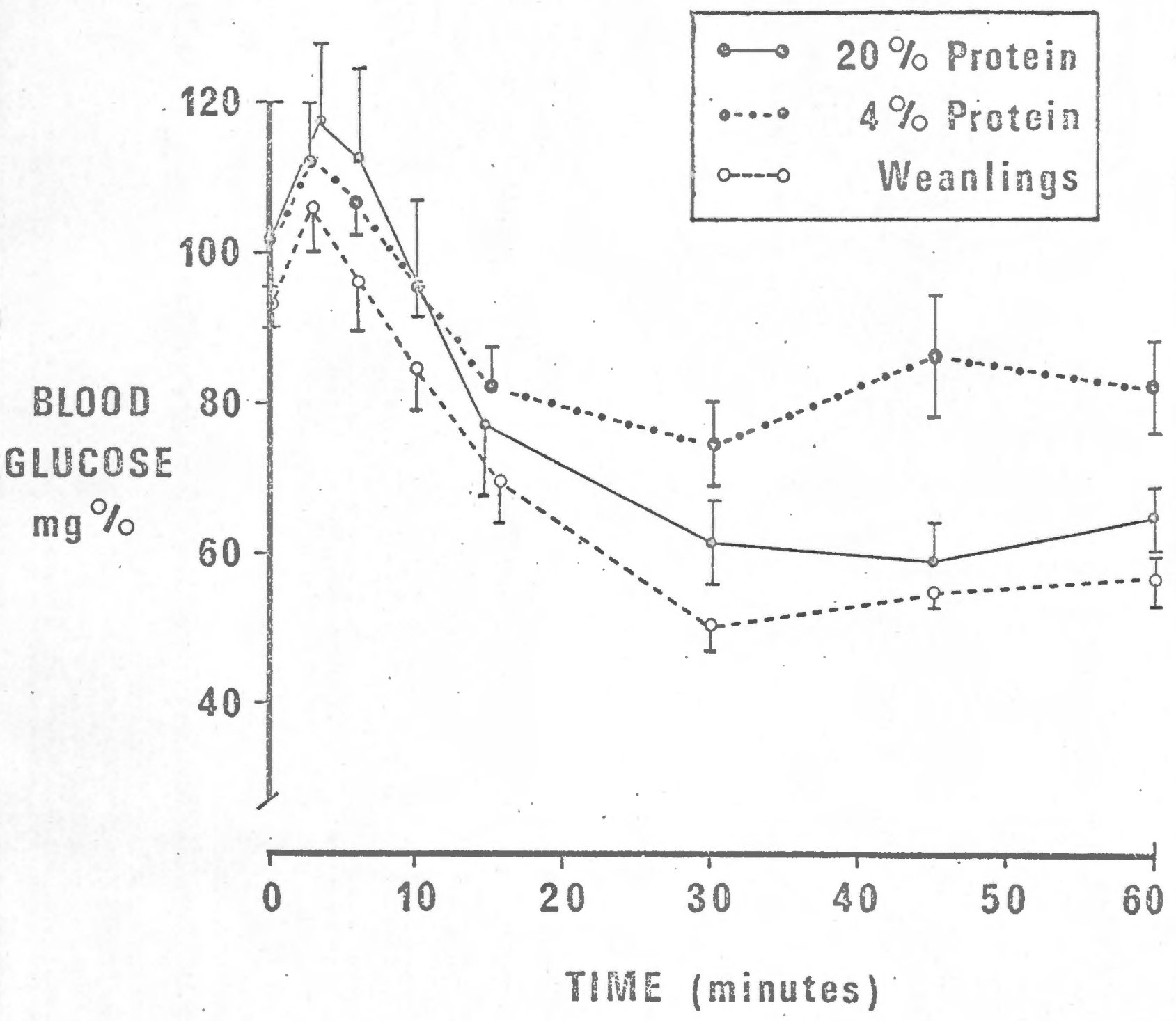

Fig. 19.1 Blood glucose concentrations after intravenous tolbutamide. 


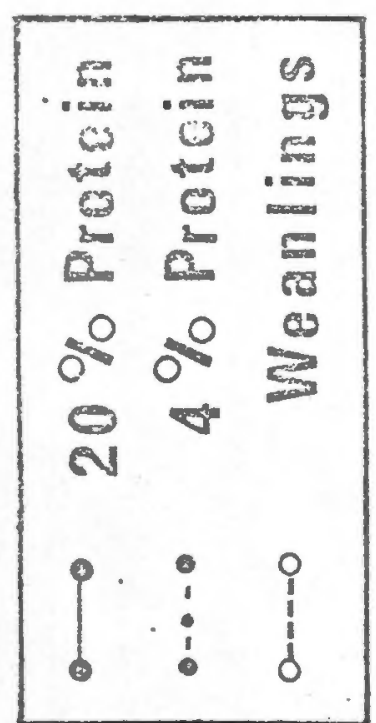

$90 \quad \vdots \quad T 0$

נُ

20

(5)

$-\infty$

$\infty$

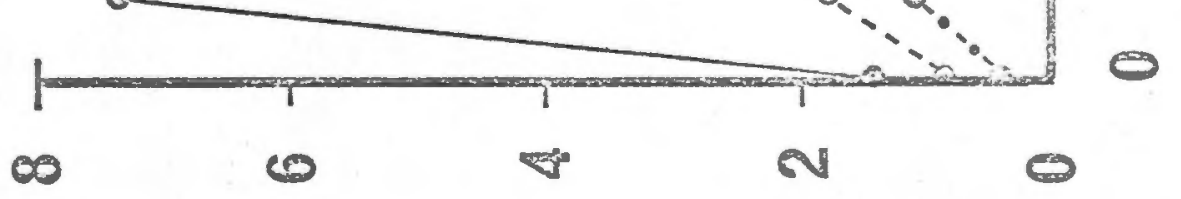

$\stackrel{N}{\sim}$

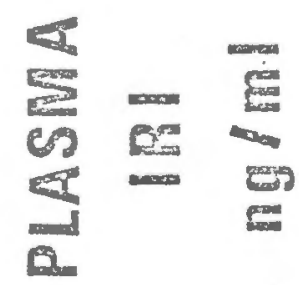

$\underset{\substack{\infty \\ \text { I }}}{\dot{\infty}}$ 
1. There were no significant differences in blood glucose concentrations between weanling and $20 \%$ proteinfed rats at any of the time intervals.

2. During the first 30 minutes following intravenous tolbutamide administration, there were no significant differences between the blood glucose concentrations of the $4 \%$ protein and $20 \%$ protein-fed rats $(p>0.1)$ Blood glucose concentrations were higher however in the malnourished animals at 45 minutes $(p<0.02)$ and 60 minutes $(p<0.05)$. 3. During the first 15 minutes after intravenous tolbutamide administration there was no statistically significant difference between mean blood glucose concentrations of the weanling and $4 \%$ protein-fed rats. Thereafter the $4 \%$ protein-fed rats had significantly higher blood glucose levels $(p<0.002)$ than the weanling rats.

(b) Changes in plasma insulin concentration following intravenous tolbutamide administration. (See fig. 19.2 and Tables B17,B18 and B19).

1. $4 \%$ protein-fed rats had plasma insulin concentrations which were significantly lower than the $20 \%$ protein-fed animals at the following time intervals: 0 minutes $(p<0.02)$, $3,6,10$ minutes $(p<0.002), 15$ minutes $(p<0.02)$ and 60 minutes $(p<0.002)$.

2. Weanling rats had lower median insulin concentrations than the $20 \%$ protein-fed animals but statistical significance was only found at 3 and 6 minutes $(p<0.02)$.

3. Weanling rats had higher median insulin concentrations than the $4 \%$ protein-fed rats at all time intervals but this 
was only statistically significant at the following times. 3 minutes $(p<0.05), 10$ minutes. $(p<0.002), 15$ minutes $(p<0.02)$, 30 minutes $(p<0.05)$ and 60 minutes. $(p<0.02)$. Summiry of results and discussion

When compared to the $20 \%$ protein-fed rats, both the malnourished and weanling rats show impaired early insulin release following intravenous tolbutamide. Despite their poor insulin response weanling rats, however, had a normal hypoglycaemic response to tolbutamide, while the malnourished rats had mean blood glucose levels higher than the $20 \%$ controls after 15 minutes.

The difference between $4 \%$ protein-fed and weanling rats in their hypoglycaemic response to tolbutamide may be attributed to the fact that weanling rats had higher plasma insulin levels than the $4 \%$ protein-fed rats. Although these differences were small they were shown to be statistically significant at $3,10,15$ and 60 minutes after tolbutamide.

A difference in the responsiveness to the extrapancreatic effects of the sulfonylureas (Feldman and Lebovitz, 1969; Beyer et al, 1973) may account for the anomaly of a normal hypoglycaemic response to tolbutamide with a poor insulin response to this drug, as shown by the weanling rats. This study was done in the hope that a defect limited to the $\beta$ cell. glucoreceptor might be uncovered by showing that either the malnourished animal or the weanling rat had a normal insulin response to tolbutamide. However, the insulin response to tolbutamide was poor in both these groups 
of animals, though better in the weanling animals than in the malnourished rats.

The poor insulin response to both intravenous

glucose (see Chapter 13) and intravenous tolbutamide shown by weanling rats led to the next investigation. 
CHAPTER 20

THE 'INTRAVENOUS' GLUCOSE AND ' AMINOPHYLIINE 'TEST

\section{Introduction}

Although the purpose of this thesis as outlined in Chapter. 1 was to investigate the effects of proteincalorie deficiency on insulin release in malnourished rats, weanling rats were investigated as well for two reasons:

(1) They were used as weight-matched controls, to indicate that any differences between the insulin responses of $20 \%$ protein-fed rats and $4 \%$ protein-fed rats was not due to the small size of the malnourished animals.

(2) Weanlings were also used to explore the possibility of the poor insulin response in malnutrition being due to a functionally "immature" pancreas, as had been suggested by Heard et al (1961).

Weanling rats in common with the malnourished animals have been shown to have:

(1) A diminished insulin response to intravenous glucose (Chapter 13).

(2) A diminished insulin response to intravenous tolbutamide (Chapter 19).

On the other hand they did show a normal insulin response to oral glucose (Chapter 14), which was significantly greater than that of the malnourished animals when portal insulin concentrations were compared (Chapter 17).

Aminophylline was used as an intravenous stimulus in an effort to find some other difference between the 
insulin responses of the weanling and malnourished rats. Aminophylline was chosen for the following reasons:

(a) It had been shown to induce insulin release in rats previously shown not to respond to intravenous glucose (Turtle et al, 1967).

(b) Pagliara et al (1973) had reported that a child with transient neonatal diabetes was able to respond to caffeine (another methyl xanthine alkaloid) with a good insulin response during a phase when there was no glucose and tolbutamide mediated insulin response.

(c) Caffeine has also been shown to improve the glucoseinduced (Lambert et al, 1969a) or tolbutamide-induced (Lambert et al, 1969b) insulin release of foetal pancreatic tissue. In view of the last mentioned findings, glucose plus aminophylline was chosen as the stimulus in the three groups of rats.

Although foetal rat tissue has been reported not to show glucose stimulated insulin release, while two day old newborn rats were able to respond to glucose stimulation (Asplund et al, 1969), it was thought that 21 day old weanling rats might show an improved insulin release if they were given both glucose and aminophylline.

Method

Overnight fasted rats were given an intravenous injection of aminophylline (Nutrated, Propan) diluted in $12.5 \%$ dextrose to provide a dose of $6.25 \mathrm{mg} / \mathrm{ml}$. Each animal was given $1 \mathrm{ml} / \mathrm{l} 00 \mathrm{~g}$ body weight via a tail vein and blood samples were taken at $0,3,6,10,15,20,25$, and 
30 minutes. Blood glucose and plasma insulin

concentrations were determined as described in Appendix $A$. Calculations

Glucose disappearance rates after glucose plus aminophylline $(\mathrm{Kg}+\mathrm{a})$ were determined as described for the conventional intravenous glucose tolerance test (see

Chapter 13). Care was taken to note any delay in collecting blood samples.

\section{Results}

In Table 20.1 the $\mathrm{Kg}+\mathrm{a}$ values of the three groups of animals are compared with the $\mathrm{Kg}$ values previously shown in Table 13.1. In fig.20.1, the changes in concentration with time of the median insulin values are plotted for the 3 groups of animals. Individual values for blood glucose and plasma insulin concentrations appear in Tables B20, B2I and B22.

A. Comparison of $\mathrm{Kg}$ (glucose a lone) and $\mathrm{Kg}+\mathrm{a}$ (glucose plus aminophylline) values

Table 20.1

\begin{tabular}{|c|c|c|c|}
\hline & $20 \%$ Protein & $4 \%$ Protein & Weanling \\
\hline $\begin{array}{l}\mathrm{Kg} \\
(\mathrm{n})\end{array}$ & $7.44 \underset{(10)}{ \pm} 0.42$ & $5.29 \pm 0.57$ & $5.23 \pm 0.30$ \\
\hline$\underset{(n)}{\mathrm{Kg}}+\mathrm{a}$ & $6.19 \pm 0.53$ & $4.43 \pm 0.28$ & $4.05 \pm 0.33$ \\
\hline
\end{tabular}

1. Kgta values were significantly lower in both the $4 \%$ protein-fed rat $(p<0.02)$ and weanling rats $(p<0.005)$ when these are compared to the $20 \%$ protein-fed animals. 2. There was no statistical difference in the mean $\mathrm{Kg}+\mathrm{a}$ 

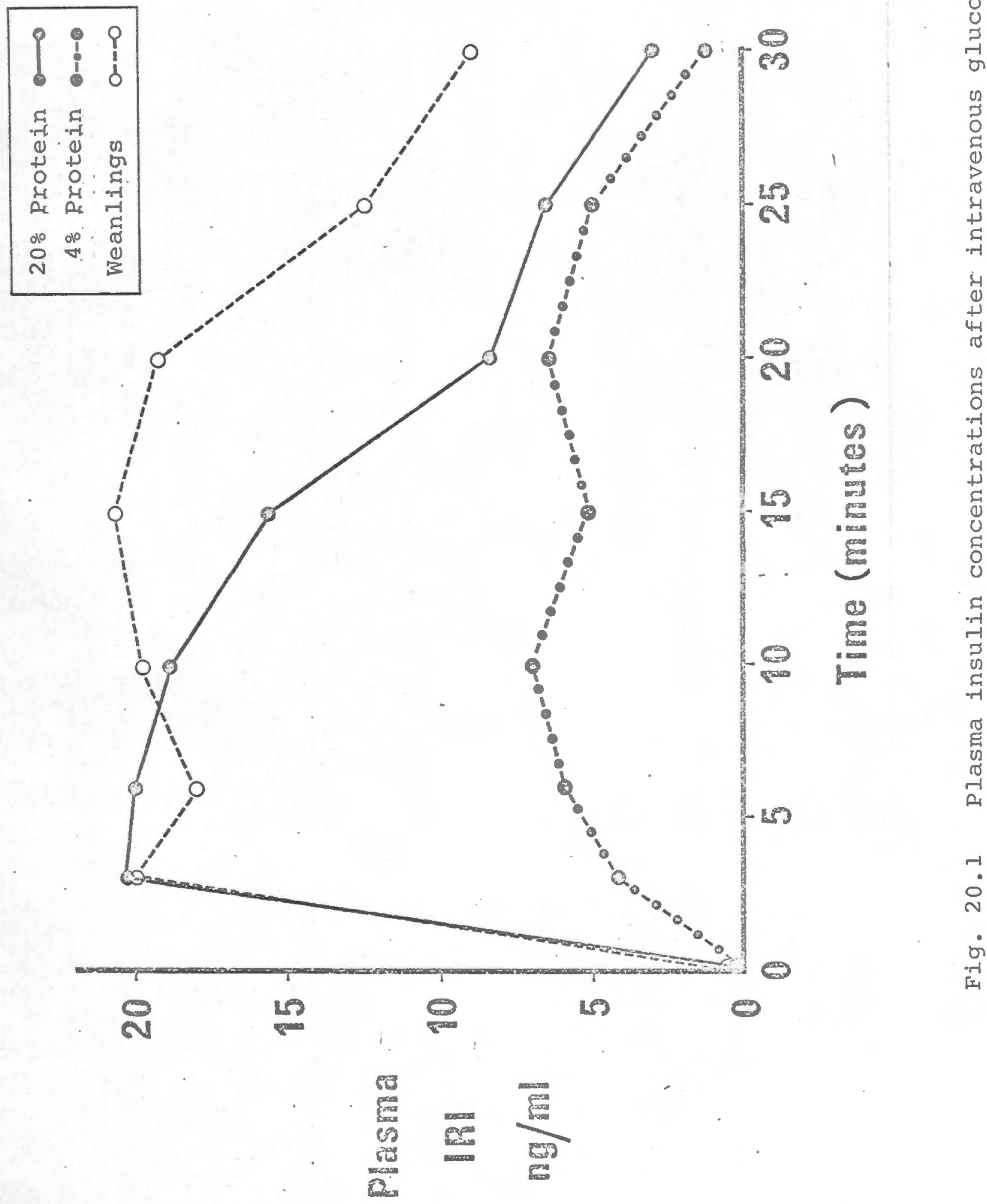
levels of the weanling and $4 \%$ protein-fed rats ( $p>0.1)$. 3. For each group of rats studied, the mean $\mathrm{Kg}+\mathrm{a}$ level was lower than their mean $\mathrm{Kg}$ level but the difference between the two indices was only significantly different in the weanling rats $(p<0.02)$.

B. The insulin response to glucose plus aminophyliline

1. There was no significant difference in the plasma insulin concentrations between the weanling and $20 \%$ proteinfed rats throughout the test period.

2. Weanling rats showed significantly higher plasma insulin concentrations than the malnourished animals throughout the test, with $\mathrm{p}$ values $<0.002$ at 3,6 , and 15 minutes;

$p$ values $<0.02$ at 10 and 30 minutes, and $p<0.05$ at 20 and 25 minutes.

3. The $20 \%$ protein-fed rats had higher median plasma insulin concentrations than the malnourished rats with $p<0.002$ at 3 and 6 minutes and $p<0.02$ at 10 and 15 minutes. There was no statistical significance in the difference between the insulin concentrations in these two groups after 15 minutes.

\section{Summary of results}

All 3 groups of animals show a greater insulin response to intravenous glucose plus aminophylline than to intravenous glucose alone. But whereas in the latter test the insulin response was impaired in weanlings when they were compared to the $20 \%$ protein-fed rats, both these groups now show no statistically significant difference in their insulin response. The $4 \%$ protein-fed rats showed 
an impaired insulin response when compared to both the $20 \%$ protein-fed and the weanling rats.

Despite the greatex than normal insulin response to intravenous glucose plus aminophylline than to intravenous glucose alone, the glucose disappearance rate after aminophylline $(\mathrm{Kg}+\mathrm{a})$ was less than the glucose disappearance rate after glucose alone $(\mathrm{kg})$. This finding is in agreement with the report by Penhos et al (1972) of insulin-resistant hyperglycaemia induced by aminophylline. Aminophylline inhibits phosphodiesterase, the enzyme that inactivates cyclic AMP in the body (Butcher and Sutherland, 1962). Since cyclic AMP is the second messenger, mediating the effect of many hormones, it is not surprising that aminophylline produces many different effects on the body. Sutherland and Robison (1969) have stressed the central role played by cyclic AMP in the control of carbohydrate metabolism and insulin release. One may speculate at length about the possible defects in cyclic AMP formation or inactivation to explain the differences in the insulin response to aminophylline and glucose between weanling and malnourished rats.

There is however insufficient data from these experiments to ascribe a specific role to cyclic AMP in explaining the difference in the insulin response between the weanling and malnourished rats.

The importance of this study lies only in the clear demonstration of a difference in insulin response between the malnourished rats and the younger weight-matched controls 
(weanling rats). While insulin responses to both intravenous glucose and intravenous tolbutamide were impaired in both these groups of animals, intravenous glucose plus aminophylline "normalised" the insulin response of the weanling rats and did not have the same effect in the malnourished rats. One can argue from this that the decreased insulin responsiveness in the malnourished rat is probably not due to a simple immaturity of pancreatic islet function, but must have some other cause. 
CHAPTER 21

A SHORT : SUMMARY OF : PANCREATIC $\beta$ CELL
FUNCTION TESTS IN : MALNOURISHED RATS

A short summary of the abnormalities found in the malnourished rat:

1. Rats maintained on a $4 \%$ protein diet have low fasting plasma insulin concentrations.

2. These animals show a poor insulin response to all provocative stimuli used in this study

(a) intravenous glucose

(b) oral glucose

(c) intravenous tolbutamide

(d) intravenous glucose plus aminophylline

3. This impairment of insulin release cannot be ascribed to the small size of the animals. It might have been argued that the larger $20 \%$ protein-fed rats $(90 \mathrm{~g})$ were able to tolerate the procedures used during these tests better than the smaller (30 g) malnourished rat. However, weight-matched weanling rats (30 g) have been shown to have

(a) normal insulin response to oral glucose

(b) a normal insulin response to intravenous glucose plus aminophylline

4. The fact that the weanling rats, though 3 weeks younger than the malnourished animals, have shown the normal responses described above makes it unlikely that the abnormality of the malnourished rat is due to simple failure of maturation of the pancreas. 


\section{CHAPTER 22}

\section{PLASMA AND TISSUE : POTASSIUM CONCENTRATIONS \\ IN PROTEIN-CALORIE MALNOURISHED RATS}

There is some experimental evidence to implicate potassium depletion as a possible cause for the glucose intolerance and diminished insulin release found in human protein calorie malnutrition.

\section{Potassium and glucose tolerance}

Experimental potassium depletion in humans has been claimed to cause glucose intolerance (Sagild et al, 1961). Impaired glucose tolerance has been reported in a number of clinical states associated with potassium depletion, viz. primary hyperaldosteronism (Conn, 1965), uraemia (Spergel et al, 1967b) and starvation (Anderson et al, 1969); potassium supplementation in these conditions reversed the abnormality.

\section{Potassium and insulin release}

The role of potassium in insulin release appears to be confirmed by the work of Hiatt et al (1972) who showed that potassium infusion into dogs resulted in a rise of peripheral plasma insulin concentration and a gradual fall of plasma glucose, concentration, whereas potassium chloride infusions into pancreatectomised dogs produced no change in the fasting hyperglycaemia and no change in the barely detectable insulin concentration. This fact, combined with the report by Sagild et al (1961) that potassium depletion had no effect on the human response to exogenous 
insulin, favours an impairment of insulin release as the cause of the glucose intolerance associated with potassium deficiency.

In vitro studies using the isolated perfused rat pancreas (Grodsky and Benett, 1966), pieces of rabbit pancreas (Hales and Milner, 1968), and foetal rat pancreatic tisșe in organ culture (Lambert et al, 1969b) have shown that increased potassium concentrations in the media, even in the absence of glucose, lead to increased insulin secretion.

Potassium deficiency in human protein-calorie malnutrition

Potassium depletion, as shown by measurement of total body potassium (TBK), is a frequent finding in human protein-calorie malnutrition (Mann et al, 1972). This reduction in TBK is accompanied by a reduced muscle potassium concentration (Alleyne et al, 1970), which can therefore be used as an index of potassium depletion.

Does $K$ deficiency cause the diminished insulin release of human PCM?

Mann (1972) claimed that potassium supplementation in children with PCM, prior to protein repletion, improved their insulin response 5 and 20 minutes after an intravenous glucose load. This finding suggests that $\mathrm{K}$ deficiency may be the cause of the diminished insulin release found in protein-calorie malnutrition. In view of the evidence:

(i) that potassium depletion impaired insulin release and glucose tolerance, 
(ii) that potassium repletion under these conditions reversed the abnormalities,

(iii) that protein calorie malnutrition was associated with potassium deficiency as well as glucose intolerance,

(iv) and that potassium supplementation could improve insulin release,

it became important to see whether the protein depleted rat did not suffer from potassium deficiency. This might explain the glucose intolerance and diminished insulin release found in the malnourished animal.

Forbes and Lewis (1956) have shown that in man 60\% of the total body potassium occurs in muscle tissue. It would appear reasonable therefore to expect a change in total body potassium to be reflected in the concentration of potassium within the muscles. In fact Alleyne et al (1969) have shown from analyses of post-mortem material of children dying of protein-calorie malnutrition that "the muscle bears the brunt of the potassium depletion and loss from brain and other vital organs is modest".

In rats (Whang and Welt, 1963) found that the loss of total body potassium was reflected in a reduced potassium concentration in the muscles under experimental conditions where there were no changes in serum potassium concentration. It was decided, therefore, to measure serum and muscle potassium concentrations using the latter as an index of total body potassium depletion. Potassium and sodium concentrations. were also measured in liver tissue, although 
this organ has not been shown to have reduced potassium concentrations in experimentally induced potassium deficiency (Gardner et al, 1950; Mondon et al, 1968). Experimental method

All animals were fasted overnight. Under ether anaesthesia cardiac blood was collected into heparinised capillary tubes. The plasma was separated immediately and portions of liver and gastrocnemius muscle were removed from the exsanguinated animals. Sodium and potassium concentrations were estimated on the plasma and on nitric acid digests of the fat extracted dried tissue (for details of the method, see Appendix A). In the analysis of the tissues electrolyte concentrations are expressed as $\mathrm{mEg} / \mathrm{l} 00 \mathrm{~g}$ fat free dry weight (FFDW).

\section{Results}

Individual results appear in Tables B23, B24 and B25.

Table 22.1 shows the mean tissue and plasma sodium and potassium concentrations in the experimental animal as compared to the control and potassium deficient animals of Mondon et al (1968). It should be noted that the two series are not strictly comparable in that Mondon's rats were older, weighing 110-120 grams at the start of the experiment and that sodium and potassium concentrations were estimated on dry tissue and not fat free dry tissue. 


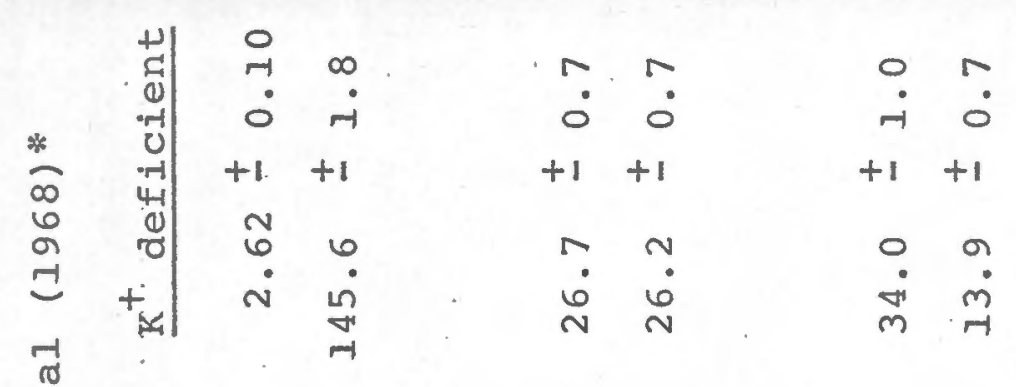

$+$

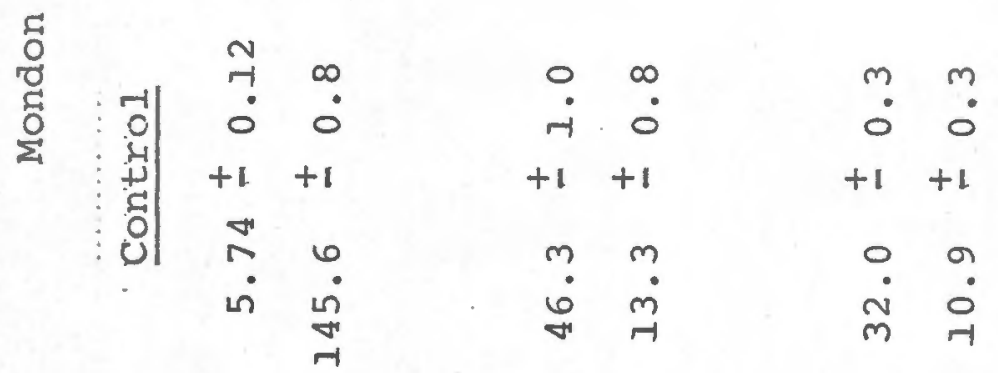

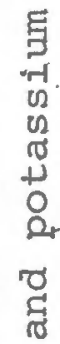

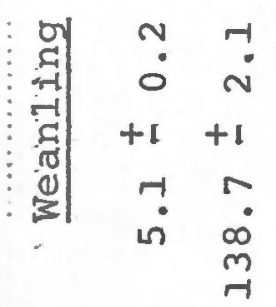

$\stackrel{0}{\circ} \quad \dot{0}$

in

$+1+1$

$+1+1$

$\stackrel{\bullet}{\infty} \stackrel{\bullet}{\sim}$

ה.

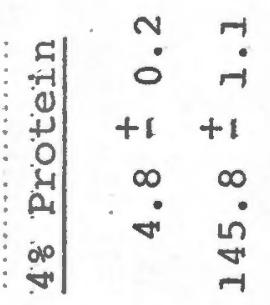

$\because \pi$

$\stackrel{m}{\circ} \dot{0}$

$\begin{array}{ll}\dot{0} & 0 \\ \dot{m} & \dot{m} \\ \dot{m}\end{array}$

寻

.7

ט

$\dot{0}$
0
$\stackrel{-}{-1}$
$\stackrel{0}{0}$
0

:

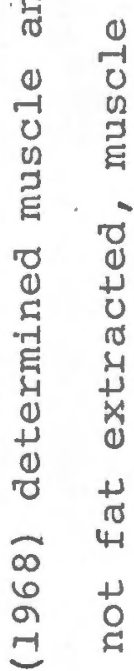

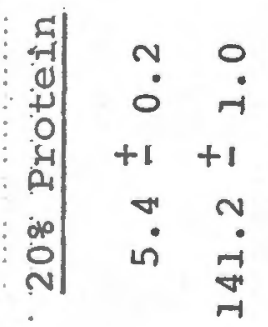

$\ddot{0} \quad \dot{0}$

$\because \ddot{0}$

मू

$+1+1$

$+1+1$

$\stackrel{\sim}{\circ} \underset{\sim}{\stackrel{4}{*}}$

$\stackrel{0}{\dot{m}} \stackrel{a}{\sim}$

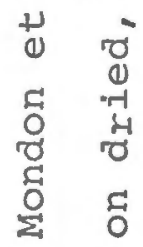

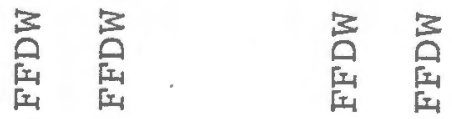

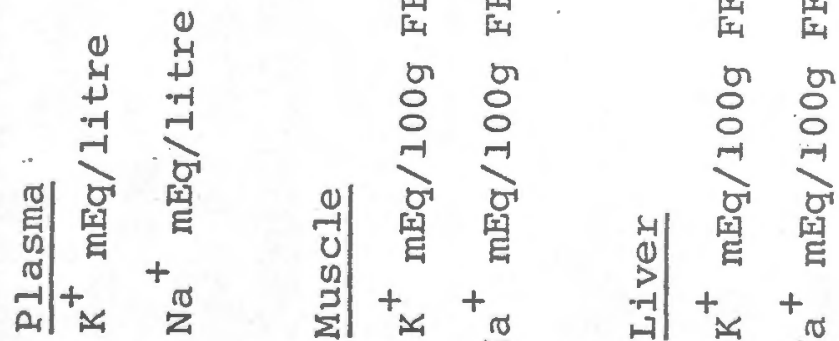


The differences between the mean fasting plasma potassium concentrations in the $4 \frac{2}{2}$ protein-fed rats compared to the weanling and $20 \%$ proterinffed rats were not statistically significant (pp0.1 and $0.1>p>0.05$ respectively). There was no statistically significant difference in the mean muscle potassium concentrations between the $4 \%$ protein-fed and $20 \%$ protein-fed rats $(p>0.1)$, and the $4 \%$ protein-fed and weanling rats $(p>0.05)$.

This is in stark contrast to the results of Mondon et al (1968) (Table 22.1) where the potassium depleted animals showed a plasma potassium concentration less than half that of the controls associated with a $43 \%$ reduction in muscle potassium concentration.

The liver potassium concentrations were significantly elevated in the $4 \%$ protein-fed rats, when compared to both weanling and $20 \%$ protein-fed controls $(p<0.001)$. The biological significance of this increase in liver potassium concentration in malnourished rats is not clear.

\section{Discussion}

This study has failed to demonstrate potassium depletion in protein-calorie deficient rats. Nevertheless these animals have diminished insulin release and impaired glucose tolerance, and it was decided to examine the experimental evidence often quoted as substantiating potassium deficiency as a cause of glucose întolerance.

Gardner et al (1950) were able to show impaired oral glucose tolerance in rats after 90 - 120 days on a potassium deficient diet. Glucose tolerance however was normal 
after 40 - 60 days on the same diet although the degree of potassium deficiency as estimated by the muscle potassium levels were similar during both time periods.. If one accepts muscle potassium concentration as an index of total potassium depletion, this should lead one to suspect some other factor apart from potassium deficiency as being responsible for the glucose intolerance.

Fuhrman (1951), using younger (4 weeks old) rats produced severe potassium deficiency after only 7 days of dietary potassium restriction. Using pair-fed controls he demonstrated impaired intravenous glucose tolerance in the potassium depleted animals. He noted however that because of the method of pair feeding these potassium deflcient rats had in effect fasted longer than the controls. Spergel et al (1967a) remarked on the difficulty of producing potassium deficiency in rats with dietary restriction alone, and combined this restriction with the administration of desoxycorticosterone acetate (DOCA) to "achieve hypokalaemia and depletion of body potassium stores in an acute experiment". DOCA was discontinued 1 week prior to testing to avert the corticosteroid effects on carbohydrate metabolism while the deficient diet maintained the hypokalaemic state. There was no difference between the glucose disappearance rates $(\mathrm{Kg})$, in control and potassium deficient animals. Despite the lower muscle and serum potassium levels in the latter group, there were no significant differences in the mean fasting or post glucose insulin and free fatty acid concentrations. 
It should be noted that plasma insulin concentrations were estimated 2 hours after the glucose load and not at 3 minutes as has been done in this work. The difference between the fasting and 2 hour insulin concentrations after intravenous glucose was significantly greater in the control animal than in the hypokalaemic rat suggesting some impairment of insulin release to the authors, but not of consequence if one recalls the importance of the early (3-6 minute) insulin peak in determining intravenous glucose tolerance (see Chapter 13). - Spergel also noted that his potassium depleting regimen caused "retardation of growth" which suggests that these animals might very well have been protein-calorie deficient.

The failure of relatively acute potassium depletion in rats to cause marked changes in glucose tolerance appears to be confirmed by recent work with humans. Kaess et al (1971) used healthy male volunteers to induce a 3-11음 loss of total body potassium by combining a dietary deficiency of potassium with the administration of cation exchange resins and diuretics. This degree of potassium deficiency though able to produce symptoms (headache, fatigue, weakness, irritability, polydypsia and polyuria) and signs (ECG changes, hypokalaemia, and metabolic alkalosisl of potassium deficiency, produced no change in the intravenous glucose tolerance, free fatty acid clearance or insulin release. There were only slight changes in the pattern of insulin release.

Gorden (1973) used healthy volunteers to induce hypokalaemia with a combination of a potassium deficient 
diet, 9-a-fluorohydrocortisone and chlorothiazide.

Relatively minor changes in glucose tolerance and insulin release occurred despite significant hypokalaemia, alkalosis and ECG changes. He concluded that the glucose intolerance found in certain clinical states associated with potassium deficiency could not be ascribed to the potassium deficiency alone but resulted from "a complex interplay of the primary disease state and potassium deficiency".

It appears that the relationship between acute potassium depletion, glucose intolerance and diminished insulin release, is not as well defined as some workers (Sagild et al, 1961; Conn, 1965) have suggested. This does not imply that potassium plays no role in insulin release, but that a more critical approach is necessary in assessing it: clinical role in insulin release. Although Grodsky and Benett (1966) showed an increase in insulin release from the perfused rat pancreas when potassium concentration was increased from $4 \mathrm{mEq} / 1$ to $8 \mathrm{mEq} / 1$ in the absence of glucose, Howell and Taylor (1968) found that changes in the potassium concentration of the medium between $3 \mathrm{mM}-8 \mathrm{mM}$ had no effect on glucose induced insulin release from pancreatic slices. Unphysiologically high concentrations of potassium such as the $60 \mathrm{mM}$ potassium concentration used by Hales and Milner (1968) to induce insulin release cannot be quoted without mentioning that complete absence of potassium from the medium also induced insulin release. Although Lambert et al (1969b) 
did show that increasing the potassium concentration of the medium from $6+i 2 \mathrm{mEq} / \mathrm{l}$ did increase the rate of insulin release from foetal pancreatic tissue, the insulin secretion rate was even greater in the complete absence of potassium.

Caution is necessary before extrapolating from these in vitro studies to effects on the whole animal, especially when unphysiological concentrations of stimuli have been used in vitro.

Is potassium deficiency a constant feature of PCM?

The failure to demonstrate potassium deficiency in the malnourished rat model when it is reported to be so common in human protein calorie malnutrition (Hansen and Brock, 1954; Alleyne, 1970; Nichols et al, 1972) deserves comment. Mann etal (1972) reported that "almost all children with PCM have, or have had, a recent illness, the commonest being diarrhoeal disease and pneumonia". Alleyne (1970) found that total body potassium (TBK) was related to the number of stools passed in the first 5 days after admission, while low TBK values have also been found in children suffering from severe pulmonary infections (Mann, 1972). It has been suggested that the low TBK values found in PCM are "due, at least in part, to the associated or preceding illness" (Mann et al, 1972). Since the experimental animals used in this work did not suffer from diarrhoea or pneumonia and in view of the general difficulty in producing potassium deficiency in rats without resorting to other manoeuvres such as administration 
of diuretic agents (Spergel et al, 1967al it is not surprising that these animals did not show eyidence of muscle potassium depletion.

Whether one accepts a diminished muscle potassium concentration to result from the infective complications of protein-calorie malnutrition, or to be a secondary metabolic consequence of protein calorie malnutrition itself (affecting the tissues' capacity to store or conserve this ion, (Nichols et al,1972), it would appear from the experimental evidence presented in this thesis that muscle potassium deficiency is not a constant feature of proteincalorie malnutrition.

\section{Conclusion}

Potassium deficiency has been thought to contribute to the abnormal glucose tolerance and diminished insulin release associated with protein-calorie malnutrition. The failure to demonstrate potassium deficiency in the glucose intolerant protein-calorie malnourished rat leads one to conclude that its role in the aetiology of the glucose intolerance of PCM has been exaggerated. Summary of chapter

1. Evidence has been presented which suggests that potassium depletion produces glucose intolerance and impaired insulin release in man and animals.

2. It has been proposed by others that the potassium deficiency so frequently encountered in human PCM causes their abnormal glucose tolerance and impaired insulin release. 3. Using muscle potassium concentration as the 
criterion, there was no evidence of potassium deficiency in the proteinncalorie malnourished rats which did however show impaired glucose tolerance and diminished insulin release.

4. Some of the experimental rat models used by others to demonstrate abnormal glucose tolerance and diminished insulin release after potassium depletion, also showed evidence of malnutrition, in that they failed to grow adequately. It is suggested that it was the associated malnutrition rather than the potassium depletion, which was responsible for the abnormalities in glucose tolerance and insulin release.

5. In support of the above, recent work has been quoted from human experiments to show that healthy persons subjected to acute potassium depletion did not show the gross abnormalities in glucose tolerance and insulin release that was expected.

6. Though not denying the fact that potassium (as do other cations such as sodium and calcium) plays some part in insulin release, in many cases the in vitro effects were noted to occur well outside the normal or physiological range of potassium.concentrations.

7. Although potassium deficiency does occur frequenty in human protein calorie malnutrition and some regard it as one of the effects of PCM, It is often related to the presence of complicating ilinesses such as gastromenteritis and pneumonia, and should perhaps be regarded as a complication rather than an inevitable consequence of pure protein-calorie malnutrition. 
CHAPTER 23

IIGHT : MICROSCORIC EXAMINATION : OF THE PANCREAS

1. Qualitative study

Tests of pancreatic beta cell function (as summarised in Chapter 21) have shown that malnourished rats have a marked impairment of insulin release. This abnormality has not been shown to be due to potassium deficiency (Chapter 22). The possibility that pancreatic islet pathology might account for the diminished insulin response in malnourished rats was considered since some workers (James and Coore, 1970a) have claimed that malnutrition results in persistent impairment of insulin secretion, although not all workers agree (Becker et al, 1971). The abnormalities in pancreatic histology in human malnutrition have been reviewed in chapter 6 .

Since the rat model used in this study differed in some respects from that used by others, it was thought necessary to investigate the light microscopic appearance of the pancreas in these animals, in order to determine if there were any gross histological abnormality in the pancreatic islet tissue to account for their poor insulin response to various stimuli.

Methods

Six rats from each of the 3 groups of animals were killed, Formalin fixed pancreatic tissue from these animals was stained with haematoxylin and eosin. In order to avoid observer bias, all slides were examined by 
two experienced pathologists who were not aware from which group of animals the sections came.

\section{Results}

Both pathologists reported independently that they could detect no abnormality in the pancreatic tissues of any of the animals. Neither the acinar nor endocrine tissue of the pancreas was found to be abnormal in malnourished rats.

At the time of killing these rats, some of the malnourished animals were noted to have oedema of the pancreas, but this was not reported by either pathologist although they were requested to look out for this abnormality. Dehydration of the tissue during the fixation process might have obscured this finding. Discussion

A. The normal acinar histology of $4 \%$ protein-fed rats. The rapid turnover of protein found in the pancreas (Tarver and Schmidt, 1942) occurs mainly in the acinar tissue (Wheeler et al, 1949), making this organ particularly vulnerable to the effects of protein-calorie malnutrition (Ramalingaswami, 1969). Acinar cell atrophy, dilatation of the tubules and fibrosis have been reported in humans (Davies, 1948) and reproduced in rats on a protein-deficient diet (Vẹghelyì et al, 1950al. The anatomical and functional changes in the exocrine pancreas in human and experimental malnutrition have been the subject of a recent review (Pitchumoni, 19731.

The $4 \%$ protein-fed rat used in this study has been 
shown to have many features in common with human proteinm calorie malnutrition, namely failure to gain weight, fatty infiltration of the liver and hypoalbuminaemia (see Chapter 171. However the inability to find any abnormality of the acinar tissue in these animals is not in accord with the findings of some other workers using malnourished rats (Platt et al, 1962; Vêghelyi et al, 1950a; Sidransky and Farber, 1958). The failure to demonstrate microscopic evidence of acinar atrophy does not exclude loss of pancreatic acinar tissue. A reduction in the rate of replacement rather than an increase in the rate of destruction of acinar tissue would not be detected histologically, unless quantitative studies were done. Macroscopically the pancreas in these malnourished rats appeared to be reduced in volume when compared to the control pancreas. No measurements of the total pancreatic volume or weight were, however, taken in this study. Klotz et al (1972) despite an inability to detect gross acinar atrophy or fibrosis in rats fed a non-protein diet, were still able to show that these animals had a reduced pancreatic volume. They did however report atrophy of individual cells.

Heller et al (1958) could show no microscopic abnormalities in the pancreas of animals on a proteindeficient diet, despite the fact that these animals showed gross fatty infiltration of the liver.

Some of the differences in the reports of pancreatic histology by different workers may be due to 
some of the following factors:
(a) the age at which animals were subjected to the protein deficient diet
(b) the method of feeding
(c) the nature of the diet
(d) the duration of the deficiency

B. The normal islet histology in the $4 \%$ protein-fed rats

The failure to demonstrate any gross abnormality of the pancreatic islet tissue in this study is not surprising in view of the preponderance of negative reports in human studies (reviewed in Chapter 6). Indication for a further study

The investigation discussed above while demonstrating no abnormality in individual cells or groups of cells within the pancreatic islets, does not give any indication of the total pancreatic islet volume. In fact the report of normal acinar histology despite the clinical observation that the pancreas was reduced in volume led to a suspicion that perhaps the total pancreatic islet volume was also reduced in the malnourished rats. This led to the next investigation.

\section{Quantitative study}

Total pancreatic islet volume of malnourished rats Protein-calorie deficiency has profound effects on all tissues of the body and has been shown to act by reducing their rate of growth (Hill et al, 1970). If pancreatic islet tissue was more susceptible than other tissues to the effect of protein-calorie deficiency, one 
might expect a disproportionate decrease in the pancreatic islet volume when this is expressed as a fraction of the body weight. Heard et al (1958) reported a 39\% decrease in the volume of individual islet cells, in pigs on a protein-deficient diet. A reduction in total pancreatic islet volume over and above the reduction in total body weight might possibly explain the diminished insulin release observed in malnourished rats. Tejning (1947) had already shown that changes in the dietary composition produced measurable changes in total pancreatic islet volume. It was therefore decided to measure pancreatic islet volume in malnourished rats, comparing them to control and weanling rats, in order to determine whether any reduction in islet volume may account for the diminished insulin release in malnourished animals.

\section{Method}

Pancreatic islet volumes of overnight fasted rats were determined by the method of Tejning (1947) as modified by Hellman (1970). The details of this method and notes on its validity appear in Appendix $A$. Results

Individual results appear in Table B26 and are plotted in fig. 23.1, in which islet volumes are expressed as a fraction of body weight.

1. Malnourished rats have a significantly reduced total pancreatic islet volume when compared to both weanling $(p<0.002)$ and $20 \%$ protein-fed rats $(p<0.001)$. 2. Weanling rats had a higher mean pancreatic islet 


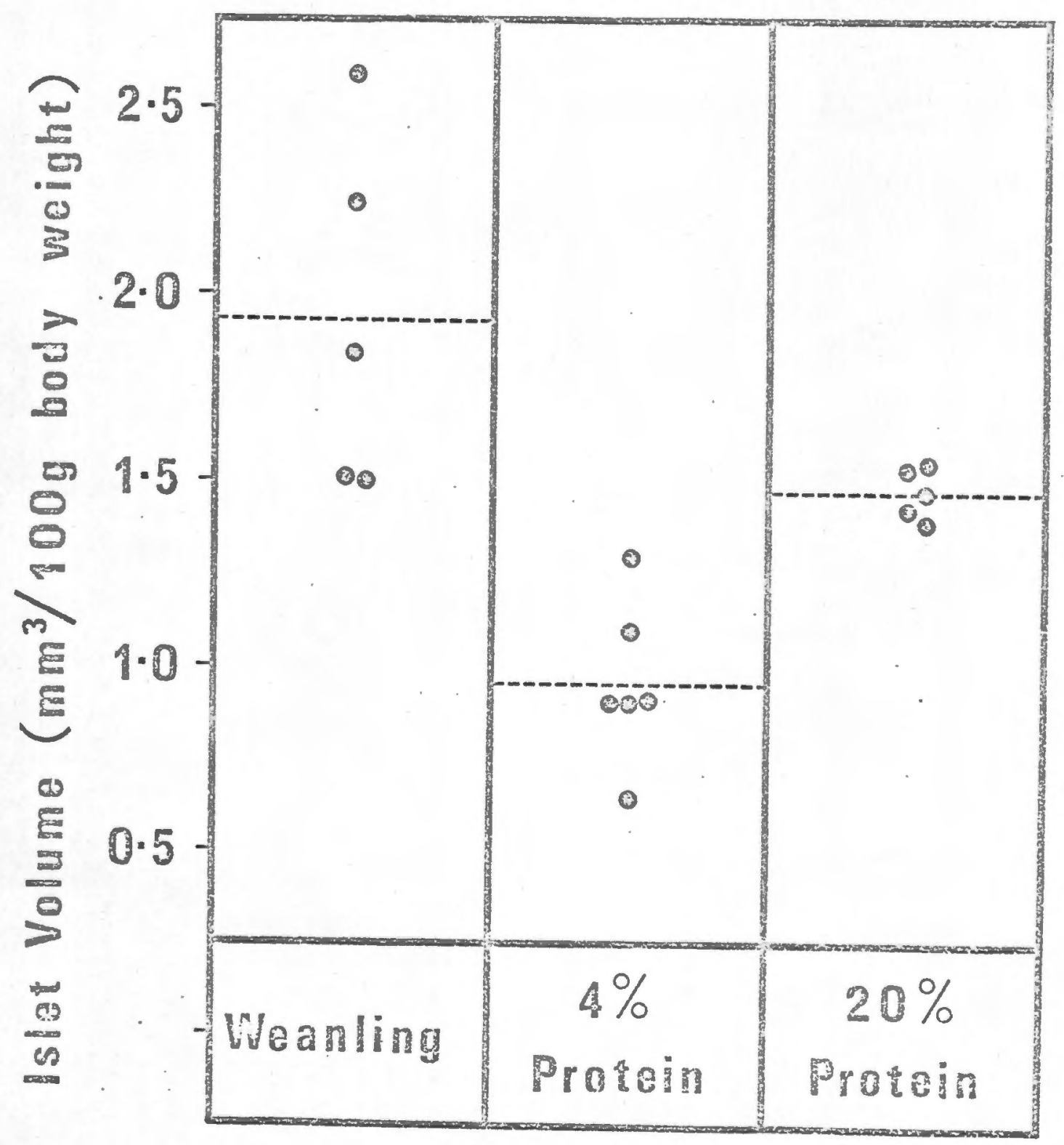

Fig. 23.1 Total pancreatic islet volumes in the three groups of rats expressed as a fraction of body weight. 
volume than the $20 \%$ protein-fed rats though the difference was not statistically significant $(p>0.05)$.

\section{Discuision}

On comparing the mean islet volumes of the malnourished rats $\left(0.959 \mathrm{~mm}^{3} / 100 \mathrm{~g}\right.$ body weight) with that of the $20 \%$ protein-fed rats $\left(1.475 \mathrm{~mm}^{3} / 100 \mathrm{~g}\right.$ body weight), the malnourished rats are found to have a $35 \%$ reduction in islet volume. This considerable reduction in islet volume probably contributes to the diminished insulin release of the malnourished rats. However it is felt that the degree of reduction in islet volume is far less than the degree of impairment of insulin release shown by the malnourished rats during the various provocative tests. Some other factor or factors such as an impairment of the insulin releasing mechanism, or a reduction in the total amount of insulin within individual islets may be operative. 
A PRELIMINARY REPORT ON THE ULTRASTRUCTURAL CHANGES

IN THE PANCREATIC ISLETS OF MALNOURISHED RATS

Since the malnourished rats showed a diminished release of insulin to a number of provocative stimuli and since the reduction in the pancreatic islet volume could not entirely explain this diminished insulin release, it was decided to determine whether there were any abnormalities of the ultrastructure of the beta cells. Although these animals were not overtly diabetic, ultrastructural changes have been previously reported in normoglycaemic rabbits after treatment with "subdiabetogenic" doses of alloxan (Volk et al, 1969).

Method

Fasted rats were anaesthetised with halothane (Fluothane). The abdominal aorta was cannulated just above the bifurcation using fine polythene tubing. The chest was then opened and the thoracic aorta clamped. The right atrium was opened while a $0.1 \mathrm{M}$ phosphate buffer, $\mathrm{pH} 7.2$ was allowed to flow through the aortic cannila. Within 10 minutes, when most of the blood appeared to have been flushed out of the viscera, the perfusion fluid was changed to $5 \%$ glutaraldehyde in the same buffer.

After a further 10 minutes of glutaraldehyde perfusion during which the liver and gut became hard, the pancreas was dissected free from its attachments. Pancreatic islets were then dissected out of the pancreatic tissue under a stereoscopic dissecting microscope. Pancreatic 
islets could be easily recognised as pale ovoid structures when examined with indirect lighting against a dark background.

Pancreatic islets were kept in the glutaraldehyde solution for a further 5 hours before being washed in phosphate buffer and post fixed in veronal buffered $1 \%$ osmium tetroxide for 1 hour. After dehydration in acetone the tissue was embedded in Spurrs medium. Sections were stained with uranium and lead salts and studied in a Siemens 101 electron microscope.

Results

A. Control animals ( $20 \%$ protein-fed rats)

The peripherally located alpha cells resembled those described by Orci et al (1970). The granules observed in the beta cells which occupied the inner zones of the islets were largely of the dense type, as is normally said to be the case in the rat (Creutzfeldt et al, 1970b): See fig. 24.1

B. Malnourished rats (4\% protein-fed rats) The most obvious abnormality which has been observed in a number of animals was a change in the type of granules found in the beta cells. Although it was not possible to ascertain if any alteration in their number had occurred, a much greater proportion of the granules was of the pale variety (see fig.24.2). This change did not affect all the beta cells and some were probably within normal limits.

The alpha cells did not show any conspicuous changes. 


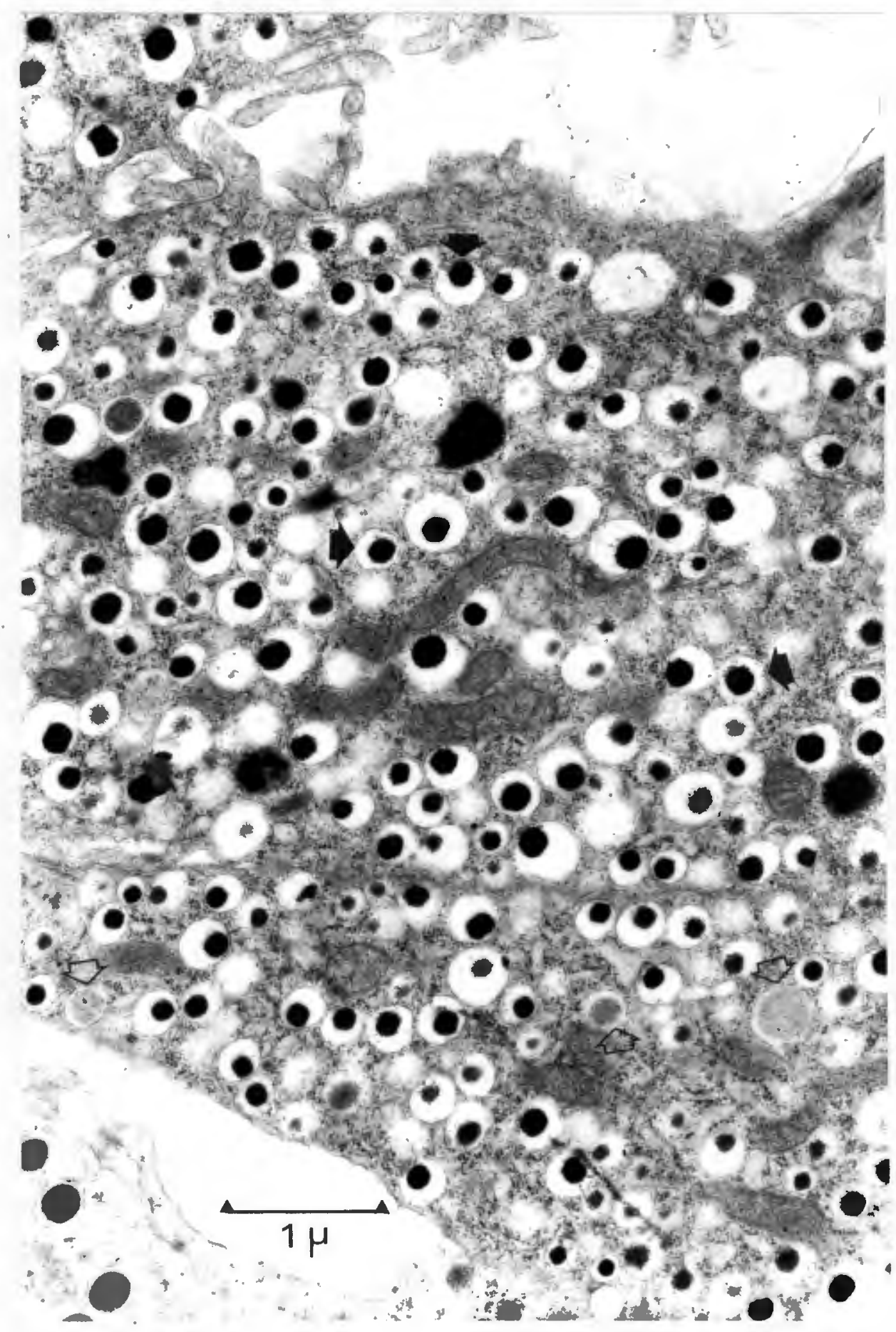

Fig. 24.1 Electron micrograph of $\beta$ cell of pancreatic islet of $20 \%$ protein-fed rat. Hollow arrows indicate pale granules. Solid arrows indicate dense granules. Magnification: $\quad 22,000 x$ 


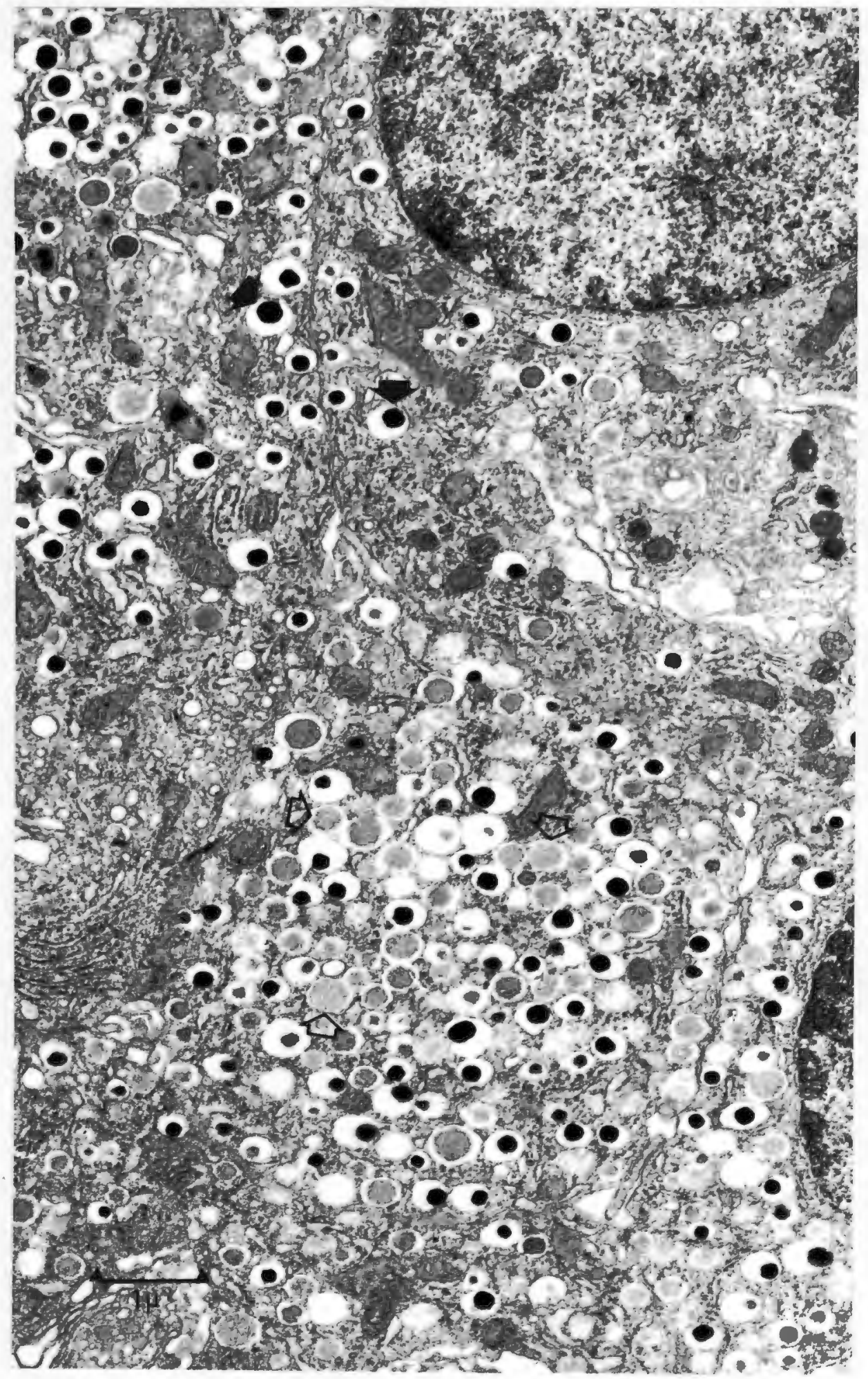

Fig. 24.2 Electron micrograph of $\beta$ cell of pancreatic islet of $4 \%$ protein-fed rat. Hollow arrows indicate pale granules. Solid arrows indicate dense granules. Magnification: $16,250 \mathrm{x}$. 
Foci of cellular degeneration were noted in some of them. Comment

A reduction in the electron density of beta cell granules has been demonstrated in malnourished rats. Reduced electron density of the beta granules has been described in several experimental situations associated with conditions of beta cell stimulation such as cortisoneinduced hyperglycaemia and administration of tolbutamide (Lazarus and Volk, 1970). This finding has also been reported in both spontaneous (hyperglycaemic) diabetes mellitus in guinea-pigs (Munger and Lang,1973) and in normoglycaemic rabbits after administration of alloxan and cortisone (Volk et al, 1969).

The decrease in electron density has been attributed to a possible reduction in insulin concentration of the granules (Munger and Lang, 1973) or to a change in the physical characteristics of the insulin itself (Lazarus and Volk, 1970).

The fact that malnourished rats have low fasting plasma insulin concentrations and show a poor insulin response to a number of stimuli, does appear to be in accordance with the first hypothesis. It is suggested that a reduction in the pancreatic islet volume combined with an abnormality of the beta granules of malnourished rats may contribute to their diminished insulin responses. 
SUMMARY AND CONCLUSIONS 
CHAPTER 25

\section{SUMMARY AND CONCLUSION}

The purpose of this study was to determine the effects of protein-calorie deficiency on glucose tolerance and insulin release in young rats. Weanling rats placed on a $4 \%$ protein diet for 3 weeks failed to gain weight, developed hypoalbuminaemia and fatty infiltration of the liver, features commonly found in human protein-calorie malnutrition.

These animals were used as the experimental model and their glucose tolerance and insulin release compared to littermates maintained for 3 weeks on an isocaloric $20 \%$ protein diet. Since it had been suggested that some of the abnormalities in glucose tolerance and insulin release might be due to failure of maturation, another group, the weanling rats, were also employed as controls.

Malnourished rats showed both oral and intravenous glucose intolerance with diminished insulin release to a number of provocative stimuli. These stimuli included oral glucose, intravenous glucose, intravenous tolbutamide and intravenous glucose plus aminophylline.

While intravenous glucose intolerance was marked, oral glucose intolerance was surprisingly mild in the face of a very poor insulin response to this stimulus. Others have ascribed normal oral glucose tolerance in malnourished animals to impaired glucose absorption, but the glucose disappearance rate from the gut lumen was found to be higher in the malnourished animals. Despite 
the high rate of glucose disappearance from the gut lumen in malnourished rats, portal glucose concentrations did not rise as high as would be expected. This suggested that there was either a block in glucose transport or that the gut epithelium itself was rapidly metabolising the glucose before it could reach the portal circulation.

Some workers have claimed that the glucose intolerance demonstrated in malnourished humans and animals was due to insulin resistance rather than diminished insulin release. In the experimental animal model employed in this thesis there was no evidence of insulin resistance. The glucose intolerance could be adequately explained on the basis of their poor insulin responses. The low fasting plasma insulin concentrations found in malnourished rats could alone be cited as evidence against insulin resistance. Nevertheless insulin tolerance tests were performed and demonstrated that malnourished rats were not resistant to the hypoglycaemic action of exogenous insulin. In fact these animals showed a marked impairment of their ability to correct insulin-induced hypoglycaemia. This latter abnormality had also been noted in other experimental models of protein-calorie malnutrition and according to the data presented in this thesis, does not appear to be due to an impairment in insulin degradation. The half disappearance time of endogenous insulin after intravenous glucose was similar in the $20 \%$ protein-fed and the $4 \%$ protein-fed rats. No further investigations were done to explain the inability of malnourished rats to correct insulin-induced hypoglycaemia, but an abnormality in 
glucagon release or a failure of the fatty liver to respond to glucagon has been suggested.

In an attempt to explain the diminished insulin release of malnourished rats, a number of investigations were done: (1) Failure of maturation of the pancreas was excluded on the basis of the ability of weanling rats to show a normal insulin response to oral glucose and to intravenous glucose plus aminophylline. Malnourished rats did not respond normally to these stimuli, although both weanling and malnourished rats showed a poor insulin response to intravenous glucose.

(2) Potassium deficiency was excluded after investigations revealed no difference in the plasma and muscle potassium concentrations between malnourished rats and controls. (3) A 35\% reduction in pancreatic islet volume combined with the demonstration of an ultrastructural abnormality of the beta granules may partly account for the poor insulin release demonstrated in malnourished rats.

Since rats on a low protein diet voluntarily reduce their total intake it is not possible to say whether it was the protein or the caloric deficiency that was responsible for the abnormalities shown. However, in human proteincalorie malnutrition the deficiency is also a mixed one involving protein, calories and probably vitamins and minerals as well, with infection as a further complication. There was no evidence of infection in the malnourished rats used for this work but it is difficult to exclude the possibility of viral infections in these animals. Those 
animals however that appeared ill and persistently lost weight were excluded from the study.

Despite the diminished glucose tolerance and impairment of insulin release demonstrated in malnourished rats, they were nevertheless able to maintain normal fasting blood glucose concentrations. None of the animals were overtly diabetic and it is impossible to say from this study whether malnutrition in the young may possibly be a cause of diabetes mellitus in the adult. The reduction in pancreatic islet volume and the ultrastructural abnormality of the beta granules (the latter has been described in diabetic and latent diabetic animals) may still be completely reversible.

Further investigations are necessary to determine whether refeeding these rats with normal diets will correct the abnormalities in beta cell structure and function. 
Alexander, H.D. and Sauberlich, H.E. (1957)

The influence of lipotropic factors on the prevention of nutritional edema in the rat.

J.Nutr. 61, 329-341.

Alleyne, G.A.O. (1970)

Studies on total body potassium in malnourished infants.

Factors affecting potassium repletion.

Br.J.Nutr. 24, 205-212.

Alleyne, G.A.O., Halliday, D., Waterlow, J.C. and Nichols, B.L. (1969)

Chemical composition of organs of children who died

from malnutrition.

Br.J.Nutr. 23, 783-790.

Alleyne, G.A.O. and Scullard, G.H. (1969)

Alterations in carbohydrate metabolism in Jamaican

children with severe malnutrition.

clin.Sci. 37, 631-642.

Alleyne, G.A.O., Millward, D.J. and Scullard, G.H. (1970) Total body potassium, muscle electrolytes, and glycogen in malnourished children.

J.Pediat. $76,75-81$.

Alleyne, G.A.O., Trust, P.M., Flores, H. and Robinson, H. (1972)

Glucose tolerance and insulin sensitivity in malnourished children.

Br.J.Nutr. 27, 585-592.

Amatuzio, D.S., Stutzman, F.I., Vanderbilt, M.J. and Nesbitt, S. (1953)

Interpretation of the rapid intravenous glucose tolerance test in normal individuals and in mild diabetes mellitus. J.clin. Invest. $32,428-435$.

Anderson, J.W., Herman, R.H. and Newcomer, K.I. (1969) Improvement in glucose tolerance of fasting obese patients given oral potassium.

Am.J.clin.Nutr. 22, 1589-1596.

Asplund, K., Westman, S. and Hellerström, C. (1969)

Glucose stimulation of insulin secretion from the isolated pancreas of foetal and newborn rats.

Diabetologia 5, 260-262.

Aynsley-Green, A. and Alberti, K.G. (1973)

Diuretics and carbohydrate metabolism: The effects of furosemide and amiloride on blood glucose, plasma insulin and cations in the rat.

Diabetologia 9, 34-42. 
Aynsley-Green, A., Biebuych, J.F. and Alberti, K.G.M.M. (1973)

Anaesthesia and insulin secretion: the effects of diethylether, halothane, pentobarbitone sodium and ketamine hydrochloride on intravenous glucose tolerance and insulin secretion in the rat.

Diabetologia $9,274-281$.

Baig, H.A. and Edozien, J.C. (1965)

Carbohydrate metabolism in kwashiorkor.

Lancet 2, 662-665.

Basabe, J.C., Lopez, N.I., Viktora, J.K. and Wolff, F.W. (1971)

Insulin secretion studied in the perfused rat pancreas. 1. Effect of tolbutamide, leucine and arginine; their interaction with diazoxide, and relation to glucose. Diabetes $20,449-456$.

Becker, D.J., Pimstone, B.I., Hansen, J.D.I. and Hendricks, S. (1971)

Insulin secretion in protein-calorie malnutrition.

I. Quantitative abnormalities and response to treatment.

Diabetes 20,542-551.

Becker, D.J., Pimstone, B.L., Hansen, J.D.I., MacHutchon, B. and Drysdale, A. (1972)

Patterns of insulin response to glucose in protein-calorie malnutrition.

Am.J.clin.Nutr. 25, 499-505.

Belcher, E.H. and Vetter, H., Eds. (1971)

Radioisotopes in Medical Diagnosis. p. 263.

Butterworth and Co. (Publishers) Ltd. London.

Berg, A. (1973)

The Nutrition Factor. Its role in national development. p.2. The Brookings Institution. Washington, D.C.

Berson, S.A. and Yalow, R.S. (1965)

Some current controversies in diabetes research. Diabetes 14, 549-572.

Beyer, J., Haupt, E., Cordes, U., Kutschera, J. and Schöffling, K. (1973)

Different amounts of insulin secretion following an equal

total decrease of blood glucose as an indication of possible extrapancreatic activities of different sulfonylurea drugs.

Horm. Metab.Res. 5, 9-13.

Blackard, W.G. and Nelson, N.C. (1970)

Portal and peripheral vein immunoreactive insulin concentrations before and after glucose infusion.

Diabetes 19, 302-306. 
Blackard, W.G. and Nelson, N.C. (1971)

Portal vein insulin concentrations in diabetic subjects. Diabetes $20,286-288$.

Bose, J.P., De, U.N. and Mukerjee, P. (1946)

A preliminary study of the biochemical changes in

starvation cases.

Indian J.med.Res. 34, 143-150.

Bowie, M.D. (1964)

Intravenous glucose tolerance in kwashiorkor and marasmus. S.Afr.med.J. 38, 328-329.

Bras, G., Waterlow, J.C. and DePass, E. (1956)

Further observations on the liver, pancreas and kidney in malnourished infants and children. I. The relation of certain histopathological changes in liver, pancreas and kidney.

J.Trop.Pediat. 2, 147-158.

Bray, G.A. (1960)

A simple efficient liquid scintillator for counting aqueous solutions in a liquid scintillation counter. Analyt.Biochem. 1, 279-285.

Brown, M.J. (1925)

The sugar content of the blood in normal and under-nourished children, and the effect of fat on the absorption of carbohydrate.

Q.Jl.Med. 18, 175-190.

Butcher, R.W. and Sutherland, E.W. (1962)

Adenosine $3^{\prime}, 5^{\prime}$-phosphate in biological materials. I. Purification and properties of cyclic $3^{\prime}, 5^{\prime}$-nucleotide phosphodiesterase and use of this enzyme to characterize adenosine $3^{\prime}, 5^{\prime}$-phosphate in human urine. J.biol.Chem. 237, 1244-1250.

Butterfield, W.J.H., Abrams, M.E. and Whichelow, M.J. (1971) The 25-g intravenous glucose tolerance test: A critical appraisal.

Metabolism 20, 255-265.

Cahill, G.F. (1971)

Physiology of insulin in man.

Diabetes 20, 785-799.

Cahill, G.F. and Soeldner, J.S. (1969)

Glucose homeostasis: A brief review. In: Mathematical Biosciences, Supplement 1. Hormonal Control Systems. Proceedings of a Symposium. October 1967, California. pp.88-114. Eds. Stear, E.B. and Kadish, A.H.

American Elsevier Publishing Co. Inc. New York. 
Camain, R. and Pierchon, N. ( 1954 )

Lesions of the pancreas in kwashiorkor. In: Malnutrition in African Mothers, Infants and Young Children. Report of Second Inter-African (C.C.T.A.) Conference on Nutrition. Gambia, 1952. Her Majesty's Stationery Office, London, p. 146.

Campbell, J.A.H. (1956)

The morbid anatomy of infantile malnutrition in Cape Town. Arch.Dis.Child. 31, 310-314.

Cerasi, E. (1967)

An analogue computer model for the insulin response to glucose infusion.

Acta endocr. , Copnh. 55, 163-183.

Cerasi, E. and Luft, R. (1969)

Disappearance rate of exogenous insulin, insulin sensitivity, responses of plasma growth hormone and cortisol and urinary epinephrine to hypoglycemia in prediabetic subjects. Horm. Metab.Res. 1, 221-223.

Chalkley, H.W. (1944)

Method for the quantitative morphologic analysis of tissues.

J.natn.Cancer Inst. 4, 47-53.

Charette, W.P., Kadish, A.M. and Sridhar, R. (1969)

Modeling and control aspects of glucose homeostasis. In: Mathematical Biosciences, Supplement 1. Hormonal Control Systems. Proceedings of a Symposium. October 1967, California. pp.115-149. Eds. Stear, E.B. and Kadish, A.H. American Elsevier Publishing Co. Inc. New York.

Chaudhuri, K.G. (1948)

Nutritional disorders following gastro-enteritis in children.

Acta paediat., Stockh. 36, 110-112.

Chernick, S.S. and Scow, R.O. (1958)

Intravenous glucose tolerance test in hypophysectomised rats.

Am.J.Physiol. 192, 517-520.

Conn, J.W. (1965)

Hypertension, the potassium ion and impaired carbohydrate tolerance.

New Engl.J.Med. 273, 1135-1143.

Cook, G.C. (1967)

Glucose tolerance after kwashiorkor.

Nature, Lond. 215, 1295-1296. 
Cori, C.F. (1925)

The fate of sugar in the animal body. I. The rate of absorption of hexoses and pentoses from the intestinal tract.

J.biol.Chem. 66, 691-715.

Creutzfeldt, W., Feurle, G. and Ketterer, H. (1970a)

Effect of gastrointestinal hormones on insulin and glucagon secretion.

New Engl.J.Med. 282, 1139-1141.

Creutzfeldt, W., Creutzfeldt, C. and Frerichs, H. (1970b)

Evidence for different modes of irsulin secretion.

In: The Structure and Metabolism of the Pancreatic Islets. Proceedings of an International Symposium, Umeå, Sweden. February 1969. Eds. Falkmer, S., Hellman; B. and Täljedal, I-B. pp. 181-198. Pergamon Press, Braunschweig, Hungary.

Davidson, M.B: (1971)

Studies on the mechanism of pentobarbitol-induced glucose intolerance.

Horm.Metab.Res. 3, 243-247.

Davies, J.N.P. (1948)

The essential pathology of kwashiorkor.

Lancet $1,317-320$.

De Santis, R.A., Garcia, M.G., Czerwinski, C., Van Lan, V., Gutman, R.A., Recant, L. and Penhos, J.C. (1973)

Effects of glucocorticoid and aminophylline on glucose intolerance of adrenalectomized rats.

Endocrinology 92, 716-721.

Donly, D.L. (1961)

The influence of long adaptation to various diets on the glucose tolerance curve in male and female rats.

Proc.Nutr.Soc.Sth.Afr. 2, 82-86.

Doumas, B.T., Watson, W.A. and Biggs, H.G. (1971)

Albumin standards and the measurement of serum albumin with bromocresol green.

Clinica chim.Acta. 31, 87-96.

Drury, R.A.B. and Wallington, E.A. Eds. (1967)

Carleton's Histological Technique. pp.124-126, 4th edn. oxford University Press, New York/Toronto.

Duffy, T., Phillips, N. and Pellegrin, F. (1973)

Review of glucose tolerance - a problem in methodology. Am.J.med.Sci. 265, 117-133.

Duncan, L.J.P. (1956)

The intravenous glucose tolerance test. Q.J1.exp.Physiol. 44, 85-96. 
du Plessis, J.P. (1973)

Personal Communication.

National Institute for Nutritional Diseases of the South

African Medical Research Council, Pretoria.

Dyck, D.R. and Moorhouse, J.A. (1966)

A high-dose intravenous glucose tolerance test.

J.clin.Endocr. 26, 1032-1038.

Enwonwu, C.O. and Sreebny, L.M. (1970)

Experimental protein-calorie malnutrition in rats.

Biochemical and ultrastructural studies.

Exper.Mol.Path. 12, 332-353.

Erwald, R., Hed, R., Nygren, A., Röjdmark, S., Sundblad, I. and Wiechel, K.-I. (1973)

Insulin concentration in portal and peripheral venous

blood after oral glucose in human pancreatitis.

Acta med.Scand. 194, 103-109.

Feldman, J.M. and Lebovitz, H.E. (1969)

Appraisal of the extrapancreatic actions of sulfonylureas.

Arch.intern.Med. 123, 314-322.

Folin, O. and Ciocalteu, V. (1927)

on tyrosine and tryptophane determinations in proteins. J.biol.Chem. 73, 627-650.

Forbes, G.B. and Lewis, A.M. (1956)

Total sodium, potassium and chloride in adult man.

J.clin. Invest. 35, 596-600.

Franckson, J.R.M., Ooms, H-A., Bellens, R., Conard, V. and Bastenie, P.A. (1962)

Physiologic significance of the intravenous glucose

tolerance test.

Metabolism 11, 482-500.

Frohman, L.A., Goldman, J.K. and Bernadis, L.I. (1972)

Studies of insulin sensitivity in vivo in weanling rats with hypothalamic obesity.

Metabolism 21, 1133-1142.

Fuhrman, F.A. (1951)

Glycogen, glucose tolerance and tissue metabolism in potassium-deficient rats.

Am.J.Physiol. 167, 314-320.

Gardner, L.I., Talbot, N.B., Cook, C.D., Berman, H. and Uribe, C.R. (1950)

The effect of potassium deficiency on carbohydrate metabolism. J.Lab.clin.Med. 35, 592-602.

Gillman, J. and Gilbert, C. (1958)

Fatty liver of endocrine origin with special reference to fatty liver of malnourished African infants.

Br.med.J. 1, 57-63. 
Gillman, J., Gilbert, C. and Savage, N. (1962)

Endocrine control of the fatty liver and serum lipids in baboons with special reference to the disorder of lipid metabolism in kwashiorkor.

Metabolism 11, 800-813.

Goberna, R., Fussgänger, R.D., Raptis, S., Telib, M. and Pfeiffer, E.F. (1971)

The role of the exocrine pancreas in the stimulation of insulin secretion by intestinal hormones. II. Insulin responses to secretin and pancreozymin in experimentallyinduced pancreatic exocrine insufficiency.

Diabetologia 7, 68-72.

Goldfine, I.D., Kahn, C.R., Neville, D.M., Roth, J., Garrison, M.M. and Bates, R.W. (1973)

Decreased binding of insulin to its receptors in rats with hormone induced insulin resistance.

Biochem.biophys.Res.Commun. 53, 852-857.

Gorden, P. (1973)

Glucose intolerance with hypokalaemia. Failure of shortterm potassium depletion in normal subjects to reproduce the glucose and insulin abnormalities of clinical

hypokalemia.

Diabetes $22,544-551$.

Grey, N.J., Goldring, S. and Kipnis, D.M. (1970)

The effect of fasting, diet, and actinomycin $D$ on insulin secretion in the rat.

J.clin. Invest. $49,881-889$.

Grodsky, G.M. and Benett, L.L. (1966)

Cation requirements for insulin secretion in the isolated perfused pancreas..

Diabetes $15,910-913$.

Hadden, D.R. (1967)

Glucose, free fatty acid, and insulin interrelations in kwashiorkor and marasmus.

Lancet 2, 589-593.

Hales, C.N. and Milner, R.D.G. (1968)

The role of sodium and potassium in insulin secretion from rabbit pancreas.

J.Physiol.Lond. 194, 725-743.

Hansen, J.D.í. (1968)

Features and treatment of kwashiorkor at the Cape. In: Calorie Deficiencies and Protein Deficiencies. Proceedings of a Colloquium. Cambridge, April 1967. Eds. McCance, R.A. and Widdowson, E.M. pp. 33-48, J and A Churchill Ltd., London. 
Hansen, J.D.L. and Brock, J.F. (1954)

Potassium deficiency in the pathogenesis of nutritional oedema in infants.

Lancet 2,477 .

Hazlewood, C.F. and Nichols, B.I. (1969)

Changes in muscle sodium, potassium, chloride, water and voltage during maturation in the rat: An experimental and theoretical study.

Bull.Johns Hopkins Hosp. 125, 119-133.

Heard, C.R.C. (1966)

Effects of severe protein-calorie deficiency on the

endocrine control of carbohydrate metabolism.

Diabetes $15,78-89$.

Heard, C.R.C., Platt, B.S. and Stewart, R.J.C. (1958)

The effects on pigs of a low-protein diet with and without additional carbohydrate.

Proc.Nutr.Soc. 17, xli-xlii.

Heard, C.R.C., Durbin, P.A.J. and Platt, B.S. (1961)

Delayed maturation of protein-deficient pigs as indicated by response to intravenous insulin and glucose.

Proc.Nutr.Soc. 20, XX (Abstracts).

Heard, C.R.C. and Turner, M.R. (1967)

Glucose tolerance and related factors in dogs fed diets of suboptimal protein value.

Diabetes 16, 96-107.

Heard, C.R.C. and Henry, P.A.J. (1969a)

Glucose tolerance and insulin sensitivity.

Clin.Sci. 37, 37-44.

Heard, C.R.C. and Henry, P.A.J. (1969b)

The insulinogenic response to intravenous glucose in

dogs fed diets of different protein value.

J. Endocr. 45, 375-386.

Heller, H., Hewer, T.F., Hughes, J.M. and Schnieden, H. (1958)

The effect of diuretics, cortisone and prednisolone on

weanling rats with oedema produced by an African plantain

diet.

Br.J.Nutr. 12, 52-64.

Hellman, B. (1970)

Methodological approaches to studies on the pancreatic islets. Diabetologia 6, 110-120.

Hetenyi, G. (1971)

The regulation of glucose production and utilisation in the intact animal.

Acta diabet. lat. 8, 213-227. 
Hiatt, N., Davidson, M.B. and Bonorris, G. (1972)

The effect of potassium chloride infusion on insulin secretion in vivo.

Horm.Metab.Res. 4, 64-68.

Hill, D.E., Holt, A.B., Parra, A. and Cheek, D.B. (1970)

The influence of protein-calorie versus calorie restriction

on the body composition and cellular growth of muscle

and liver in weanling rats.

Johns Hopkins Med.J. 127, 145-163.

Himsworth, H.P. (1939)

The mechanism of diabetes mellitus.

Lancet 2 , $1-6$.

Hoffman, W.S. (1937)

A rapid photoelectric method for the determination of glucose in blood and urine.

J.biol.Chem. 120, 51-55.

Holmes, E.G. and Trowell, H.C. (1948)

Formation of hepatic glycogen in normal Africans and in those suffering from malignant malnutrition.

Lancet 1 , 395-398.

Howard-Jones, N. (1947)

Wien.klin.Wschr. 59, 837, 857

As quoted in Lancet 1, 320 (1948).

Howell, S.I. and Taylor, K.W. (1968)

Potassium ions and the secretion of insulin by Islets of Langerhans incubated in vitro.

Biochem.J. 108, 17-24.

Hugget, A. St. G. and Nixon, D.A. (1957)

Use of glucose oxidase, peroxidase and o-dianisidine in determination of blood and urinary glucose.

Lancet $2,368-370$.

Hunter, W.M. and Greenwood, F.C. (1962)

Preparation of Iodine-131 labelled human growth hormone of high specific activity.

Nature, Lond. 194, 495-496.

Ikkos, D. and Luft, R. (1957)

On the intravenous glucose tolerance test.

Acta endocr., Copnh. 25, 312-334.

James, W.P.T. (1968)

Intestinal absorption in protein-calorie malnutrition.

Lancet $1,333-335$.

James, W.P.T. and Coore, H.G. (1970a)

Persistent impairment of insulin secretion and glucose tolerance after malnutrition.

Am.J.clin.Nutr. 23, 386-389. 
James, W.P.T. and Coore, H.G. (1970b)

Persistent impairment of insulin secretion and glucose tolerance after malnutrition.

Am.J.clin.Nutr. 23, 388, fig.l.

Jelliffe, D.B. (1959)

Protein-calorie malnutrition in tropical preschool children. J.Pediat. 54, 227-256.

Kaess, H., Schlierf, G., Ehlers, W., von Mikulicz-Radecki, J.-G., Hassenstein, P., Walter, K., Brech, W. and Hengstmann, J. (1971)

The carbohydrate metabolism of normal subjects during potassium depletion.

Diabetologia 7, 82-86.

Kershaw, T.G., Neame, K.D. and Wiseman, G. (1960)

The effect of semi-starvation on absorption by the rat small intestine in vitro and in vivo.

J.Physiol., Lond. 152, 182-190.

Kirsch, R.E., Brock, J.F. and Saunders, S.J. (1968a)

Experimental protein-calorie malnutrition.

Am.J.clin.Nutr. 21, 820-826.

Kirsch, R.E., Saunders, S.J. and Brock, J.F. (1968b)

Animal models and human protein-calorie malnutrition. Am.J.clin.Nutr. 21, 1225-1228.

Kirsch, R.E., Saunders, S.J. and Brock, J.F. (1968c)

Amino acid transport in experimental protein-calorie malnutrition.

Am.J.clin.Nutr. 21, 1302-1305.

Klotz, A.P., Murdock, A.I. and Svoboda, D.J. (1972)

The effect of protein deprivation on pancreatic function

in young animals and on animals in utero.

Am.J.dig.Dis. 17, 399-406.

Korec, R. (1973)

Calculation of the assimilation konstanst of glucose-Kg. Diabetologia $9,307$.

Lacy, P.E. (1970)

Beta cell secretion-from the standpoint of a pathobiologist. Diabetes 19, 895-905.

Lambert, A.E., Junod, A., Stauffacher, W., Jeanrenaud, B. and Renold, A.E. (1969a)

Organ culture of fetal rat pancreas. I. Insulin release induced by caffeine and by sugars and some derivatives. Biochim.biophys.Acta. 184, 529-539. 
Lambert, A.E., Jeanrenaud, B., Junod, A. and Renold, A.E. $(1969 b)$

Organ culture of fetal rat pancreas. II. Insulin release induced by amino and organic acids, by hormonal peptides, by cationic alterations of the medium and by other agents. Biochim.biophys.Acta 184, 540-553.

Lavine, R.L., Chick, W.L., Like, A.A. and Makdisi, T.W. (1971)

Glucose tolerance and insulin secretion in neonatal and adult mice.

Diabetes $20,134-139$.

Lazarus, S.S. and Volk, B.W. (1970)

Ultrastructural aspects of the function of rabbit $\beta$-cells. In: The Structure and Metabolism of the Pancreatic Islets. Proceedings of an International Symposium. Umea, Sweden. February 1969. Eds. Falkmer, S., Hellman, B. and Täljedal, IrB. pp. 159-170. Pergamon Press, Braunschweig, Hungary.

Lerner, R.I. and Porte, D. (1971)

Relationships between intravenous glucose loads, insulin responses and glucose disappearance rate.

J.clin. Endocr. 33, 409-417.

Levine, R. and Haft, D.E. (1970)

Carbohydrate homeostasis.

New Engl.J.Med. 283, 175-183, 237-246.

Lifshitz, F., Hawkins, R.I., Diaz-Bensussen, S. and Wapnir, R.A. (1972)

Absorption of carbohydrates in malnourished rats.

J.Nutr. 102, 1303-1310.

Loubatières-Mariani, M.M., Loubatiéres, A.L. and Chapal, J. (1973)

Analysis of the stimulating action of tolbutamide on the secretion of insulin using mannoheptulose and diazoxide. Diabetologia 9, 152-157.

Lowry, O.H. and Hastings, A.B. (1942)

Histochemical changes associated with aging: I. Methods and calculations.

J.biol. Chem. 143, 257-269.

Lowry, O.H., Rosebrough, N.J., Farr, A.I. and RandalI, R.J. (1951)

Protein measurement with the Folin phenol reagent.

J.biol. Chem. 193, 265-275.

Mann, M.D. (1972)

Potassium in young children.

Ph.D. Thesis, University of Cape Town. 
Mann, M.D., Bowie, M.D. and Hansen, J.D.I. (1972)

Potassium in protein calorie malnutrition.

S.Afr.med.J. 46, 2062-2064.

Martin, D.B., Renold, A.E. and Dagenais, Y.M. (1958)

An assay for insulin-like activity using rat adipose

tissue.

Lancet $2,76-77$.

Martin, J.M. (1969)

Factors controlling insulin secretion in vitro.

Acta diabet.lat. 6, 689-712.

Mayhew, D.A., Wright, P.H. and Ashmore, J. (1969)

Regulation of insulin secretion.

Pharmac.Rev. 21, 183-212.

McCance, R.A. (1968)

The two syndromes. In: Calorie Deficiencies and Protein

Deficiencies. Proceedings of a Colloquium. Cambridge

April 1967. Eds. McCance, R.A. and Widdowson, E.M.

p.I. J and A Churchill Ltd. London.

McIntyre, N., Holdsworth, C.D. and Turner, D.S. (1964)

New interpretation of oral glucose tolerance.

Lancet $2,20-21$.

McKiddie, M.T., Buchanan, K.D. and Hunter, I.A. (1969)

Plasma insulin studies in two hundred patients with diabetes mellitus.

Q.JI.Med. $38,445-465$.

Melzer, C.

Unpublished data.

Dept. of Physiology, Medical School, Cape Town.

Metz, R. (1960)

The effect of blood glucose concentration on insulin output.

Diabetes 9, 89-93.

Milner, R.D.G. (1971a)

Metabolic and hormonal responses to glucose and glucagon in patients with infantile malnutrition.

Pediat.Res. 5, 33-39.

Milner, R.D.G. (1971b)

Metabolic and hormonal responses to oral amino acids in infantile malnutrition.

Arch.Dis.Child.46, 301-305.

Milner, R.D.G. (1972)

Endocrine adaptation to malnutrition.

Nutr.Rev. 30, 103-106. 
Mondon, C.E., Burton, S.D., Grodsky, G.M. and Ishida, T. (1968)

Glucose tolerance and insulin response of potassium deficient rat and isolated liver.

Am.J.Physiol. 215, 779-787.

Morgan, C.R. and Iazarow, A. (1963)

Immunoassay of insulin: Two antibody system. Plasma insulin levels of normal, subdiabetic and diabetic rats.

Diabetes 12 , 115-126.

Munger, B.L. and Lang, C.M. (1973)

Spontaneous diabetes mellitus in guinea pigs. The acute cytopathology of the islets of Iangerhans.

Lab. Invest. 29, 685-702.

Nichols, B.L., Alvarado, J.M., Hazlewood, C.F. and

Viteri, F.E. (1972)

Clinical significance of muscle potassium depletion in protein calorie malnutrition.

J.Pediat. $80,319-330$.

Niemeyer, H. and Meneghello, J. (1950)

Liver steatosis in undernourished Chilean children. ii. Study on some liver function tests.

Am.J.Dis.Child. 80, 898-904.

Normet, L. (1926)

As quoted by Pitchumoni (1973)

La "aboufissure d' Annam"

Bull.Soc.Path.exot. 19, 207.

Olefsky, J., Batchelder, T., Farquhar, J.W. and Reaven, G.M: (1973a)

Disassociation of the plasma insulin response from the blood glucose concentration during glucose infusions in normal dogs.

Metabolism 22, $1277-1286$.

Olefsky, J., Farquhar, J.W. and Reaven, G. (1973b)

Relationship between fasting plasma insulin level and resistance to insulin-mediated glucose uptake in normal and diabetic subjects.

Diabetes 22, 507-513.

Orci, L., Renold, A.E. and Rouiller, Ch. (1970)

Intracellular " $\alpha$-Granulolysis" in $\alpha$-cells of diabetic animals. In: The structure and Metabolism of the Pancreatic Islets. Proceedings of an International Symposium. Umea, Sweden. February 1969. Eds. Falkmer, S., Hellman, B. and Täljedal, I-B. pp. 109-114. Pergamon Press, Braunschweig, Hungary.

Ørskov, H. and Christensen, N.J. (1966)

Disappearance-rate of exogenous human insulin. Lancet 2, 701 . 
Oxman, S.V., Maccioni, A.S., Zuñiga, A.C., Spada, R.G. and Mönckeberg, F.B. (1968)

Disturbances of carbohydrate metabolism in infantile marasmus.

Am.J.clin.Nutr. 21, 1285-1290.

Pagliara, A.S., Karl, I.E. and Kipnis, D.B. (1973)

Transient neonatal diabetes: delayed maturation of the pancreatic beta cell.

J.Pediat. 82, 97-101.

Penhos, J.C., Castillo, L., Voyles, N., Gutman, R.,

Lazarus, N. and Recant, L. (1971)

Decreased glucose tolerance in the rat following

hypophysectomy .

Endocrinology 88, 1141-1149.

Penhos, J.C., Castillo, L., Ezekiel, M., Yamaguchi, N., De Santis, R.A., Gutman, R.A. and Recant, L. (1972)

Insulin-resistant hyperglycemia produced by aminophylline. Endocrinology $90,131-137$.

Perley, M. and Kipnis, D.M. (1966)

Plasma insulin responses to glucose and tolbutamide of normal weight and obese diabetic and nondiabetic subjects. Diabetes 15, 867-874.

Peterson, D.T. and Reaven, G.M. (1971)

Evidence that glucose load is an important determinant of plasma insulin response in normal subjects.

Diabetes $20,729-733$.

Pitchumoni, C.S. (1973)

Pancreas in primary malnutrition disorders. Am.J.clin.Nutr. 26, 374-379.

Platt, B.S., Halder, K. and Doell, B.H. (1962)

pathology of acute experimental protein malnutrition in the force-fed rat.

Proc.Nutr.Soc. 2l, vi-vii.

Platt, B.S., Heard, C.R.C. and Stewart, R.J.C. (1964a) Experimental protein-calorie deficiency. In: Mammalian Protein Metabolism, Vol. 2, Eds. Munro, H.N. and Allison, J.B. pp. 445-521. Academic Press, New York and London.

Platt, B.S., Heard, C.R.C. and Stewart, R.J.C. (1964b) Experimental protein-calorie deficiency. In: Mammalian Protein Metabolism, Vol: 2, Eds. Munro, H.N. and Allison, J.B. pp. 456-458. Academic Press, New York and London. 
Platt, B.S., Heard, C.R.C. and Stewart, R.J.C. (1964c) Experimental protein-calorie deficiency. In: Mammalian Protein Metabolism, Vol. 2, Eds. Munro, H.N. and Allison, J.B. pp. 47I-472, Academic Press, New York and London.

Platt, B.S., Heard, C.R.C. and Stewart, R.J.C. (I964d) Experimental protein-calorie deficiency. In: Mammalian Protein Metabolism, Vol. 2, Eds. Munro, H.N. and Allison, J.B. p.486, Academic Press, New York and London.

Porte, D. and Pupo, A.A. (1969)

Insulin responses to glucose: evidence for a two pool system in man.

J.clin. Invest. $48,2309-2319$.

Porte, D. and Bagdade, J.D. (1970)

Human insulin secretion: An integrated approach.

Ann.Rev.Med. 21, 219-240.

Ramalingaswami; V. (1969)

Interface of protein nutrition and medicine in the tropics. Lancet $2,733-736$.

Ramalingaswami, V. and Deo, M.G. (1968)

Experimental protein-calorie malnutrition in the Rhesus monkey. In: Calorie Deficiencies and Protein Deficiencies. Proceedings of a Colloquium. Cambridge, April 1967. Eds. McCance, R.A. and Widdowson, E.M. pp. 265-275. $J$ and $A$ Churchill Ltd. London.

Raptis, S., Rau, R.M., Schröder, K.E., Hartmann, W. , Faulhaber, J.-D., Clodi, P.H. and Pfeiffer, E.F. (1971) The role of the exocrine pancreas in the stimulation of insulin secretion by intestinal hormones. III. Insulin responses to secretin and pancreozymin, and to oral and intravenous glucose, in patients suffering from chronic insufficiency of the exocrine pancreas.

Diabetologia 7, 160-167.

Rasio, E.A., Soeldner, J.S. and Cahill, G.F. (1965)

Insulin and insulin-like activity in serum and extravascular fluid.

Diabetologia 1, 125-127.

Rasio, E.A., Hampers, C.I., Soeldner, J.S. and Cahill, G.F. (1967)

Diffusion of glucose, insulin, inulin and Evans blue protein into thoracic duct lymph of man.

J.clin.Invest. 46, 903-910.

Renold, A.E. (1970)

Insulin biosynthesis and secretion- a still unsettled topic. New Engl.J.Med. 282, 173-182. 
Riggs, D.S. (1963)

The mathematical approach to physiological problems.

pp. 209-217. The Williams and Wilkins Company, Baltimore.

Riggs, D.S. (1970)

Control theory and physiological feedback mechanisms. pp. 476-481. The Williams and Wilkins Company, Baltimore.

Sacks, H. (1974)

Personal Communication.

Dept. of Medicine, Medical School, University of Cape Town, Observatory, Cape.

Sagild, U., Andersen, V. and Andreasen, P.B. (1961)

Glucose tolerance and insulin responsiveness in

experimental potassium depletion.

Acta med.Scand. 169, 243-251.

Samols, E. and Marks, V. (1966)

Disappearance rate of endogenous insulin in man.

Lancet 2,700 .

Schnieden, H., Hendrickse, R.G. and Haigh, C.P. (1958)

Studies in water metabolism in clinical and experimental malnutrition.

Trans.R.Soc.trop.Med.Hyg. 52, 169-175.

Scow, R.O. and Cornfield, J. (1954)

Quantitative relations between the oral and intravenous glucose tolerance curves.

Am.J.Physiol. 179, 435-438.

Searle, G.L., Strisower, E.H. and Chaikoff, I.I. (1954) Glucose pool and glucose space in the normal and diabetic dog.

Am.J.Physiol. 176, 190-194.

Seltzer, H.S., Allen, E.W., Herron, A.L. and Brennan, M.T. (1967)

Insulin secretion in response to glycemic stimulus: relation of delayed initial release to carbohydrate intolerance in mild diabetes mellitus.

J.clin. Invest. $46,323-335$.

Sidransky, H. and Farber, E. (1958)

Chemical pathology of acute amino acid deficiencies. I. Morphologic changes in inmature rats fed threonine-, methionine-, or histidine-devold diets.

Archs.Path. 66, 119-134.

Siegel, S. (1956)

Nonparametric statistics for the behavioural sciences. McGraw-Hill Book Company, Inc. Kōgakusha Company, Ltd., Tokyo. 
Slone, D., Taitz, I.S. and Gilchrist, G.S. (1961)

Aspects of carbohydrate metaholism in kwashiorkor with special reference to spontaneous hypoglycaemia. Br.med.J. 1, 32-34.

Smyth, D.H. (1961)

I. Methods for study of intestinal absorption in vivo. In: Methods in Medical Research, Vol. 9, Ed. Quastel, J.H. pp. 260-272. Year Book Medical Publishers Inc. Chicago.

Spergel, G., Schmidt, P., Stern, A. and Bleicher, S.J. (1967a)

Effects of hypokalemia on carbohydrate and lipid metabolism in the rat.

Diabetes $16,312-318$.

Spergel, G., Bleicher, S.J., Goldberg, M., Adesman, J. and Goldner, M.G. (1967b)

The effect of potassium on the impaired glucose tolerance in chronic uraemia.

Metabolism 16, 581-585.

Spiegel, M.R. (1961)

Theory and problems of statistics.

Schaum Publishing Co., New York.

Stead, R.H. and Brock, J.F. (I972)

Experimental protein-calorie malnutrition. Rapid induction of protein depletion signs in early-weaned rats.

J.Nutr. 102, 1357-1366.

Sutherland, E.W. and Robison, G.A. (1969)

The role of cyclic AMP in the control of carbohydrate metabolism.

Diabetes 18, 797-819.

Tarver, H. and Schmidt, C.L.A. (1942)

Radioactive sulphur studies. 1. The synthesis of methionine*. 2. Conversion of methionine sulphur to taurine sulphur in dogs and rats. 3. Distribution of sulphur* in the proteins of animals fed sulphur* or methionine*. 4. Experiments in vitro with sulphur* and hydrogen sulphide.*

J.biol.Chem. 146, 69-84.

Tejning, S. (1947)

Dietary factors and quantitative morphology of the islets of Langerhans.

Acta med.Scand. Suppl. 198, 1-154.

Tiernan, J.R., Kemball, M.L. and Soeldner, J.S. (1968)

A micromodification of the two antibody radioimmunoassay

for serum insulin.

J.Iab.clin.Med. 71, 345-349. 
Tisdall, F.T., Drake, T.G.H. and Brown, A. (1925a). The carbohydrate metabolism of the marantic infant. Am.J.Dis.Child, 30, 829-836.

Tisdall, F.T., Drake, T.G.H. and Brown, A. (1925b) The carbohydrate metabolism of infants with diarrhea, infections and acute intestinal intoxication (with a note on the use of insulin).

Am.J.Dis.Child. 30, 837-843.

Trowell, H.C., Davies, J.N.P. and Dean, R.F.A. (1954a) Kwashiorkor.

Edward Arnold (Publishers) Ltd. London.

Trowell, H.C., Davies, J.N.P. and Dean. R.F.A. (1954b) Kwashiorkor. pp. 140-144.

Edward Arnold (Publishers) Itd. Iondon.

Trowell, H.C., Davies, J.N.P. and Dean, R.F.A. (1954C)

Kwashiorkor. p. 155.

Edward Arnold (Publishers) Ltd. London.

Turner, D.S. and Young, D.A.B. (1973)

The effect of fasting and selective re-feeding on insulin release in the rat.

Acta endocr.Copnh. 72, 46-53.

Turtle, J.R., Littleton, G.K. and Kipnis, D.M. (1967)

Stimulation of insulin secretion by theophylline.

Nature, Lond. 213, 727-728.

Underwood, B.J., Duncan, C.P., Tayior, J.A. and Cotton, J.W. (1954)

Elementary Statistics.

Appleton-Century-Crofts, Inc. New York.

Vallance-Owen, J. and Wright, P.H. (1960)

Assay of insulin in blood.

Physiol.Rev. 40, 219-244.

Vêghelyi, P.V., Kemêny, T.T., Pozsonyi, J. and. Sós, J. (1950a)

Dietary lesions of the pancreas.

Am.J.Dis.Child. 79, 658-665.

Vêghelyi, P.V., Kemény, T.T., Pozsonyi, J. and sôs, J. (1950b)

Toxic lesions of the pancreas.

Am.J.Dis.Child. 80, 390-403.

Volk, B.W., Wellman, K.F., Lazarus, S.S. and Brancato, P. (1969)

Beta cell morphology and insulin immunoassay in long-term subdiabetic rabbits.

Archs.Path. 88, 413-422. 
Vranic, M., Fono, P., Kovacevic, N. and Lin, B.J. (1971) Glucose kinetics and fatty acids in dogs on matched insulin infusion after glucose load.

Metabolism 20, 954-967.

Wallace, W.M., Holliday, M., Cushman, M. and Elkington, J.R. (195I)

The application of the internal standard flame photometer to the analysis of biologic material.

J.Lab.clin.Med. 37, 621-629.

Waterlow, J.C. (1948)

Fatty liver disease in infants in the British West Indies. Spec.Rep.Ser.med.Red.Counc. London No. 263.

Welborn, T.A., Rubenstein, A.H., Haslam, R. and Fraser, R. (1966)

Normal insulin response to glucose.

Lancet 1, 280-284.

Whang, R. and Welt, I.G. (1963)

Observations in experimental magnesium depletion.

J.clin.Invest. $42,305-313$.

Wheeler, J.E., Lukens, F.D.W. and György, P. (1949)

Studies on the localization of tagged methionine within the pancreas.

Proc.Soc.exp.Biol.Med. 70, 187-189.

Widdowson, E.M. and MCCance, R.A. (1957)

Effect of a low-protein diet on the chemical composition of the bodies and tissues of young rats.

Br.J.Nutr. 11, 198-206.

Wright, P.H. (1972)

Insulin secretion and the techniques used for its study. Diab.Croat. 1, 259-264.

Yalow, R.S. and Berson, S.A. (1960)

Immunoassay of endogenous plasma insulin in man.

J.clin. Invest. 39, 1157-1175.

Yalow, R.S. and Berson, S.A. (1964)

Immunoassay of plasma insulin. In: Methods of Biochemical Analysis, Vol. 12, Ed. Glick, D. , pp. 69-96.

Interscience Publishers (a division of John Wiley \& Sons, New York, London, Sydney).

Youngs, G. (1972)

Hormonal control of pancreatic endocrine and exocrine secretion.

Gut 13, 154-161. 


\section{APPENDIX A - METHODS}

Statistical methods

A 2

Measurement of serum albumin

A 9

Measurement of total serum proteins

Measurement of total body water

Glucose and insulin estimation: general

Glucose assay

Insulin radioimmunoassay

Estimation of total pancreatic islet volume

Measurement of plasma and tissue sodium and potassium 
STATISTICAL METHODS

Two types of statistical tests were employed in this work:

A. Parametric Tests (Spiegel, 1961; Underwood et al, 1954). B. Nonparametric Tests (Siegel, 1956).

Wherever possible parametric tests were preferred as they make the best possible use of the available data. Parametric tests, however, can only be applied to normally distributed data. The cumulative relative frequency of the data plotted on probability graph paper (normal curve paper) was used as a simple test for normality. Where this plot approximated a straight line, a parametric test was used (e.g. fig.l glucose, 30 minutes after an oral glucose load).

In cases of deviation from the normal distribution (e.g. fig.2 plasma insulin, 10 minutes after intravenous glucose), nonparametric tests were used. Plasma insulin values have been shown to follow a log-normal distribution (Welborn et al, 1966) (e.g. fig.3. Data as infig.2, but with insulin values plotted on a logarithmic scale). 
Percentage.

Cumulative

Relative

Frequency

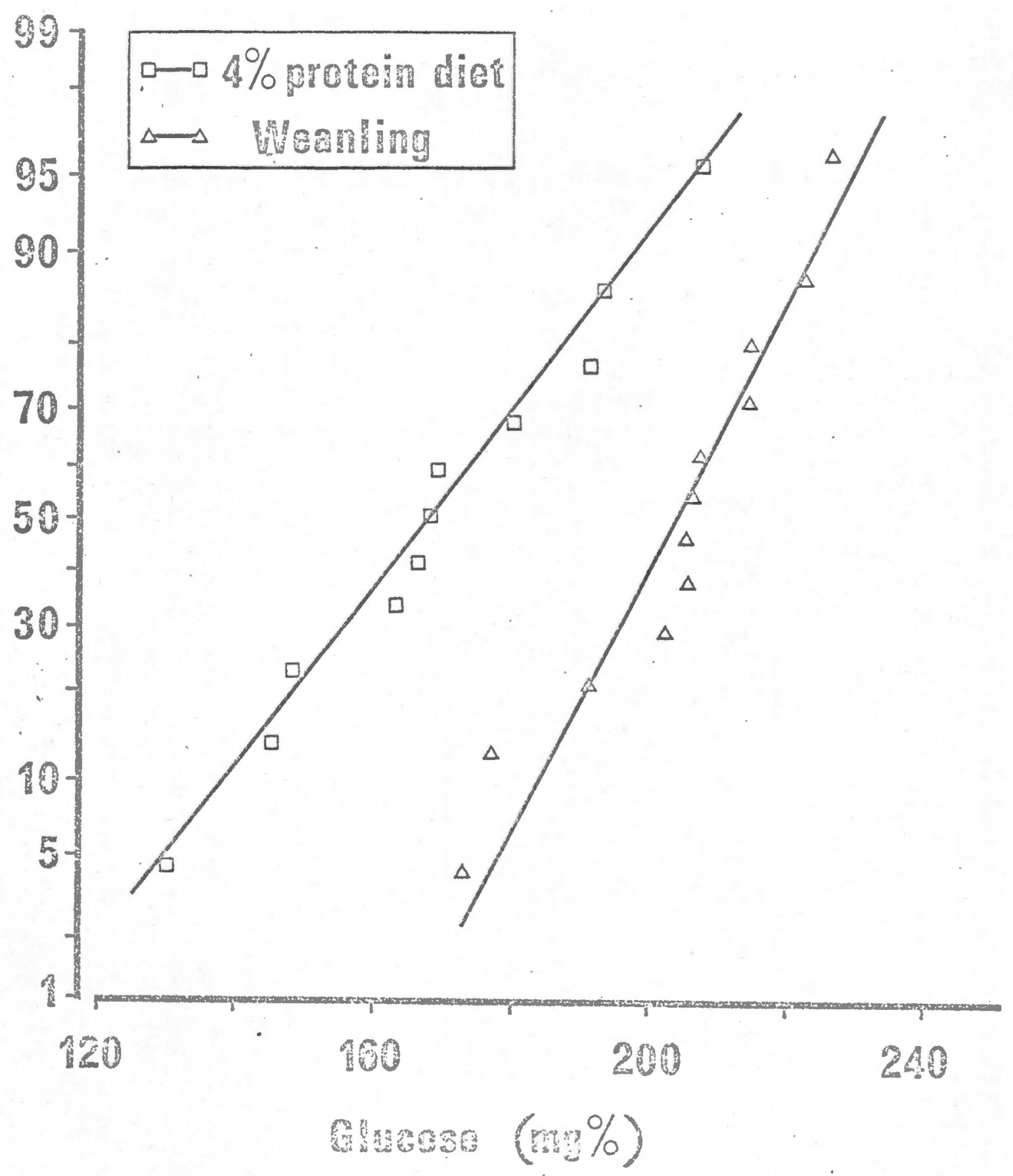

Fig.1. Blood glucose concentrations, 30 minutes after an oral glucose load. 


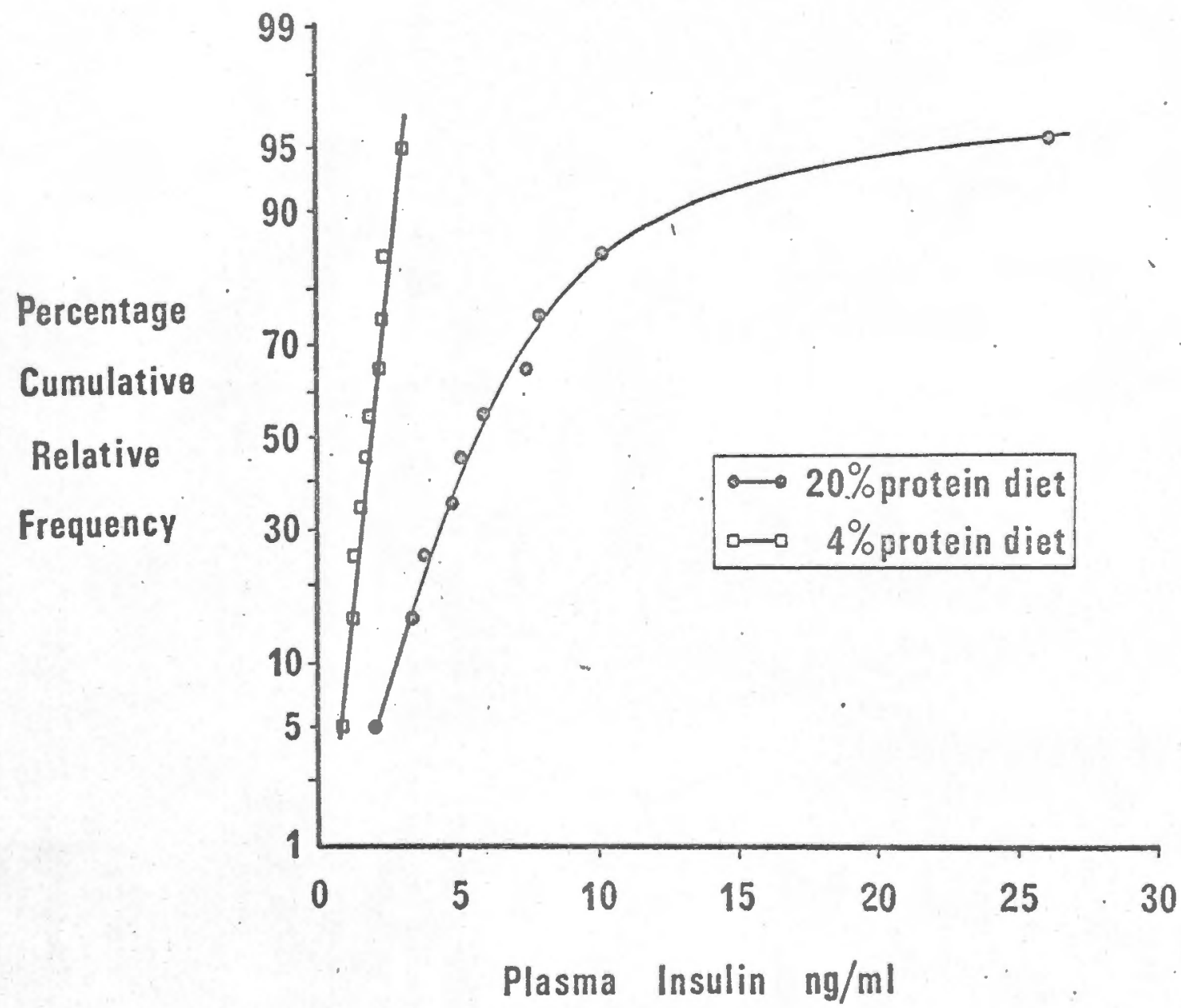

Fig. 2 Plasma insulin concentrations 10 minutes after an intravenous glucose load. 
Percentage Cumulative Relative Frequency

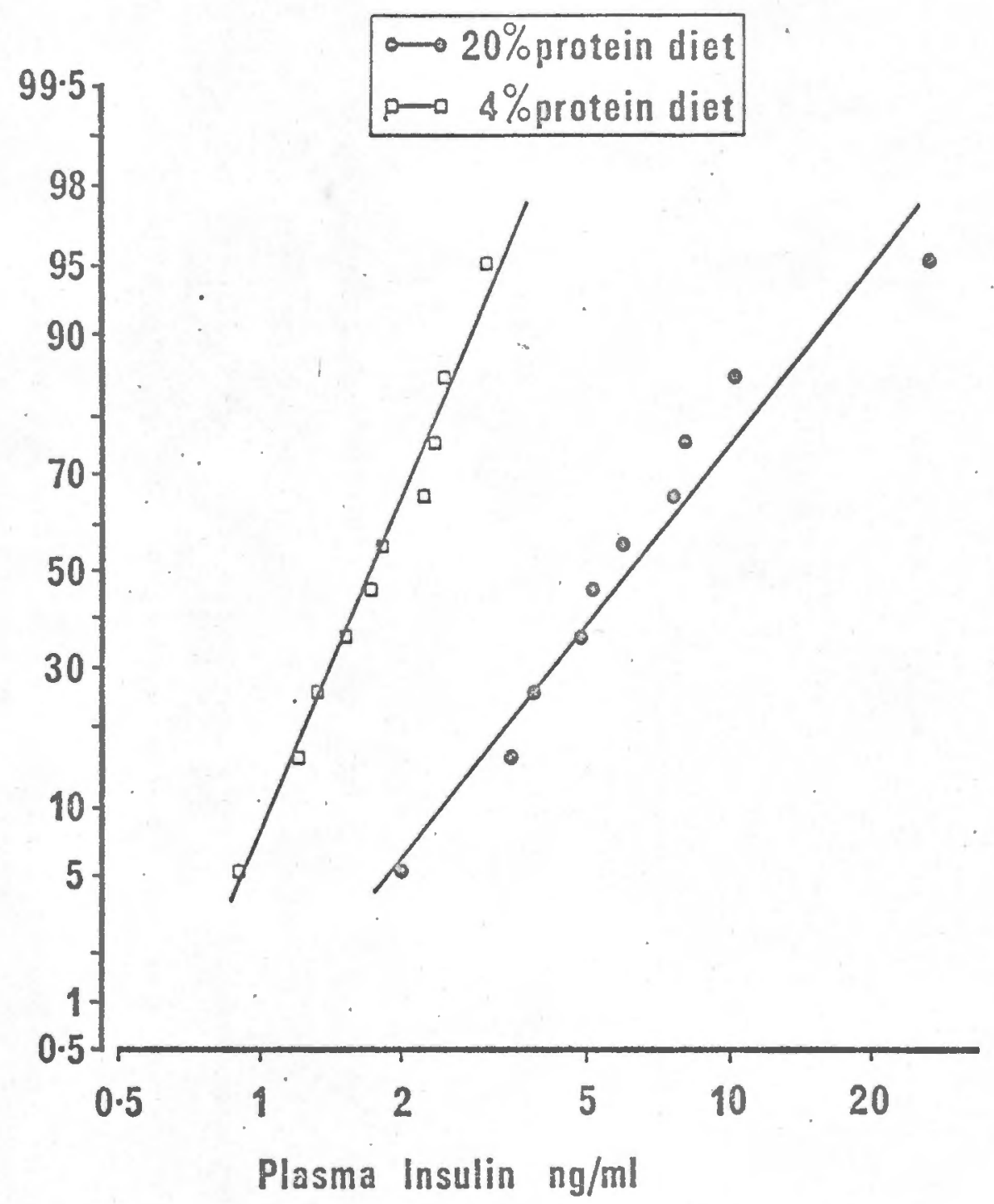

Fig.3. Data as for fig.2 plotted on a logarithmic scale. 
A. Parametric Tests

The following standard definitions were used:

The Mean, $\bar{x}=\frac{1}{n} \sum x$

where $\mathrm{n}$ = number of observations

Standard Deviation, S.D. $=\sqrt{\frac{\sum(x-\bar{x})^{2}}{n-1}}$

where $n<30$

Standard Error of the Mean $(S E M)=\frac{\text { S.D. }}{\sqrt{n}}$

Coefficient of Variation $\quad=\frac{\text { S.D. }}{\bar{x}} \times 100$

\section{'student's' $t$ test}

To compare the means $\left(\bar{x}_{1}\right.$ and $\left.\bar{x}_{2}\right)$ of two small samples $\left(n_{1}\right.$ and $\left.n_{2}\right)$ from normal populations (unknown variances assumed equal)

$$
t=\frac{\bar{x}_{1}-\bar{x}_{2}}{s \sqrt{\frac{1}{n_{1}+\frac{1}{n_{2}}}}}
$$

Where $S$ was an estimate of the standard deviation based on both samples jointly

$s^{2}=\frac{1}{n_{1}+n_{2}-2}\left[\sum x_{1}^{2}-\frac{\left(\sum x_{1}\right)^{2}}{n_{1}}+\sum x_{2}^{2}-\frac{\left(\sum x_{2}\right)^{2}}{n_{2}}\right]$

Degrees of freedom $=n_{1}+n_{2}-2$ 
Least Square Regression Line

A line of the form $y=a+b x$ was fitted to pairs of figures $\left(x_{1}, y_{1}\right), \quad\left(x_{2}, y_{2}\right), \ldots \ldots \ldots \ldots\left(x_{n}, y_{n}\right)$

when

$$
\begin{aligned}
& a=\frac{\left(\sum y \cdot\right)\left(\sum x^{2}\right)-\left(\sum x\right)\left(\sum x y\right)}{n \sum x^{2}-\left(\sum x\right)^{2}} \\
& b=\frac{n \sum x y-\left(\sum x\right)\left(\sum y\right)}{n \sum x^{2}-\left(\sum x\right)^{2}}
\end{aligned}
$$

\section{Correlation Coefficient}

$$
r=\frac{n \sum x y-\left(\sum x\right)\left(\sum y\right)}{\sqrt{\left[n \sum x^{2}-\left(\sum x\right)^{2}\right]\left[n \sum y^{2}-\left(\sum y\right)^{2}\right]}}
$$

B. Nonparametric Tests

\section{The Median}

If a set of numbers is arranged in order of magnitude, the middle value, or the arithmetic mean of the two middle values is called, the median.

The Mann-Whitney U Test

$$
\begin{aligned}
\mathrm{n}_{1}= & \text { the number of values in the smaller of the two } \\
& \text { independent groups. } \\
\mathrm{n}_{2}= & \text { the number of values in the larger of the two } \\
& \text { groups. }
\end{aligned}
$$

The values from both groups were combined and ranked in order of increasing size. 
The sum of the ranks assigned to the smaller group (sample size $\left.n_{1}\right)=R_{1}$

The sum of the ranks assigned to the other group (sample size $n_{2}$ ) $=R_{2}$

$$
U=n_{1} n_{2}+\frac{n_{1}\left(n_{1}+1\right)}{2}-R_{1}
$$

or

$$
U=n_{1} n_{2}+\frac{n_{2}\left(n_{2}+1\right)}{2}-R_{2}
$$

Both formulae yield different values for $U$. If the observed value of $U$ was larger than $\frac{n_{1} n_{2}}{2}$ it was $U$ ' and the true value of $U$ was then calculated from the following equation:

$$
\mathrm{U}=\mathrm{n}_{1} \mathrm{n}_{2}-\mathrm{U}^{\prime}
$$

\section{Levels of significance}

Values of $p$ were determined from the appropriate tables for the $t$ test, the $U$ test and correlation coefficient. Two-tailed tests were used in the determination of $p$, and where $p$ was greater than 0.05 ( $p>0.05)$, differences between sample means (or medians) were regarded as not significant (NS). 
MEASUREMENT OF SERUM ALBUMIN

The Bromocresol green method of Doumas et al (1971) was used. This dye specifically binds to albumin without reacting with globulins. A commercial preparation containing bromocresol green, buffer, surface active agent and preservative was used, (Albustrate, Warner-Lambert Company).

Procedure

Reagents were added in the following sequence:

1. $0.5 \mathrm{ml}$ AlbuStrate reagent.

2. $2 \mathrm{ml}$ distilled water.

3. $5 \mu l$ of sample or standard.

Absorbance was read 30 minutes later at $630 \mathrm{~nm}$. $\underline{\text { Standards }}$

Commercially available serum standards of known albumin concentration were used (Calibrate, Warner-Lambert Company). Absorbance was found to be linear over the working range, $1.5-4.6 \mathrm{~g} / 100 \mathrm{ml}$.

Reproducibility

An interassay coefficient of variation of $1.9 \%$ was found $(N=5)$. 


\section{MEASUREMENT OF TOTAL SERUM PROTEINS}

Total serum proteins were measured by the method of Lowry et al (1951), using a commercial preparation (Merck) of Folin reagent (Folin and Ciocalteu, 1927).

\section{Reagents}

A. $2 \% \mathrm{Na}_{2} \mathrm{CO}_{3}$ in $0.1 \mathrm{~N} \mathrm{NaOH}$.

B. $0.5 \% \mathrm{CuSO}_{4} \cdot 5 \mathrm{H}_{2} \mathrm{O}$ in $1 \%$ potassium sodium tartrate.

C. $50 \mathrm{ml}$ reagent $\mathrm{A}$ mixed with $1 \mathrm{ml}$ of reagent $B$.

E. Folin-Ciocalteu reagent (Merck) diluted 1:1 with distilled water.

\section{Procedure}

Reagents were added in the following sequence:

1. $5 \mu l$ of standard or sample.

2. $1 \mathrm{ml} 0.9 \mathrm{~N} \cdot \mathrm{NaCl}$.

3. $5 \mathrm{ml}$ Lowry reagent $\mathrm{C}$.

After 10 minutes, $0.5 \mathrm{ml}$ reagent $\mathrm{E}$ was added to all tubes with rapid mixing. Tubes were allowed to remain at room temperature for $\frac{1}{2}$ to $2 \frac{1}{2}$ hours and absorbance was read at $500 \mathrm{~nm}$.

\section{Standards}

See serum albumin determination.

\section{Calculation}

Absorbance was linear over the working range 2.4 $7.4 \mathrm{~g} / 100 \mathrm{ml}$. 


\section{MEASUREMENT OF TOTAL BODY WATER}

Principle

This method depended on the dilution of a known volume of tritiated water with exchangeable body water. $\underline{\text { Procedure }}$

Animals were fasted for approximately 3 hours and drinking water was removed 1 hour before the experiment. They were weighed, and a sample of heparinised blood was taken from a tail vein (plasma blanks). 0.1 to $0.2 \mathrm{ml}$ of tritiated water $(500 \mu \mathrm{Cl} / \mathrm{ml})$ was injected intraperitoneally using $1 \mathrm{ml}$ disposable syringes with a 26 gauge needle. To prevent loss of label during the injection, the syringe was filled in the following manner:

$0.1 \mathrm{ml}$ of air was aspirated followed by the tritiated water, then another $0.1 \mathrm{ml}$ of air. The syringe was carefully wiped dry, the needle was attached, and it was then weighed to an accuracy of $0.1 \mathrm{mg}$. The tritiated water $\left({ }^{3} \mathrm{H}_{2} \mathrm{O}\right)$ and air were injected intraperitoneally and the syringe with the needle weighed again.

During an initial pilot study heparinised blood samples were taken from a tail vein, $\frac{1}{2}$ to 3 hours following the injection (See fig.4). In later experiments a single sample was taken between $1 \frac{1}{2}$ to 2 hours after the injection. The Standard

An accurately weighed sample of ${ }^{3} \mathrm{H}_{2} \mathrm{O}$ was diluted to $50 \mathrm{ml}$ with distilled water. 
Measurement of tritium

Plasma was separated from the heparinised blood samples. $\quad 5 \mu l$ of plasma was pipetted into micro test tubes and proteins were precipitated by the addition of $80 \mu 1$ of $2 \%$ perchloric acid. After centrifugation, $50 \mu l$ of supernatant was pipetted into glass counting vials to which were added $10 \mathrm{ml}$ of scintillation fluid. This contained a mixture of 1 part of ethylene glycol monoethyl ether (Cellosolve) to 2 parts of Bray's solution (Bray, 1960). The standard solution, blanks and plasma samples were all treated in the same manner. All determinations were done in triplicate. Vials were counted in an automatic beta liquid scintillation counter with automatic external standardisation. Calculation of results

There were no differences in the external standard channel ratios of the samples and standard, thus no corrections for quenching were necessary. Background counts obtained from the plasma blanks were subtracted from those of the plasma samples. A water blank was used as a background for the standard samples. Total body water (ml) $=\frac{\text { Counts in standard X } 50}{\text { Counts in sample }} \times \frac{\text { Weight of } 3 \mathrm{H}_{2} \mathrm{O} \text { injected into animal }}{\text { Weight of } 3 \mathrm{H}_{2} \mathrm{O} \text { in standard }}$ Percentage body water $=\frac{\text { total. body water }(\mathrm{m} \cdot \mathrm{l})}{\text { body weight }(\mathrm{g})} \times 100$ 


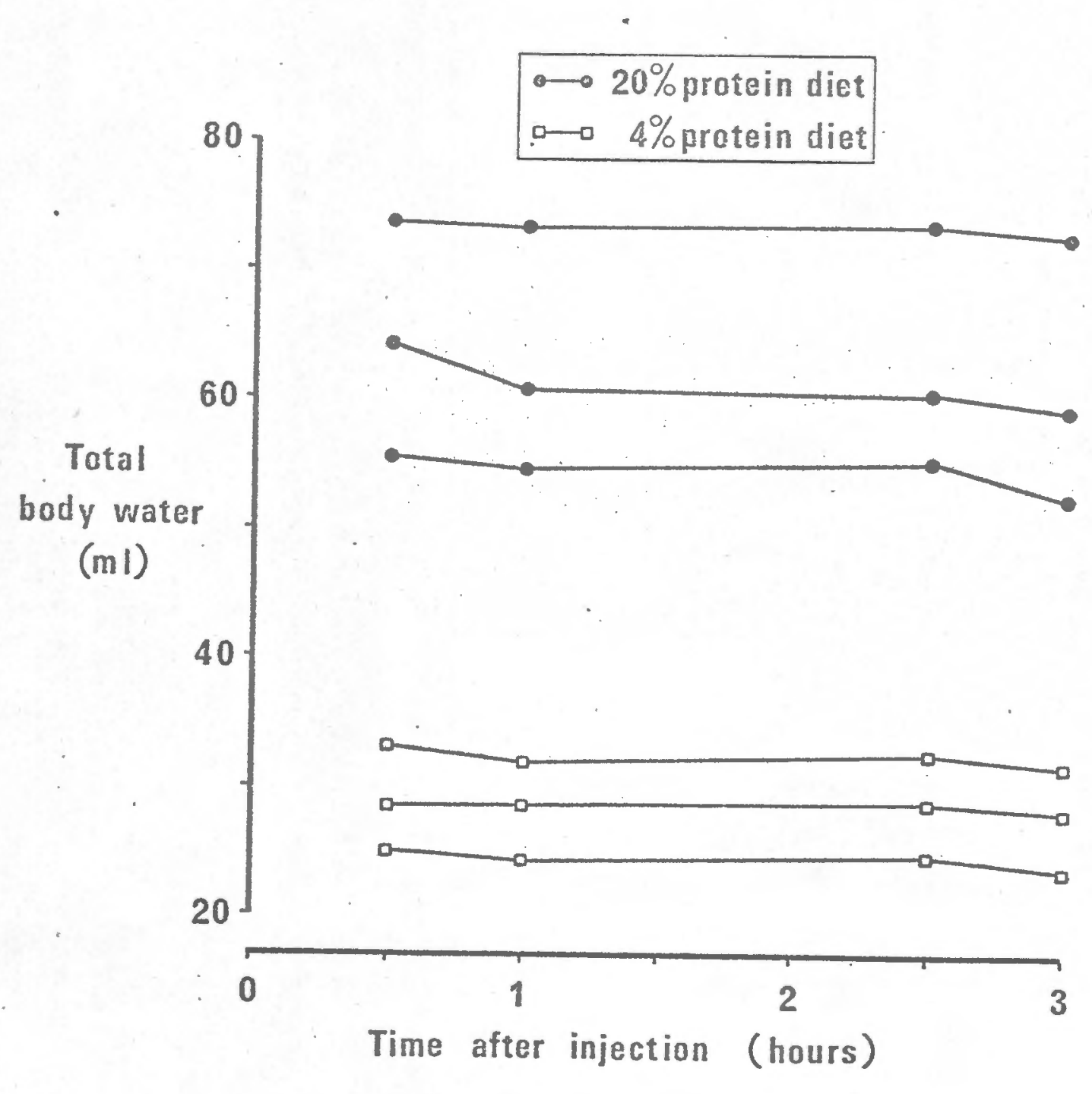

Fig.4. Effect of sampling time on estimation of total body water. 
Discussion

This method for the determination of total body water involves two assumptions. They are:

1. that tritium does not exchange with labile hydroger atoms other than those from water, and

2. that there is rapid equilibration of the $3 \mathrm{H}_{2} \mathrm{O}$ with $\mathrm{H}_{2} \mathrm{O}$ occurring before any significant loss of $3 \mathrm{H}_{2} \mathrm{O}$ by excretion.

It has been pointed out by Belcher and Vetter (1971), that the first assumption does not hold true and that values of total body water, determined by this method, are overestimated by $1-2 \%$. This is due to exchange of tritium with labile hydrogen in bicarbonate, carboxyl, hydroxyl and amino groups.

The time taken to reach equilibrium increases in the presence of oedema or other abnormal fluid accumulations (Belcher and Vetter, 1971). In this study it was found that total body water remained constant between $1-2 \frac{1}{2}$ hours after administration of the ${ }^{3} \mathrm{H}_{2} \mathrm{O}$ (fig.4). A late increase in total body water using this technique would have indicated a more slowly equilibrating exchangeable pool. In fact there was a slight decrease in body water (i.e. an increase in specific activity) between $2 \frac{1}{2}$ and 3 hours after the injection in both malnourished and normal animals, suggesting a return of tritium to plasma from labelled metabolites. 


\section{GLUCOSE AND INSULIN ESTIMATIONS}

The changes in blood sugar and plasma insulin concentrations following various stimuli form the basis of this thesis. As many as 8 samples were required from a single rat. Some rats weighed only $30 \mathrm{~g} \cdot$ Conventional techniques required approximately $0.1 \mathrm{ml}$ of blood for glucose assay (Hoffman, 1937) and at least $0.1 \mathrm{ml}$ of plasma for the insulin radioimmunoassay (Morgan and Lazarow, 1963). To avoid killing animals at varying time intervals, recently reported microassays (Tiernan et al, 1968; Lavine et al, 1971) were modified as described below. Sample collection

All animals were warmed for at least 5 minutes in front of a heater before bleeding. The tip of the tail was amputated and $50 \mu \mathrm{l}$ of blood was collected into a heparinised capillary tube and transferred to a micro test tube (Beckman Instrument Company). $\quad 5 \mu l$ of this was immediately transferred by micropipette to a new micro. test tube for glucose assay (fig.5). Plasma was separated from the remaining blood sample and $5 \mathrm{\mu l}$ aliquots were used for the insulin immunoassay. 


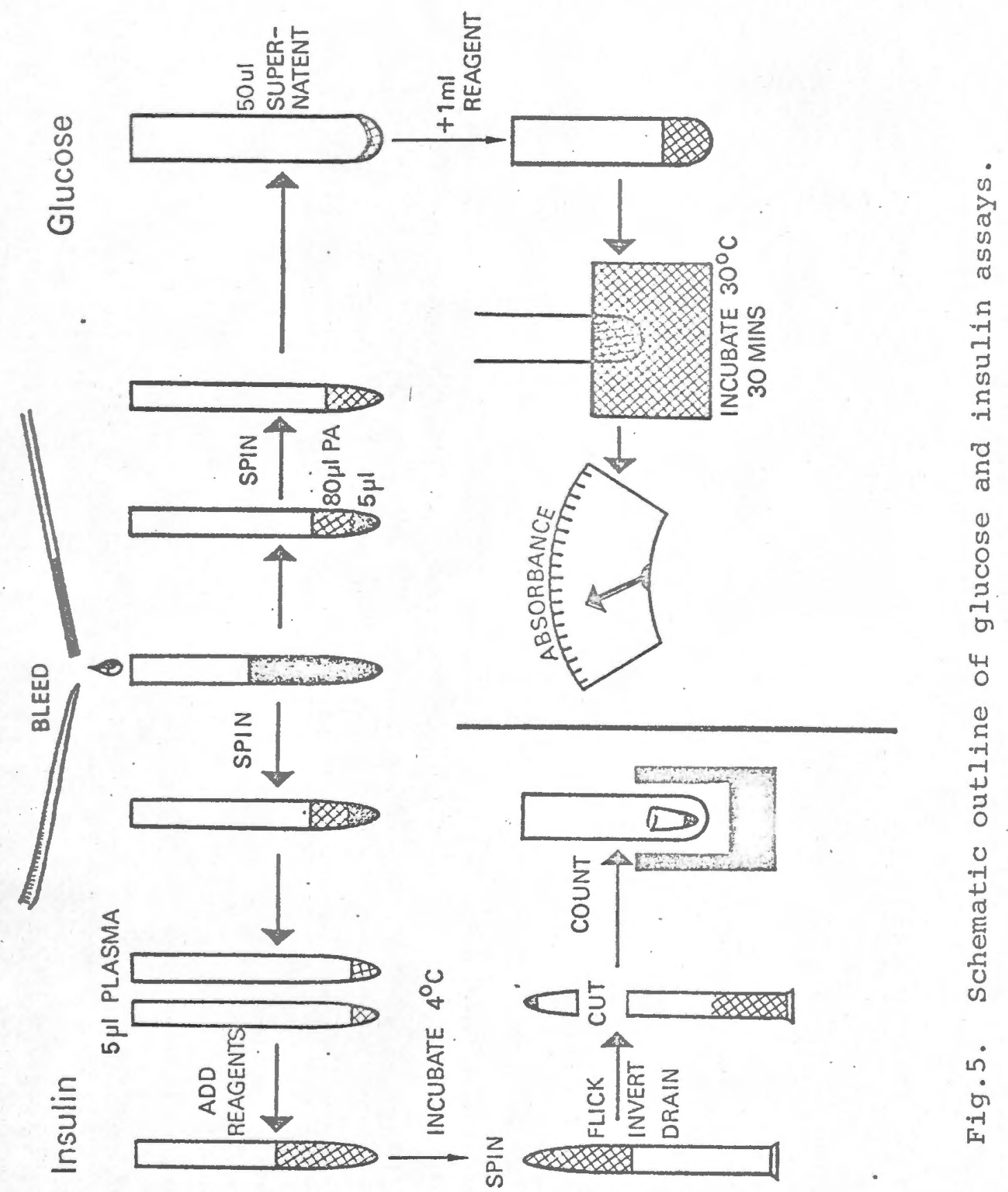




\section{A. GLUCOSE ASSAY}

Blood glucose was measured by a glucose oxidase method (Hugget and Nixon, 1957) using a 5 ul standard and sample volume.

$\underline{\text { Principle }}$

In the presence of glucose oxidase, a highly specific enzyme, glucose is oxidised to gluconic acid and hydrogen peroxide. In the presence of peroxidase, hydrogen peroxide oxidises a dye to produce a colour change which is directly proportional to the glucose concentration present in the medium.

Materials

\section{Glucose Standards}

Fresh solutions containing $0,50,100,200$ and $400 \mathrm{mg} \%$ of $D(+)$ glucose were used as standards. 1 aliquot from a pool of frozen rat plasma was included with each assay as a quality control.

\section{Glucose Reagent}

$64 \mathrm{mg}$ glucose oxidase (type II, activity 17,300 units per gram, Sigma Chemical Company) and $5 \mathrm{mg}$ horseradish peroxidase (type VI, 260 purpurogallin units per $\mathrm{mg}$ of protein, Sigma Chemical Company) were dissolved in $250 \mathrm{ml}$ of $0.2 \mathrm{M}$ phosphate buffer, $\mathrm{pH} 7.0$. A $1 \%$ solution of dimethoxybenzidine dihydrochloride (Eastman Kodak Company) in distilled water was diluted one hundred-fold with the glucose oxidase-peroxidase solution just prior to use. Method

$80 \mu l$ of $2 \%$ perchloric acid was added to the micro 
test tubes containing $5 \mu l$ of sample or standard. After centrifugation, $50 \mu 1$ of protein-free supernatant was removed from the micro test tubes and transferred to glass. test tubes. $\quad 1 \mathrm{ml}$ of glucose reagent (see above) was pipetted into each tube, which was then incubated at $30^{\circ}$ for 30 minutes. Absorbance was read in a spectrophotometer at $436 \mathrm{~nm}$ against a reagent blank (fig.5). Calculation

As absorbance was linear up to $400 \mathrm{mg} \%$, the unknown glucose values were calculated from the equation of the least square regression line.

Reproducibility

The internal standard over a 3 month period showed an interassay coefficient of variation of $4.6 \%(n=12)$.

\section{B. INSULIN RADIOIMMUNOASSAY}

\section{Principle}

This has been described by Yalow and Berson (1964) and involves competition, between a fixed amount of labelled hormone and added unlabelled hormone, for binding sites on a limited amount of specific antibody. Thus the percentage of labelled hormone that is bound to the antibody decreases in the presence of increasing amounts of unlabelled hormone. The second antibody technique of Morgan and Lazarow (1963) was used to separate bound from free labelled hormone. Materials and Methods

$\underline{\text { Standards }}$

Twice recrystallised rat insulin (lot no. RI70, 
$21.4 \mu \mathrm{U} / \mathrm{ng}$, Novo Research Laboratories) was diluted to give concentrations from 0.625 to $40 \mathrm{ng} / \mathrm{ml}$. An aliquot from a pool of frozen rat plasma was included in each assay as a quality control. All reagents as well as standards were diluted in $0.05 \mathrm{M}$ veronal buffer $\mathrm{pH} 8.6$ containing $0.25 \%$ bovine serum albumin unless otherwise indicated. Labelling of Insulin

Porcine insulin (Lot no. S8563, Novo Research

Laboratories) was labelled with ${ }^{125}$ I according to the method of Hunter and Greenwood (1962) to a specific activity of $250-300 \mu \mathrm{Ci} / \mu \mathrm{g}$.

\section{Procedure}

Because of the small volumes of sample and reagents, this immunoassay was conducted in micro test tubes. After the addition of each reagent, these tubes were capped and centrifuged.

1. $5 \mu 1$ of plasma or standard was pipetted into micro test tubes.

2. $50 \mu 1$ of 1:150,000 dilution of guinea-pig anti-insulin serum (Lot no. K5182, Wellcome Reagents Limited) was added to each micro test tube.

3. The micro test tubes were incubated for 24 hours at $4^{\circ} \mathrm{C}$.

4. Approximately $20 \mathrm{pg}$ of insulin ${ }^{125} \mathrm{I}$ in $50^{\circ} \mu \mathrm{l}$ of buffer was added to each tube.

5. The micro test tubes were incubated for 72 hours at $4^{\circ} \mathrm{C}$.

6. $50 \mu l$ of a 1:8 dilution of rabbit anti-guinea-pig precipitating serum (Lot no. K7117, Wellcome Research Laboratories) and $50 \mu 1$ of a 1:1,000 dilution of guinea- 
pig plasma were added to the reaction mixture.

Dilutions of the above two reagents were made in $0.01 \mathrm{M}$

EDTA and $0.25 \%$ bovine serum albumin in $0.05 \mathrm{M}$ veronal buffer, $\mathrm{pH} 8.6$.

7. The micro test tubes were incubated for 48 hours at $4^{\circ} \mathrm{C}$.

8. After centrifugation at $17,500 \mathrm{~g}$ for 5 minutes, the micro test tubes were inverted and 'flicked' as one would flick down a clinical thermometer. They were then kept inverted and allowed to drain for 1 hour at $4^{\circ} \mathrm{C}$.

9. The tip of each micro test tube (containing the precipitate) was cut off, put into a counting vial and counted for a minimum of 10,000 counts or 20 minutes in an automatic gamma scintillation spectrometer. (See fig.5).

Calculation

Micro test tubes, containing labelled hormone alone, were counted to give an estimate of the total counts added to each tube. Correction for non-specific binding of label to test tube or precipitate was estimated from tubes containing all reagents except the first antibody (see step 2 in procedure), which was replaced with $50 \mu l$ of buffer (the blanks).

Percentage bound $=$

Counts in sample or standard-counts in blank $\times 100$ total counts

Plasma insulin concentrations were determined from the insulin standard curve (fig.6). 
$\%$ Bound

125] Insulin

(Porcine)

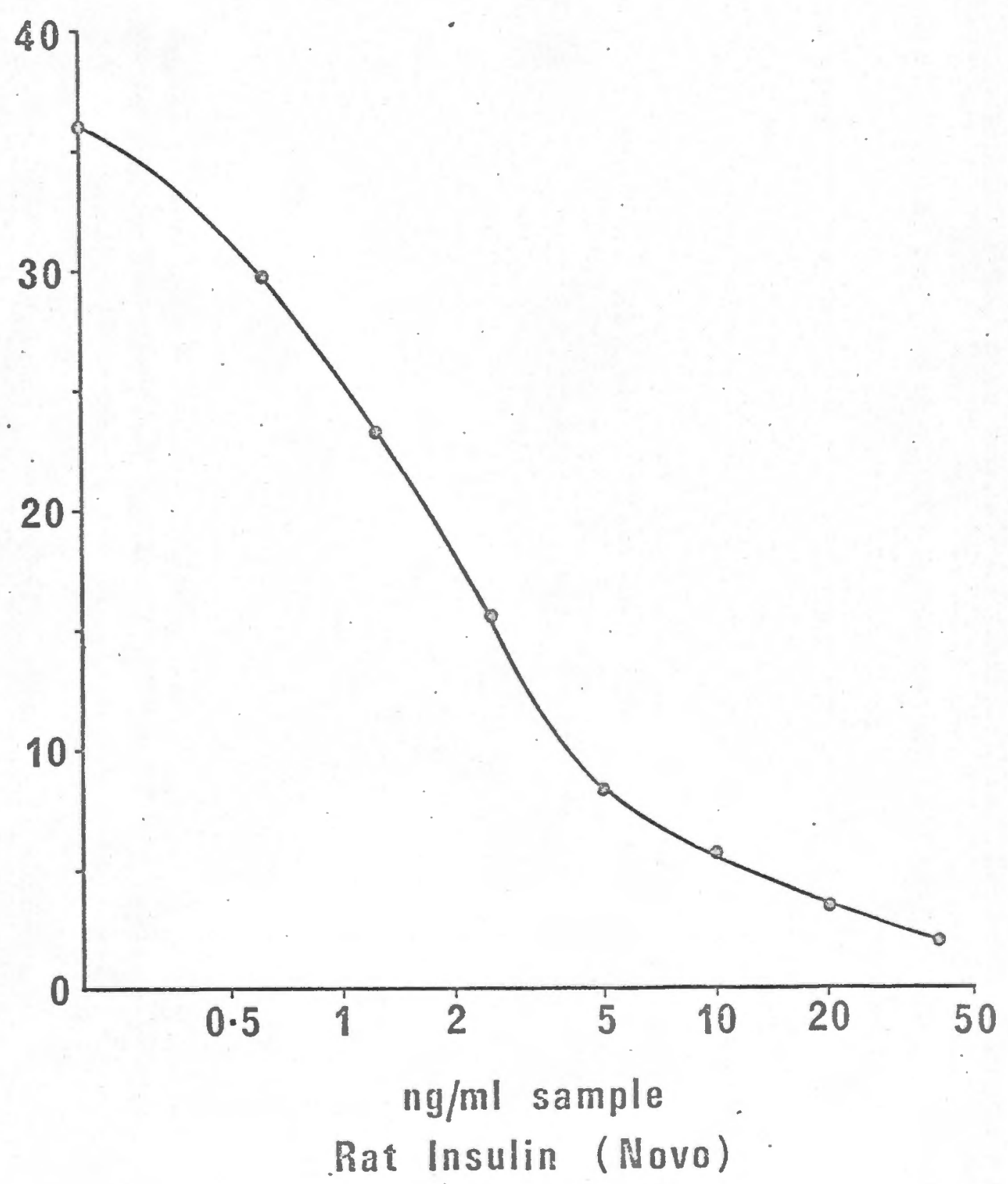

Fig.6. Standard curve obtained using $5 \mu \mathrm{l}$ of standard solution 


\section{Reproducibility}

The interassay coefficient of variation over a three month period was 10.5\% $(n=12)$, for standards reading in the mid-range of sensitivity.

Measurement of fasting plasma insulin concentration

The assay detalled above was not considered sensitive enough to detect differences in fasting plasma insulin concentrations between groups of rats. By using $10 \mu 1$ instead of $5 \mu 1$ sample volumes, and increasing the dilution of guinea-pig anti-insulin serum to $1 / 200,000$ (step 2 under procedure above), the sensitivity of the assay was increased. A plasma insulin concentration as low as $0.25 \mathrm{ng} / \mathrm{ml}$ could be determined (fig.7). 


\section{$\%$ Bound} 125 Insulin (Porcine)

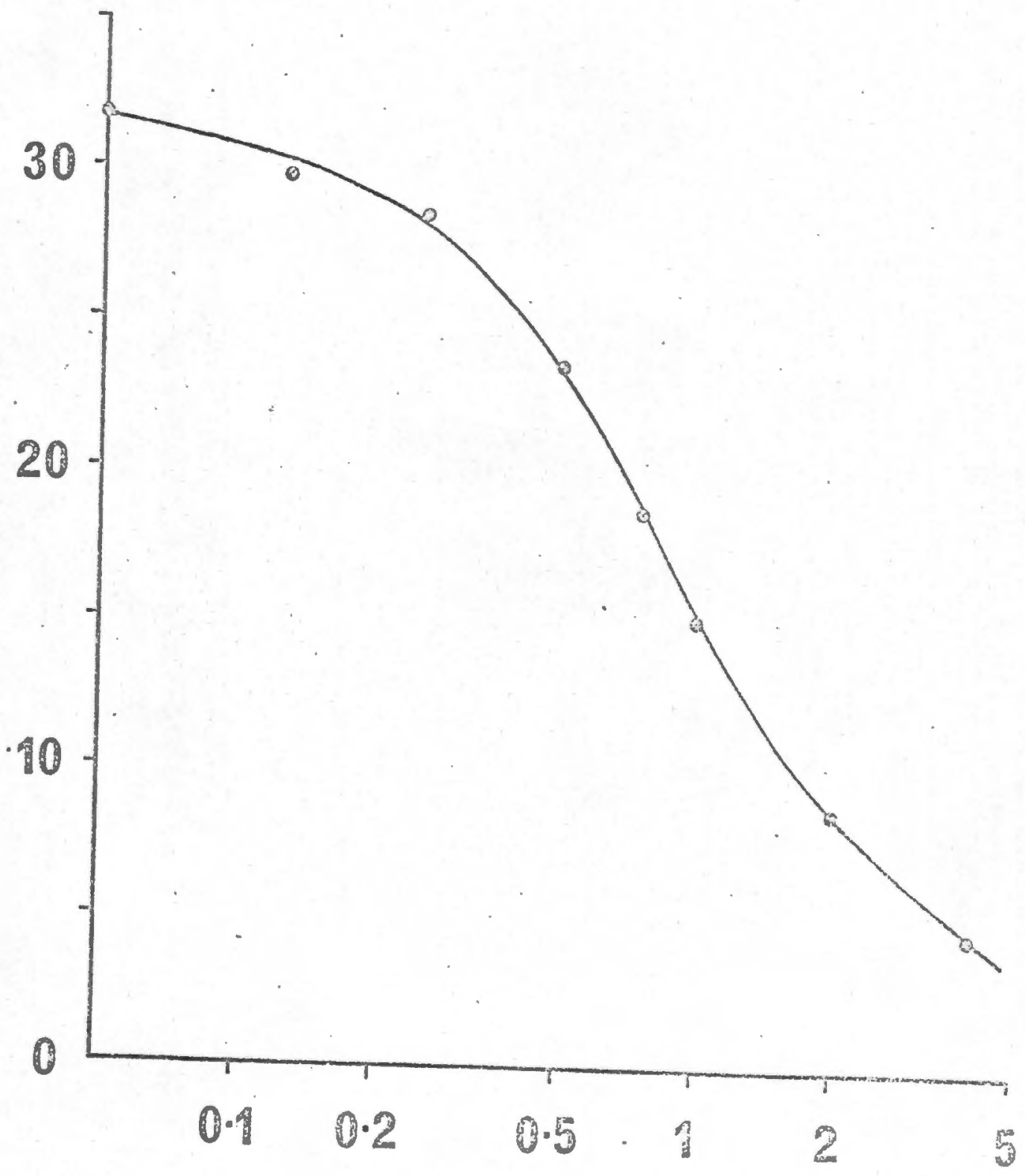

ng/m samenge

\section{Rat Insulin (hous)}

Fig.7. Standard curve obtained using $10 \mu 1$ standard volumes 
ESTIMATION OF TOTAL PANCREATIC ISLET VOLUME

Introduction

The most accurate way to measure pancreatic islet volume would be:

(a) to take serial sections of the whole pancreas,

(b) to measure the pancreatic islet area in every section,

(c) sum all the islet areas and multiply them by the thickness of each section.

Because this method is so time-consuming, other more practical methods have been described. For example, Chalkley (1944) has devised this method:

(a) measuring the total volume of the pancreas,

(b) examining random points in numerous random sections, and

(c) calculating the proportion of points striking an islet. Hence islet volume would be:

number of points striking islets $\mathrm{x}$ total pancreatic volume total number of points examined

In rats, however, this method is unsuitable because the pancreas. is not a solid discrete organ but consists of lobules dispersed diffusely throughout the mesentery. The method of Tejning (1947) is more practical and only makes two basic assumptions:

1. that islets are roughly spherical or ellipsoidal in shape, and

2. that pancreatic islets are randomly distributed throughout the pancreas independently of size.

Tejning made serlal sections 30 microns thick of the whole pancreas and measured the islet area in every tenth section. He multiplied the sum of all these 
areas by 300 microns to obtain an estimate of the total pancreatic islet volume. He has shown that this method is both reproducible and valid.

Tejning made further important observations on the numerical and volumetric distribution of the islets. These may be summarised as follows:

1. There are many more small islets than there are large islets.

2. Medium sized islets contribute the largestproportion of the islet volume.

3. The volume contributed. by the very many small islets is equal to the volume contributed by the relatively few large islets i.e. "the curve of the volumetric distribution is obviously symmetrical" (Tejning, 1947, p. 141).

As the total islet volume increases there is an increase in the number of both small and large islets with a corresponding shift in the peak of the volume curves towards larger islet diameters (fig.8) Hence as the total islet volume increases the number of large islets increase.

Hellman (1970) has examined the relationship between the number of large islets and total pancreatic islet volume and has shown it to be a linear one (fig.9). Therefore one need merely count the number of islets, greater than a fixed diameter or area, in every tenth section of the pancreas, in order to obtain an estimate of the total pancreatic islet volume. 


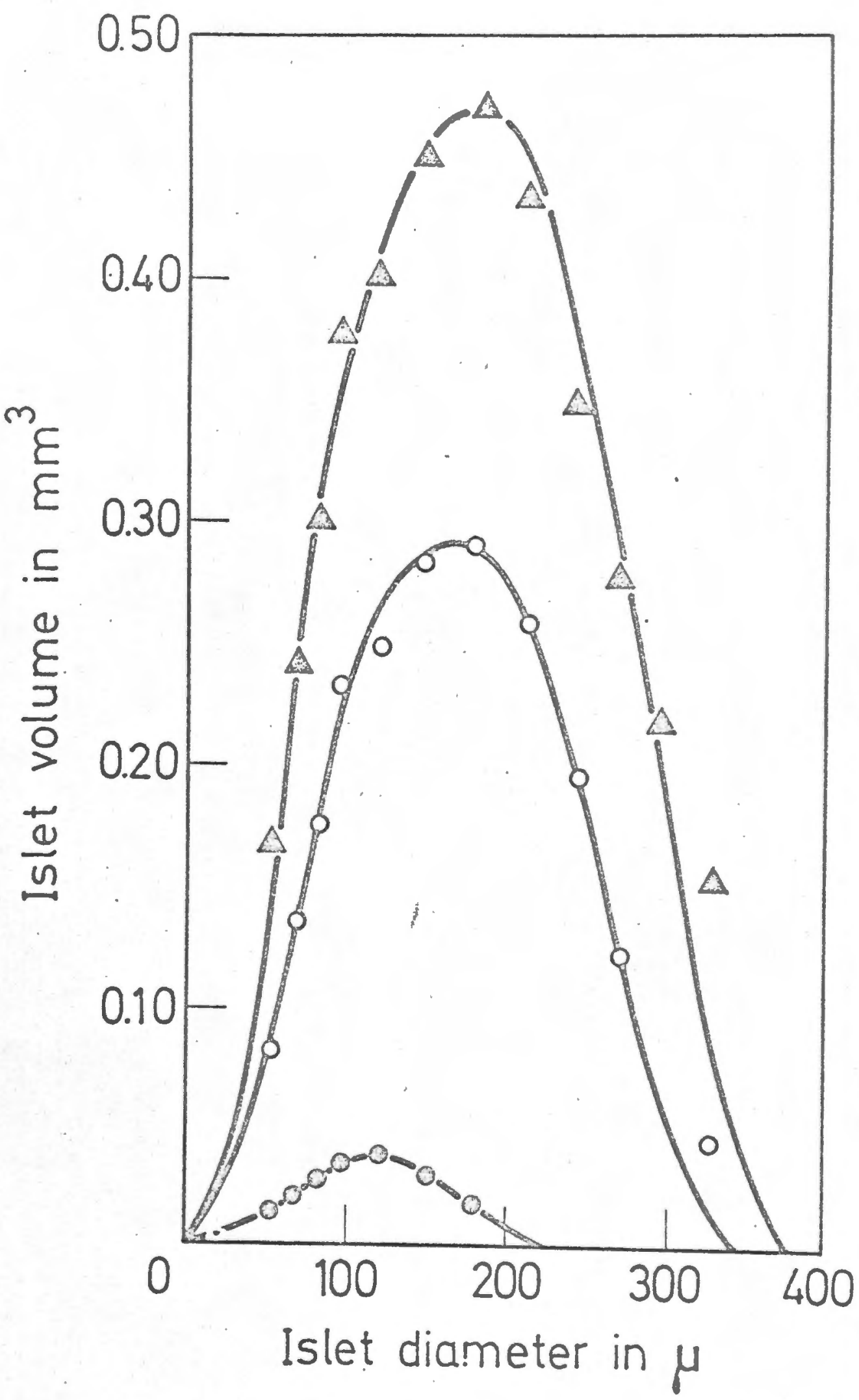

A. 26

Fig.8. The volume contribution of islets of different diameters (Hellman, 1970). With increasing islet volume peaks shift to the right. 


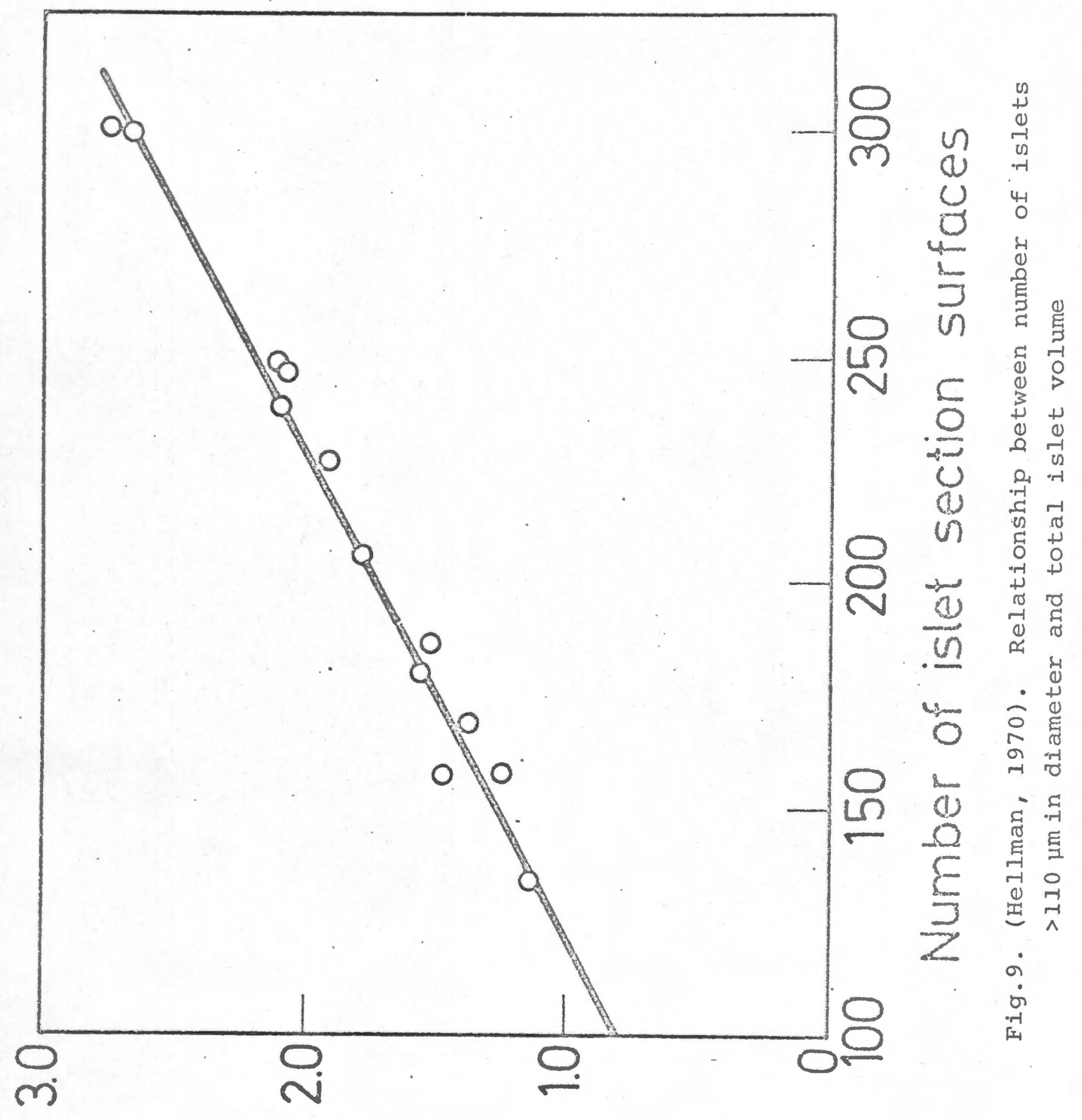

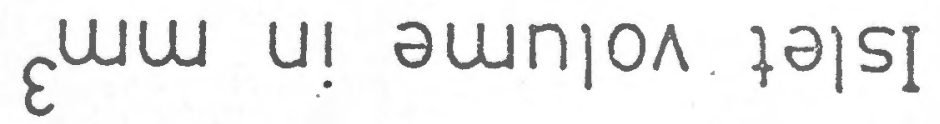




\section{Procedure}

\section{Fixation of tissues}

The pancreas with its mesentery was dissected free from its attachments to the spleen, stomach, small bowel and posterior abdominal wall. It waş fixed in $10 \%$ formalin-saline for 5 days.

\section{Dehydration}

The pancreas was washed overnight in running tap water. It was then folded, placed between two glass slides fastened together by string, and passed through the following solutions for the times stated.

(i) 708 alcohol, 7 days

(ii) $96 \%$ alcohol, 3 days

(iii) Absolute alcohol, 2 days

(iv) Absolute alcohol, 2 days

\section{Embedding}

The now permanently flattened pancreas, approximately 2-4 mm thick, was removed from between the glass slides, and embedded in low viscosity nitrocellulose (IVN) (African Explosives Iimited), by transferring the tissue through the following solutions for the times stated:

(i) Ether alcohol $(50 \% \mathrm{~V} / \mathrm{V}), 3$ days

(ii) $5 \%$ IVN in ether alcohol, 3 days

(iii) $10 \%$ LVN in ether alcohol, 3 days

(iv) 20\% LVN in ether alcohol, 6 days

A fresh solution of $20 \%$ LVN was allowed to harden in an open petri dish until it was firm. The pancreas was placed on top of this layer and covered with liquid $20 \%$ IVN. 
This was allowed to harden for approximately one week. The block of IVN containing the pancreas was trimmed to a suitable size and stored in $70 \%$ alcohol.

4. Sectioning

The block was fixed to a chuck with $20 \%$ LVN and serial sections 30 microns thick were cut from the whole pancreas using a sliding microtome. All sections were stored between layers of filter paper, soaked in $70 \%$ alcohol to prevent drying. Thirty to eighty sections were obtained depending on the size of the pancreas. 5. Staining

Every tenth section (or in the case of a small pancreas, every fifth section) was stained individually with haematoxylin and eosin, dehydrated with carbol-xylene and mounted in Canada Balsam as described by Drury and Wallington (1967).

\section{Validation of the method}

Although this method of quantitating islet volume has been validated, and in fact used by Tejning in rats on different carbohydrate, protein and fat diets, it was thought advisable to confirm that islet volume and number followed the expected distributions in protein-calorie malnutrition.

The pancreas of one animal from each of the three groups of animals was examined as follows:

I. Every tenth section (or fifth section in the case of a small pancreas) was scanned at a magnification of 125 . 
2. Using a measuring eyepiece calibrated with a stage micrometer, the mean diameter of every islet section surface was measured.

3. The mean islet diameters were sorted into six groups according to size: 0-50, 50-100, 100-150, 150-200, 200-250 and greater than $250 \mu \mathrm{m}$.

The number of islet diameters in each group as a percentage of the total was calculated. The percentage of the total volume of the pancreas contributed by each group was calculated. The volumetric and numerical distribution of islets of different diameters in the pancreas of a $4 \%$ protein-fed rat, is shown in fig.10. Note that the number of islets less than $50 \mu \mathrm{m}$ in diameter has been underestimated due to difficulty in identifying islets less than 30 microns in diameter. Despite this, the volumetric distribution is symmetrical.

Comparing the volume contributions of islets of different diameters in the three rats (fig.ll), a graph similar to that of Hellman's was obtained (compare with fig. 8).

The number of islets greater than or equal to $122 \mu \mathrm{m}$ in mean diameter, were counted in each of the already examined sections. The number of islets counted was plotted against the volume calculated for that section unit. A linear relationship was confirmed $(r=0.964)$ in all three rats, between the number of islets greater than, or equal to $122 \mu \mathrm{m}$ in diameter and the pancreatic islet volume of each section unit (fig.12). 
Summary

It has been shown that in the three animals used in this study:

1. The volume contribution by islets of different diameters is symmetrically distributed.

2. There is a linear relationship between the number of islets greater than a fixed diameter, and the pancreatic islet volume.

Thus by counting the number of islets greater than $122 \mu \mathrm{m}$ in every tenth section, it was possible to estimate the total pancreatic islet volume of that pancreas, from the equation of the line shown in fig.12. 


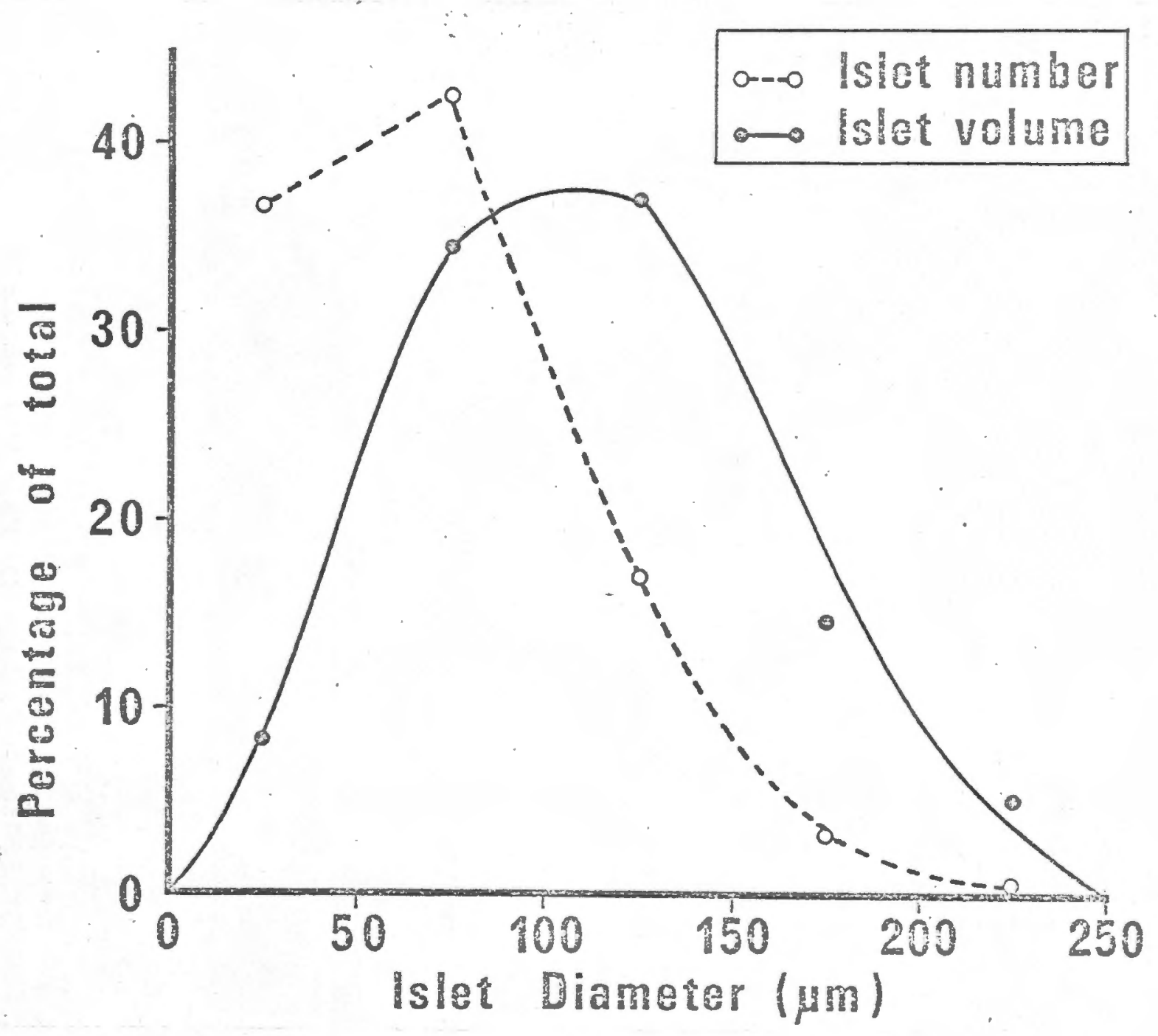

Fig. 10 The volumetric and numerical distribution of islets of different diameters in the pancreas of a $4 \%$ protein-fed rat. 


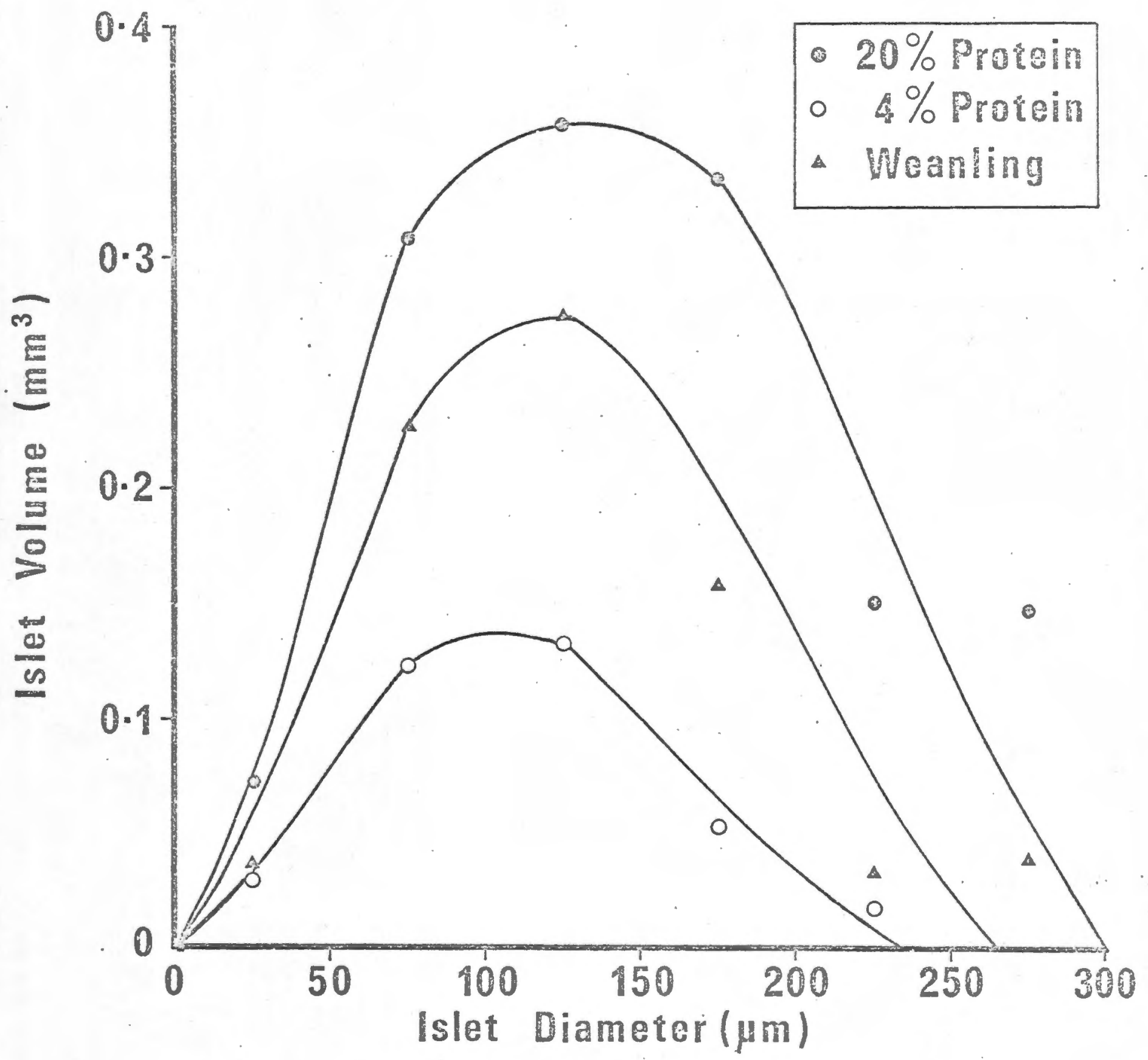

Fig.11. Volume contributions of islets of different diameters in three rats, one from each group. 


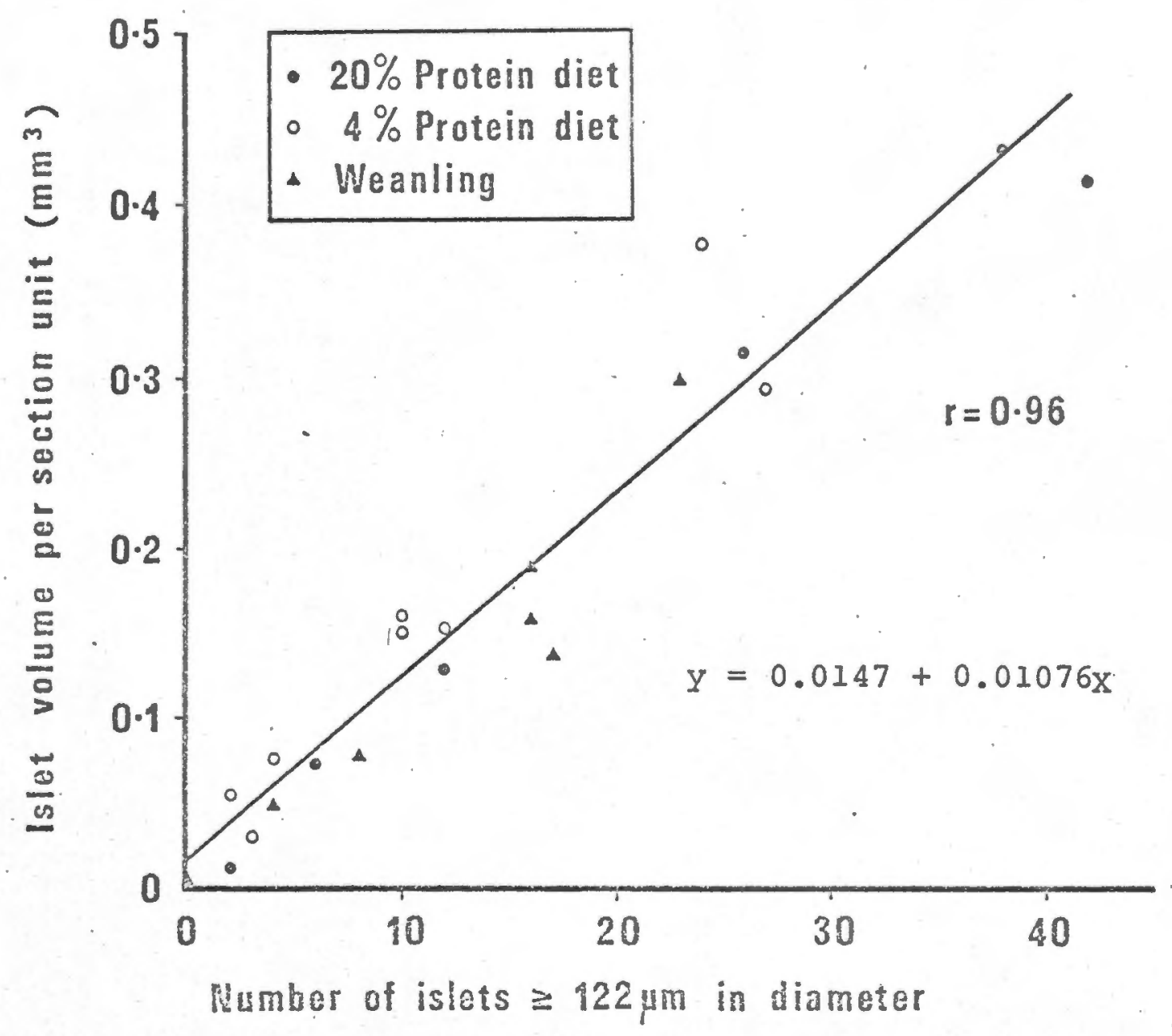

Fig. 12 Relationship between islets greater than or equal to a fixed diameter and the pancreatic islet volume. 
MEASUREMENT OF PLASMA AND TISSUE

SODIUM AND POTASSIUM CONCENTRATIONS

Methods

Collection of samples

All samples were taken from rats under ether anaesthesia, after an overnight fast. Plasma sodium and potassium concentrations

Cardiac blood was collected in heparinised capillary tubes and plasma separated immediately. $10 \mathrm{\mu l}$ of plasma or standard (140 mEq/I sodium; $5 \mathrm{mEq} / \mathrm{l}$ potassium, Instrumentation Laboratory Inc.) was diluted with $2 \mathrm{ml}$ of lithium solution $(15 \mathrm{mEq} / 1)$. Sodium and potassium were measured using a flame photometer with internal lithium standardisation '(Wallace et al, 1951). A commercial serum standard (Versatol, Warner-Lambert Company) was used for quality control.

Muscle and liver sodium and potassium concentrations Approximately 200 - $500 \mathrm{mg}$ of liver tissue and approximately $100 \mathrm{mg}$ of gastrocnemius muscle was removed from each animal and placed into tared centrifuge tubes. Tissue and tubes were weighed immediately, and again after. 8 days in an oven at $110^{\circ} \mathrm{C}$ to estimate the ary weight of the tissue. Fat was extracted with petroleum ether (B.P. $30^{\circ}$ $\left.60^{\circ} \mathrm{C}\right)$ for $48-72$ hours for the determination of the fatfree dry weight (Hazlewood and Nichols, 1969).

$10 \mathrm{ml}$ of $0.75 \mathrm{~N}$ nitric acid containing $15 \mathrm{mEq} / \mathrm{l}$ of Iithium was added to each tube. These were then placed in a boiling water bath for at least 8 hours (Lowry and 
Hastings, 1942).

After evaporative losses were made up with deionised distilled water, $0.5 \mathrm{ml}$ of the supernatant was diluted to $5 \mathrm{ml}$ with the lithium solution ( $15 \mathrm{mEq} / \mathrm{l}$ ) and analysed for potassium and sodium on a flame photometer. The standards for this determination were made up as follows:

(a) $25 \mathrm{\mu l}$ of standard solution $1100 \mathrm{mEq} / \mathrm{l}$ sodium; $100 \mathrm{mEq} / \mathrm{I}$ potassium, Instrumentation Laboratory Inc.)

(b) $0.5 \mathrm{ml}$ of $0.75 \mathrm{~N}$ nitric acid containing $15 \mathrm{mEq} / 1$ of lithium

(c) $4.5 \mathrm{ml}$ of $15 \mathrm{mEq} / \mathrm{I}$ lithium diluent.

Blanks were made up as above except that the standard solution, (a), was omitted.

Calculation

$$
\begin{aligned}
& \frac{\text { Photometer reading }}{201} \times \frac{10,000}{\text { fat free dry wt (mg) }} \\
& =\mathrm{mEq} / 100 \mathrm{~g} \text { fat free dry weight }
\end{aligned}
$$

Determination of liver fat concentration

The fat content of the liver was calculated as follows:

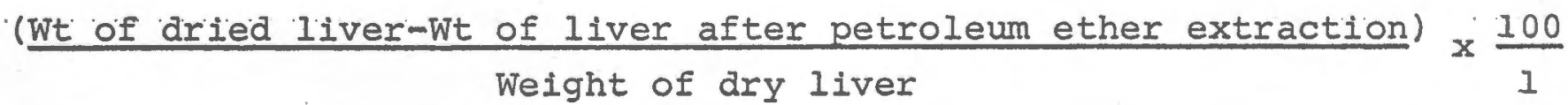
= grams fat/100 g dried liver 


\section{APPENDIX B - TABLES OF INDIVIDUAL RESULTS}

\section{Abbreviations and symbols}

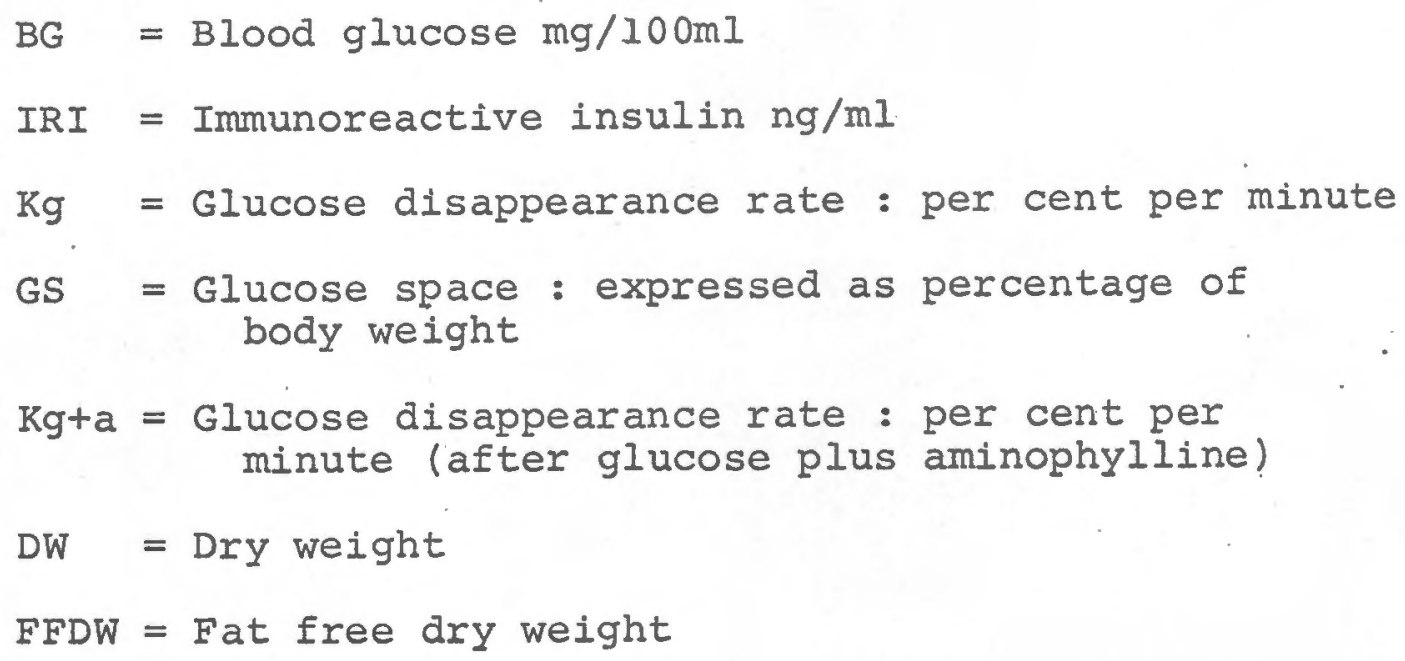


TOTAL BODY WATER

expressed as percentage of body weight (TBW\%)

\begin{tabular}{|c|c|c|c|c|c|}
\hline \multicolumn{2}{|c|}{$20 \%$ Protein diet } & \multicolumn{2}{|c|}{$4 \%$ Protein diet } & \multicolumn{2}{|c|}{ Weanling rats } \\
\hline $\begin{array}{c}\text { Rat } \\
\text { Weight } \\
g\end{array}$ & TBW\% & $\begin{array}{c}\text { Rat } \\
\text { Weight } \\
g\end{array}$ & TBW\% & $\begin{array}{c}\text { Rat } \\
\text { Weight } \\
\mathrm{g}\end{array}$ & TBW\% \\
\hline 70 & 78.5 & 30 & 82.3 & 31 & 77.7 \\
\hline 91 & 80.8 & 38 & $75 \cdot 9$ & 36 & 73.9 \\
\hline 81 & 74.9 & 41 & 79.1 & 34 & 74.1 \\
\hline 91 & $75 \cdot 9$ & 27 & 76.8 & 33 & 76.1 \\
\hline 83 & 78.4 & 31 & $73 \cdot 5$ & 33 & 76.0 \\
\hline 87 & 78.7 & 38 & 80.3 & & \\
\hline 87 & 78.4 & 32 & $77 \cdot 2$ & & \\
\hline 83 & $75 \cdot 4$ & & . & & \\
\hline Mean & $77 \cdot 6$ & & 77.7 & & $75 \cdot 6$ \\
\hline SEM & \pm 0.7 & & 1.2 & & 0.7 \\
\hline
\end{tabular}




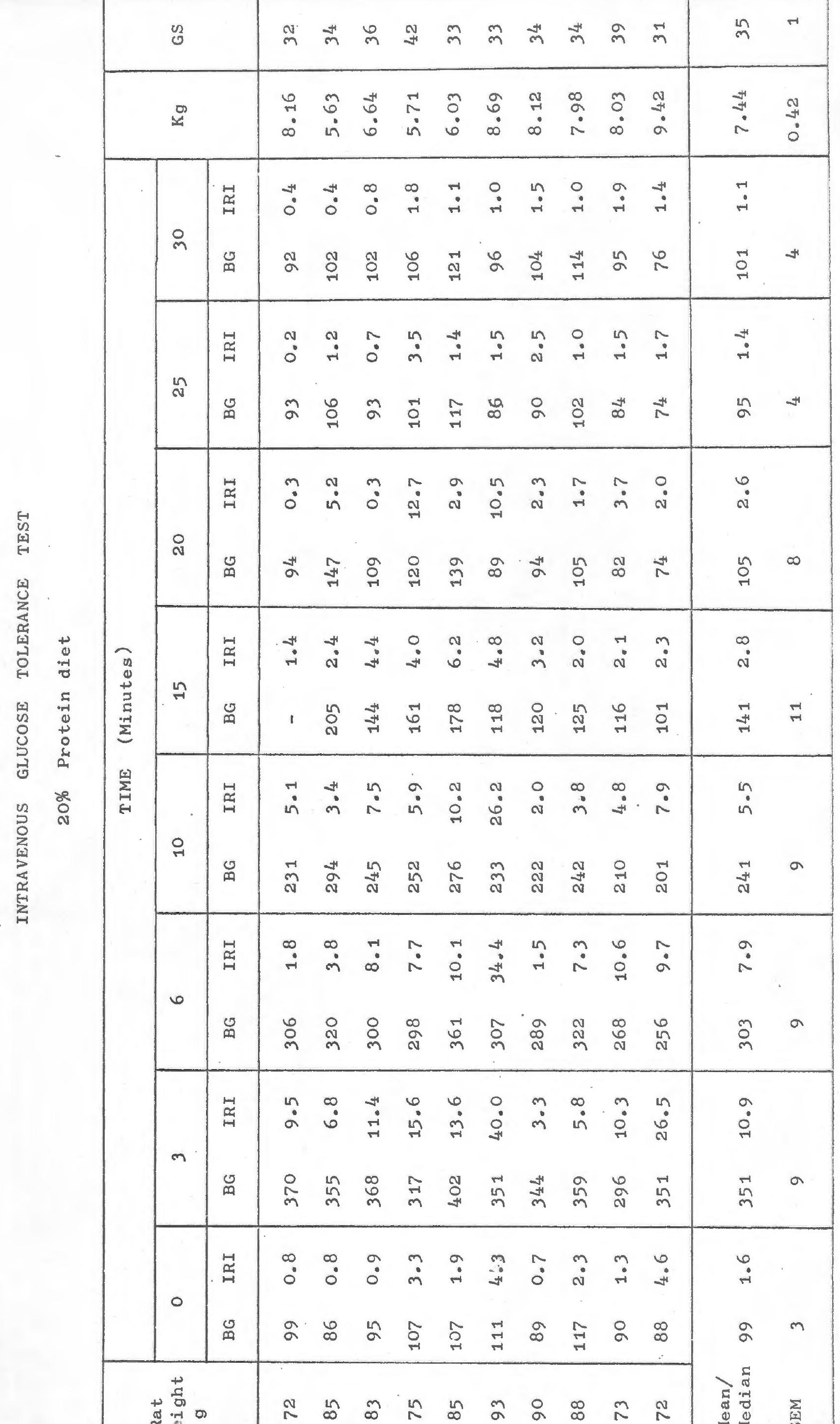




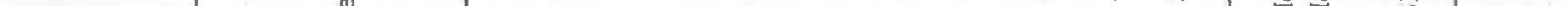




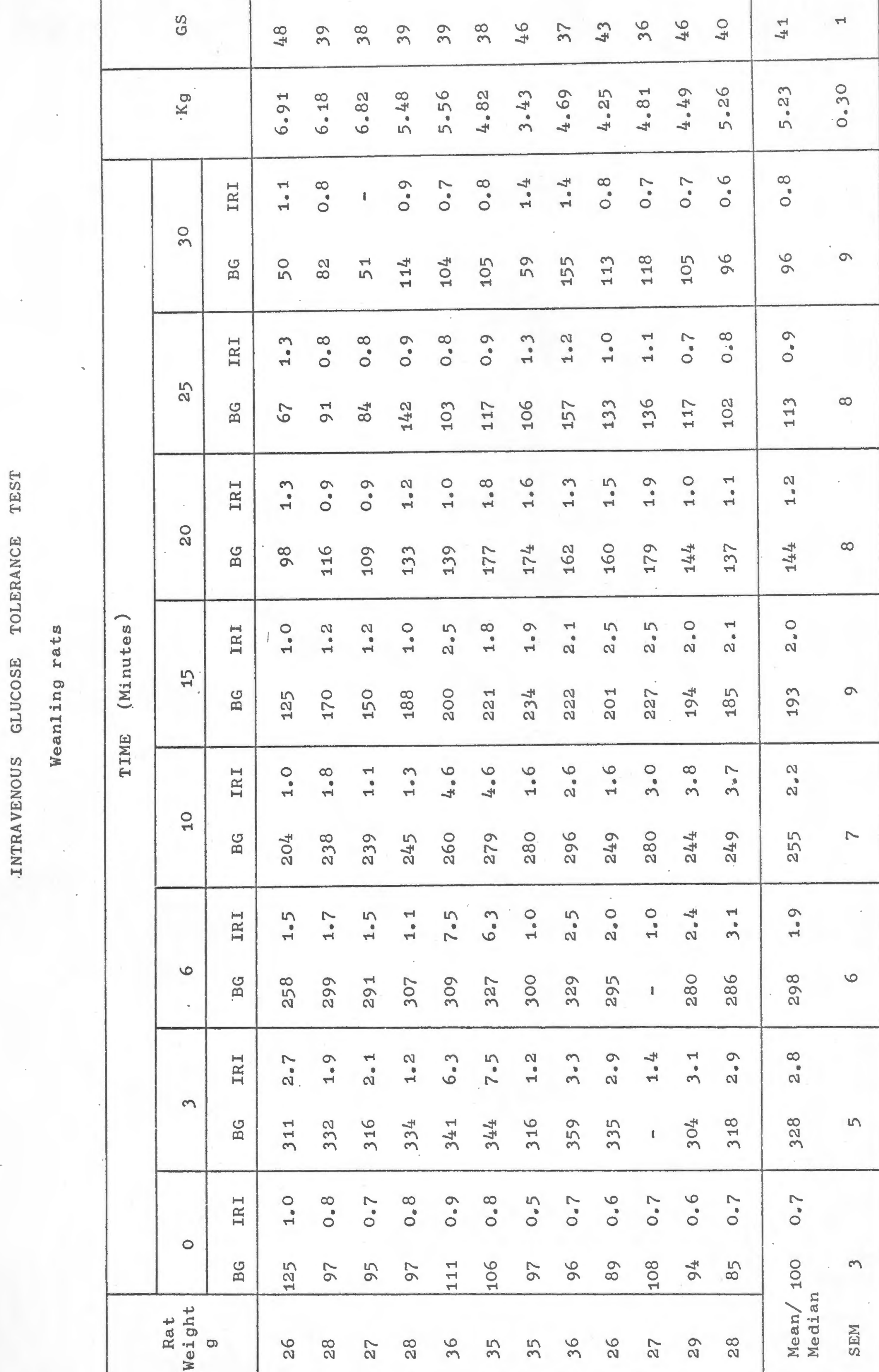




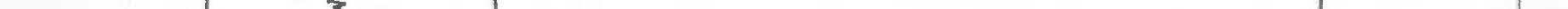




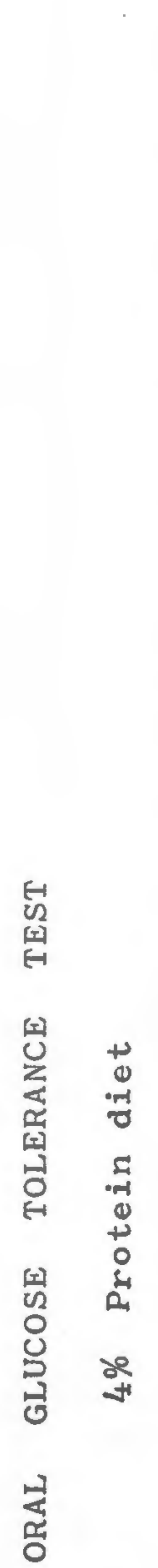

8

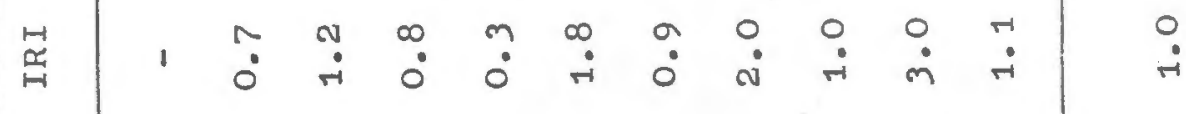

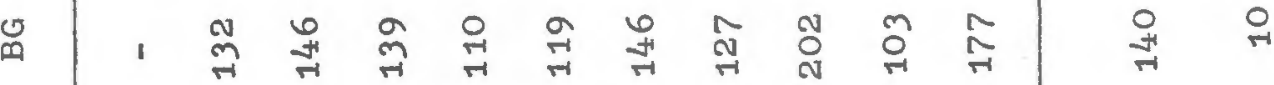

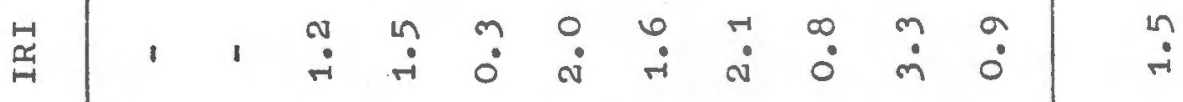

in

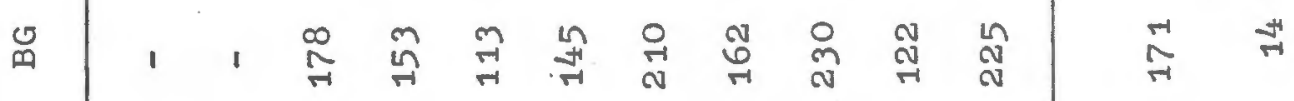

을

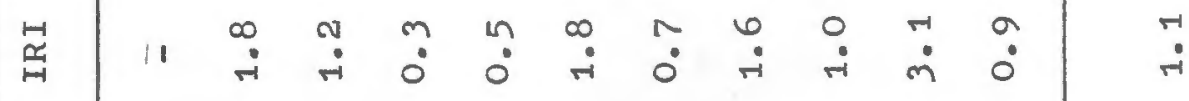

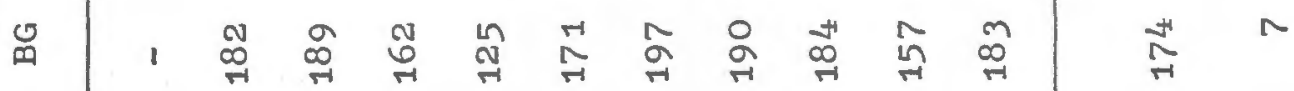

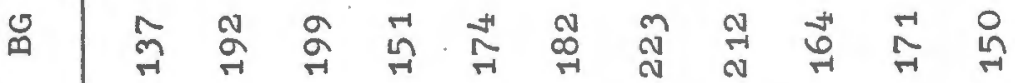

$\stackrel{\infty}{\pi}$

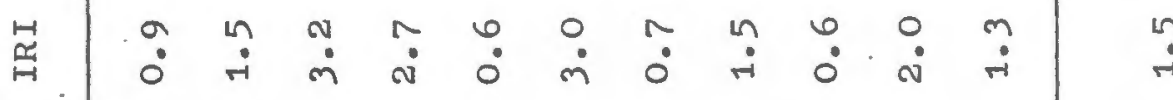

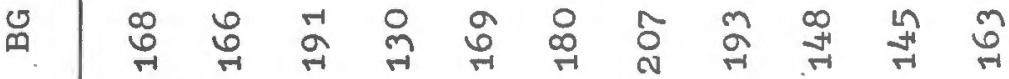

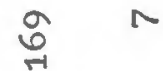

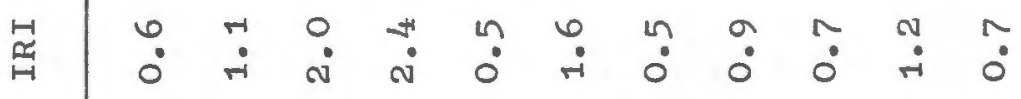

$\stackrel{9}{0}$

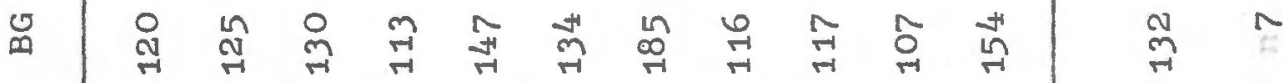

o

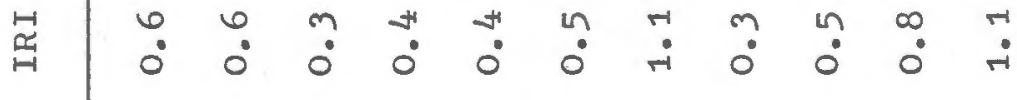

吊 


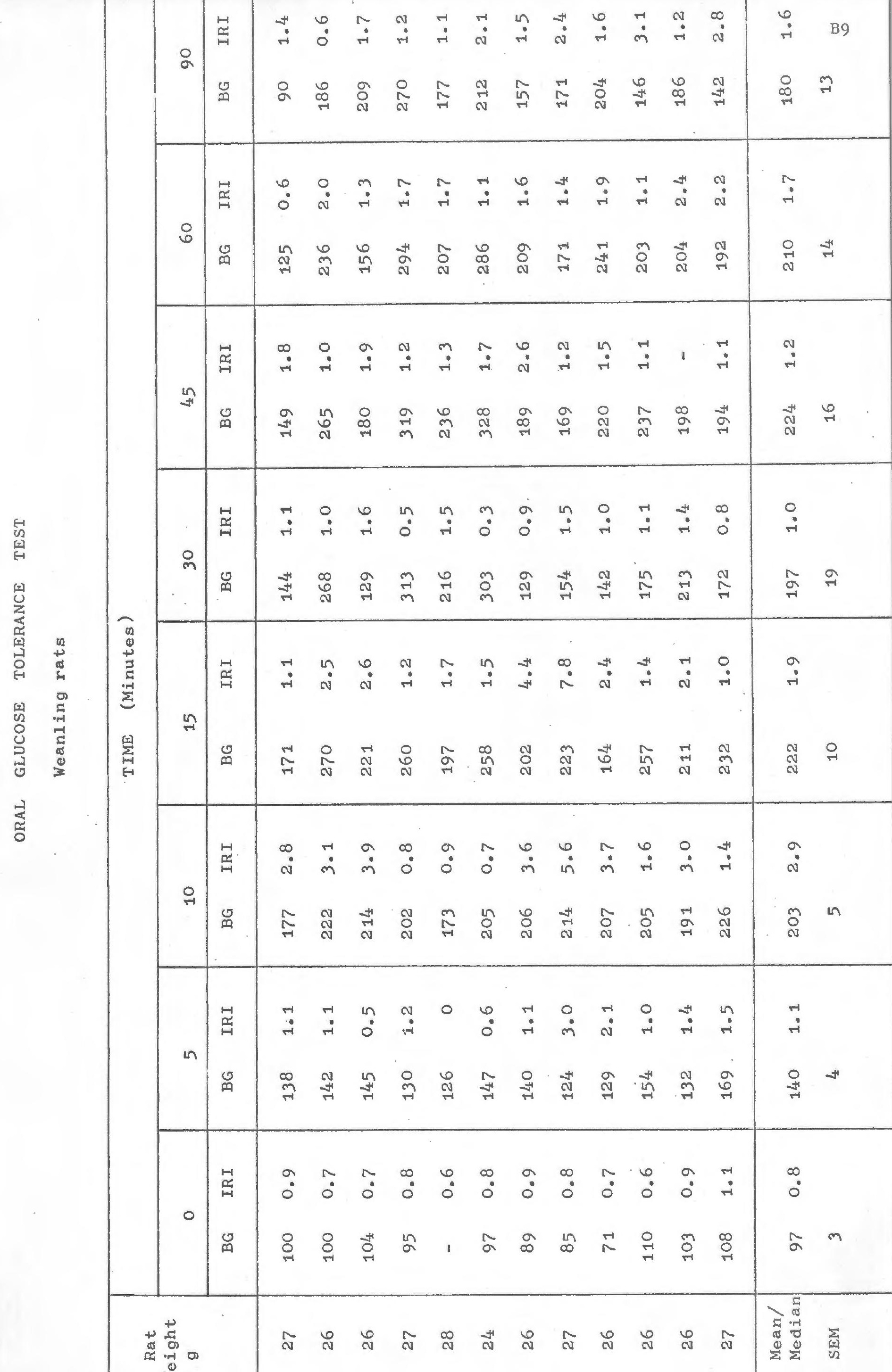


INTRAVENOUS INSULIN TOLERANCE TEST

$20 \%$ Protein diet - Blood glucose mg\%

\begin{tabular}{|c|c|c|c|c|c|c|c|c|}
\hline \multirow{2}{*}{$\begin{array}{l}\text { Rat } \\
\text { Weight } \\
\text { g }\end{array}$} & \multicolumn{7}{|c|}{ TIME (Minutes) } & \multirow[b]{2}{*}{120} \\
\hline & 0 & 10 & 20 & 30 & 45 & 60 & 90 & \\
\hline 79 & 73 & 93 & 77 & 83 & 97 & 101 & 86 & 90 \\
\hline 78 & 76 & 83 & 71 & 84 & 90 & 93 & 87 & 83 \\
\hline 70 & 79 & 101 & 71 & 77 & 77 & 96 & 93 & 99 \\
\hline 72 & 85 & 83 & 64 & 68 & 96 & 85 & 84 & 85 \\
\hline 59 & 89 & 67 & 49 & 57 & 63 & 71 & 68 & 67 \\
\hline 90 & 106 & 74 & 60 & 70 & 79 & 86 & 82 & 78 \\
\hline 85 & 94 & 53 & 40 & 46 & 61 & 64 & 74 & 64 \\
\hline 84 & 69 & 33 & 25 & 24 & 27 & 35 & 58 & 52 \\
\hline 72 & 94 & 54 & 48 & 46 & 48 & 50 & 55 & 53 \\
\hline 89 & 84 & 38 & 50 & 67 & 80 & 96 & 103 & 94 \\
\hline 74 & 87 & 47 & 37 & 45 & 66 & 68 & 77 & 60 \\
\hline 95 & 85 & 61 & 51 & 53 & 74 & 73 & 67 & 82 \\
\hline Mean/ & 85 & 66 & 54 & 60 & 71 & 77 & 78 & 76 \\
\hline SEM & 3 & 6 & 4 & 5 & 6 & 6 & 4 & 5 \\
\hline
\end{tabular}


INTRAVENOUS INSULIN TOLERANCE TEST

4\% Protein diet - Blood glucose mg\%

\begin{tabular}{|c|c|c|c|c|c|c|c|c|}
\hline \multirow{2}{*}{$\begin{array}{l}\text { Rat } \\
\text { geight }\end{array}$} & \multicolumn{8}{|c|}{ TIME (Minutes) } \\
\hline & 0 & 10 & 20 & 30 & 45 & 60 & 90 & 120 \\
\hline 25 & 71 & 67 & 42 & 41 & - & - & - & - \\
\hline 23 & 89 & 66 & 43 & 37 & 33 & 29 & 36 & 31 \\
\hline 27 & 100 & 60 & 50 & 58 & 60 & 69 & 83 & 70 \\
\hline 27 & 86 & 66 & 58 & 51 & 51 & 63 & 78 & 66 \\
\hline 26 & 103 & 59 & 51 & 45 & 55 & 60 & 75 & 85 \\
\hline 26 & 123 & 73 & 45 & 36 & 31 & - & - & - \\
\hline 30 & 66 & 54 & 36 & 39 & 46 & 52 & 48 & 51 \\
\hline 21 & 58 & 44 & 35 & 31 & - & - & - & - \\
\hline 33 & 103 & 67 & 51 & 52 & 58 & 49 & 63 & 58 \\
\hline 31 & 103 & 52 & 31 & 23 & 37 & 34 & 33 & 41 \\
\hline 33 & 87 & 48 & 33 & - & - & - & - & - \\
\hline 37 & 98 & 67 & 54 & 46 & 39 & 45 & 50 & 49 \\
\hline Mean & 91 & 60 & 44 & 42 & 46 & 50 & 58 & 56 \\
\hline SEM & 5 & 3 & 3 & 3 & 4 & 5 & .7 & 6 \\
\hline
\end{tabular}


INTRAVENOUS INSULIN TOLERANCE TEST

$$
\text { Weanling rats - Blood glucose mg\% }
$$

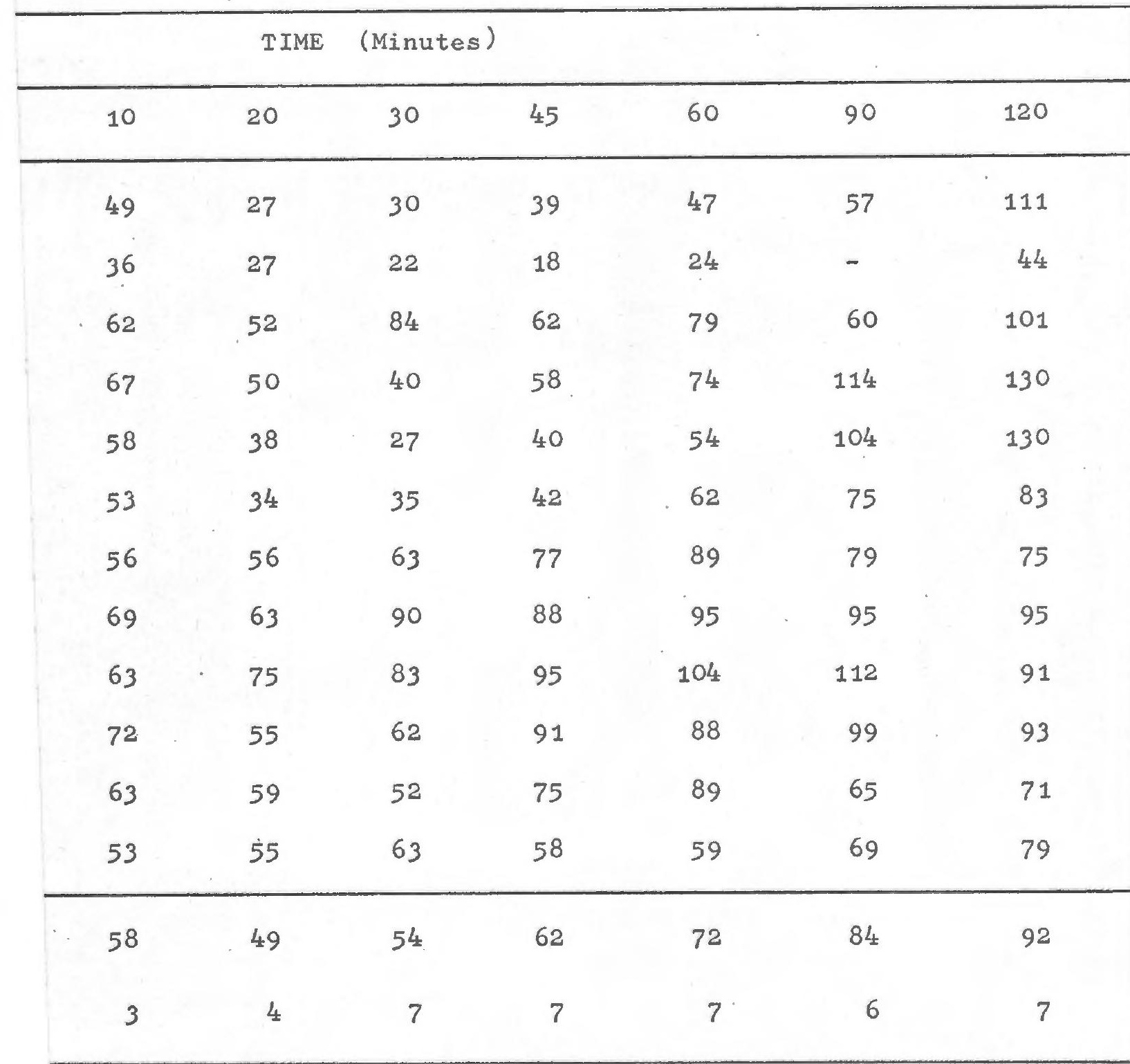




\section{GLUCOSE DISAPPEARANCE RATE FROM THE GUT (Dis Rate) \\ ( $g /$ hour $/ 100 \mathrm{~g}$ body weight)}

1. Rats killed 15 minutes after oral glucose load

\begin{tabular}{|c|c|c|c|c|c|}
\hline \multicolumn{2}{|c|}{$20 \%$ Protein diet } & \multicolumn{2}{|c|}{$4 \%$ Protein diet } & \multicolumn{2}{|c|}{ Weanling rats } \\
\hline $\begin{array}{c}\text { Rat } \\
\text { Weight } \\
\dot{g}\end{array}$ & Dis Rate & $\begin{array}{c}\text { Rat } \\
\text { Weight } \\
g\end{array}$ & Dis Rate & $\begin{array}{c}\text { Rat } \\
\text { Weight } \\
\text { g }\end{array}$ & Dis Rate \\
\hline 91 & 0.804 & 31 & 1.403 & 24 & 1. 148 \\
\hline 86 & 0.627 & 39 & 1.076 & 25 & 0.968 \\
\hline 103 & 0.334 & 26 & 0.934 & 28 & 1.159 \\
\hline 75 & 0.660 & 29 & 0.931 & 29 & 1.076 \\
\hline 70 & 0.724 & 30 & 0.660 & 29 & 0.519 \\
\hline 71 & 0.682 & 24 & 0.697 & 25 & 0.901 \\
\hline Mean & 0.639 & & 0.950 & & 0.962 \\
\hline SEM & \pm 0.066 & & \pm 0.111 & & \pm 0.098 \\
\hline
\end{tabular}

2. Rats killed 30 minutes after oral glucose load

\begin{tabular}{|c|c|c|c|c|c|}
\hline 75 & 0.526 & 26 & 0.782 & 28 & 0.640 \\
\hline & 0.401 & 31 & 0.602 & 24 & 0.692 \\
\hline & 0.358 & 25 & 0.640 & 25 & 0.646 \\
\hline & 0.492 & 28 & 0.684 & 25 & 0.548 \\
\hline 68 & 0.343 & 25 & 0.667 & 24 & 0.425 \\
\hline Mean & 0.424 & & 0.675 & & 0.590 \\
\hline SEM & \pm 0.036 & & \pm 0.030 & & \pm 0.047 \\
\hline
\end{tabular}




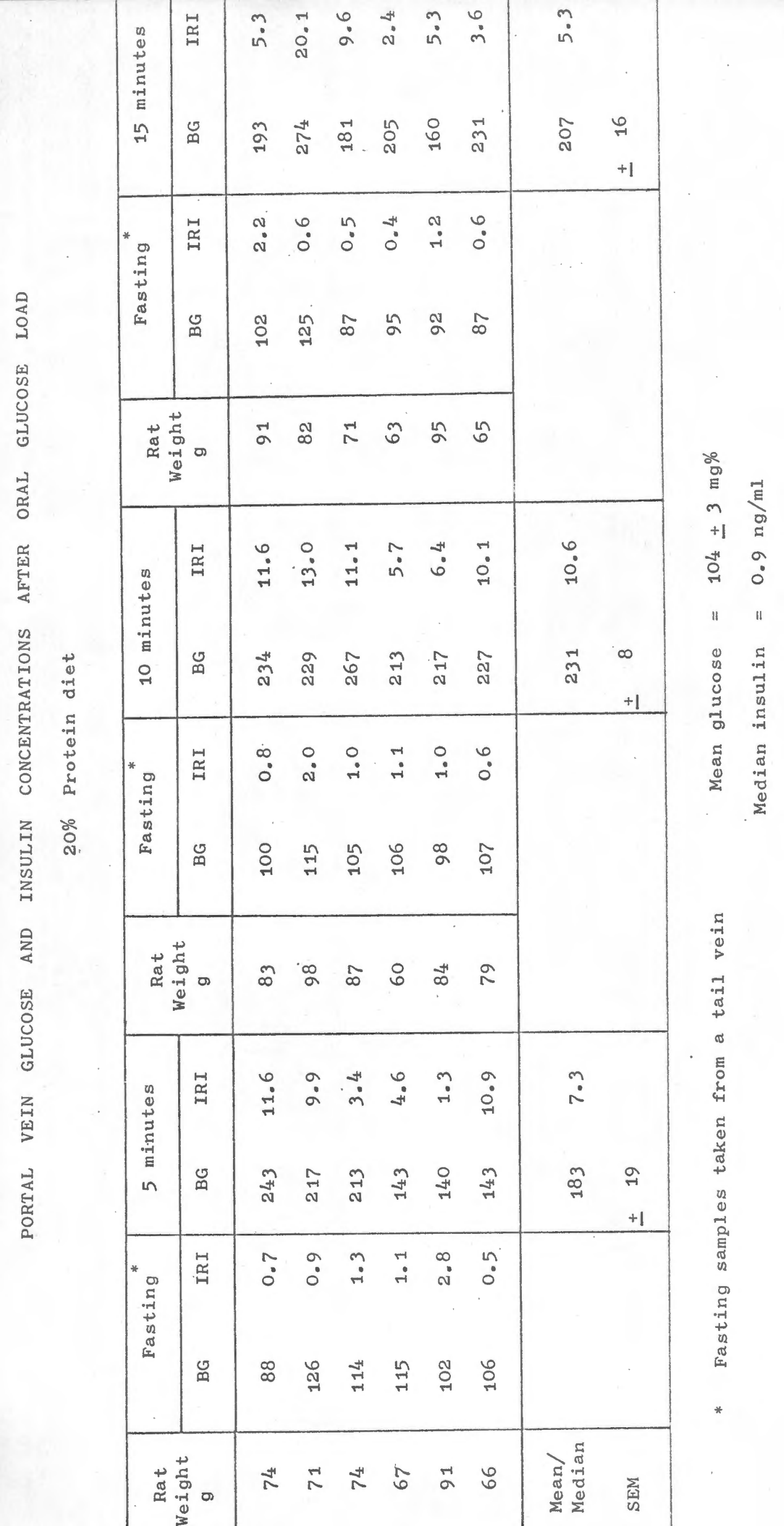




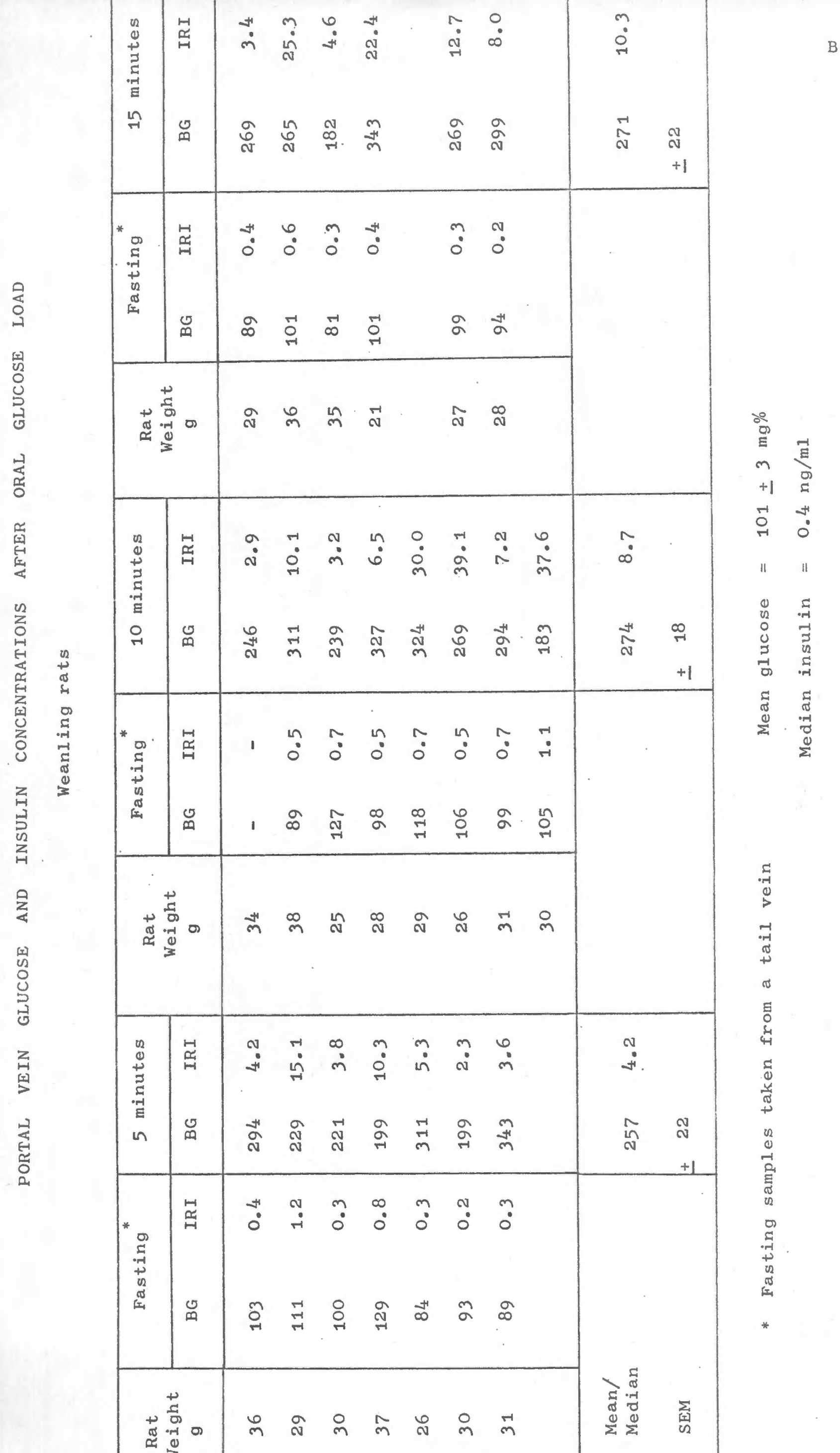




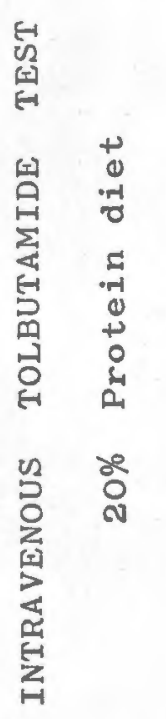

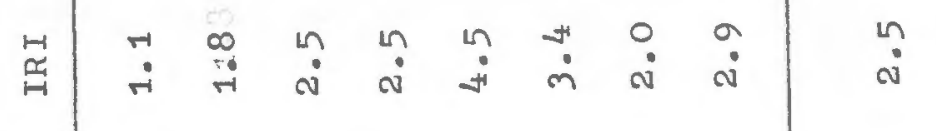

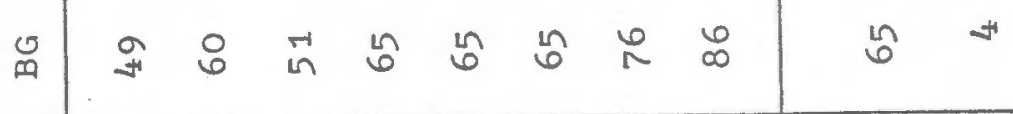

n

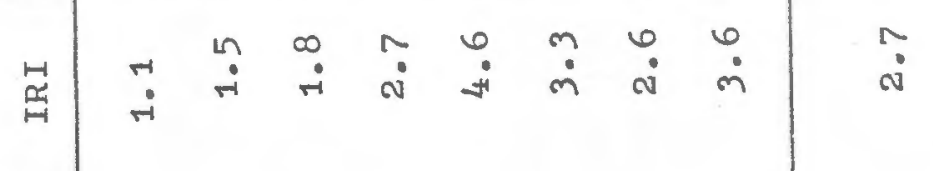

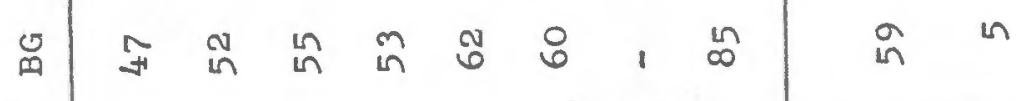

点

$\stackrel{\circ}{m}$

近

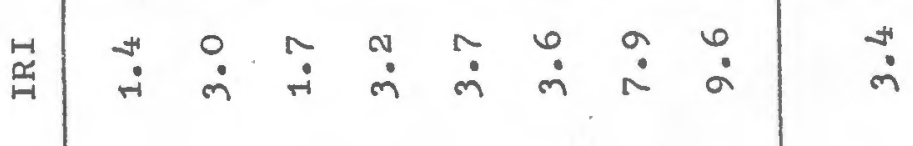

in

吕 in

$\rightarrow$

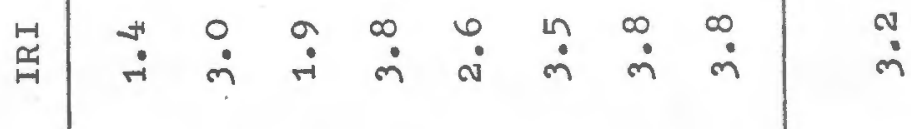

임 N

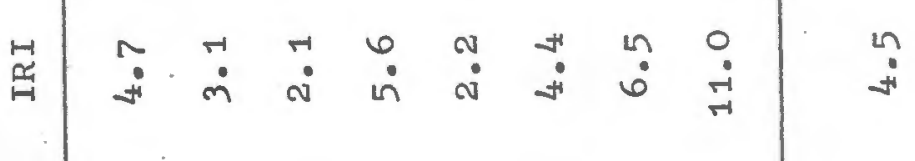

0

䒢

点

$m$

ए.

䍃

0

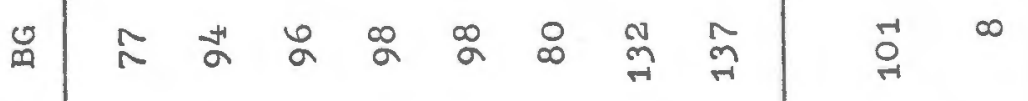

+

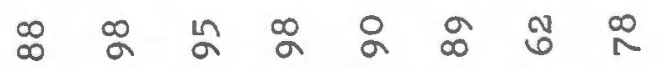

๕ุ

0
$\sum$ 


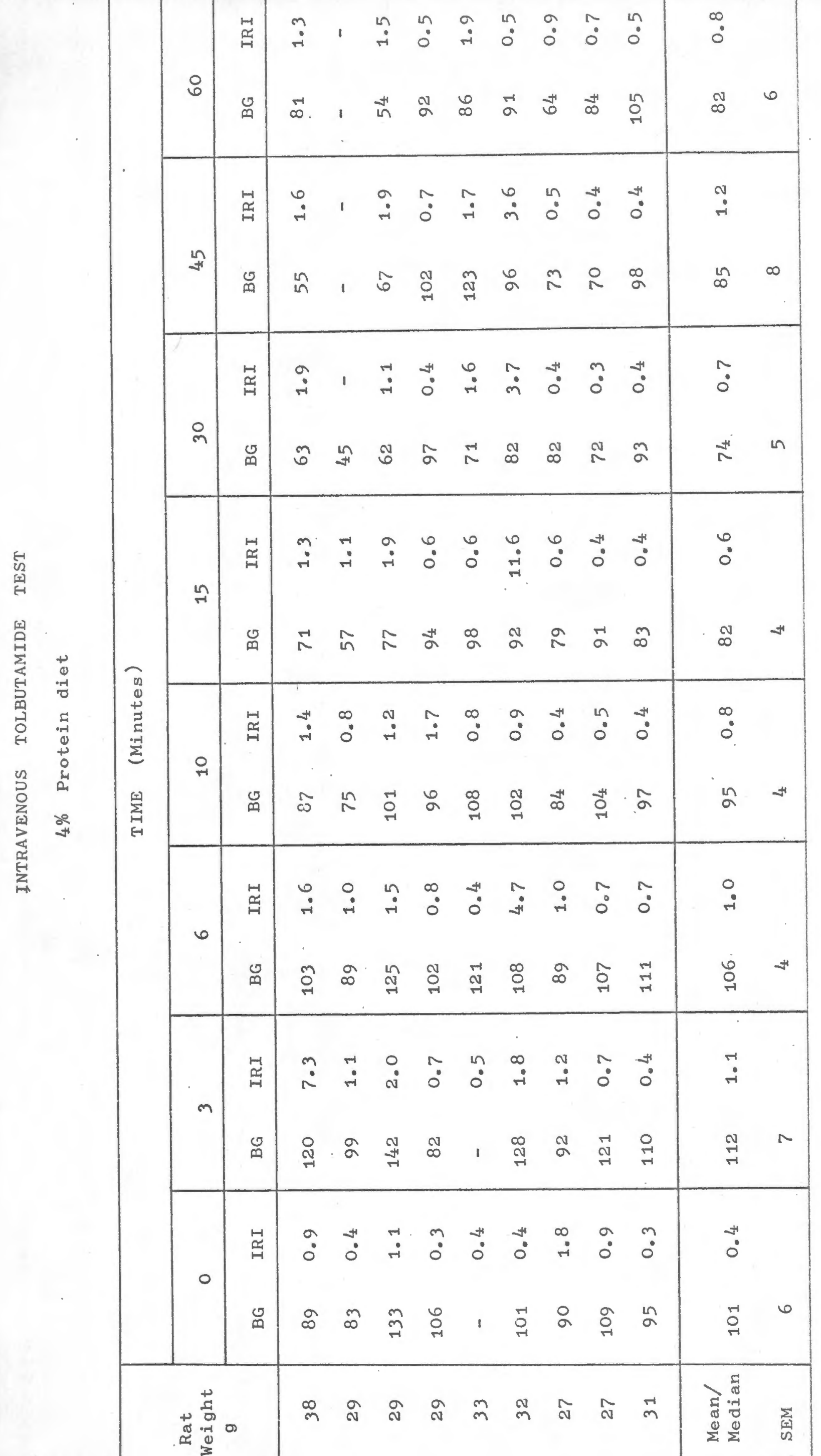




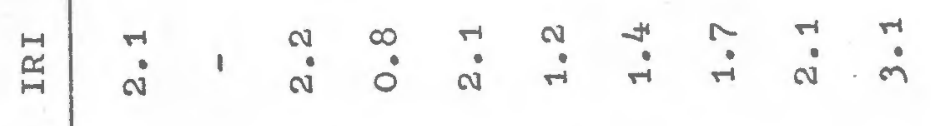

응

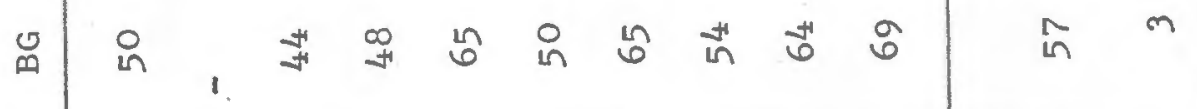

点

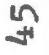

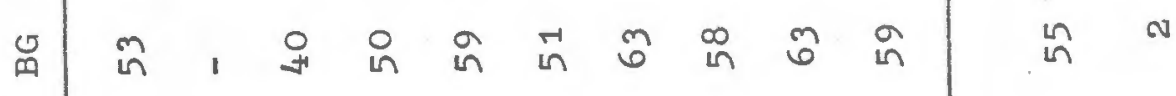

崫

은

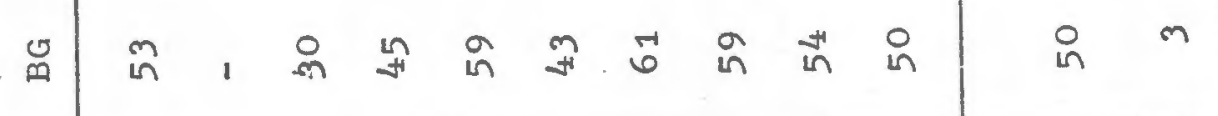

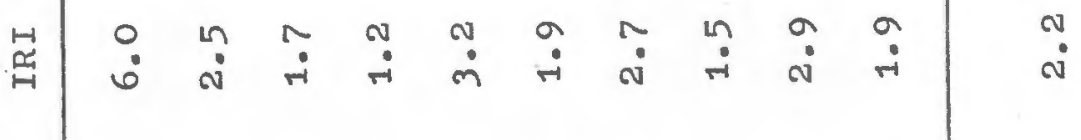

n

苞

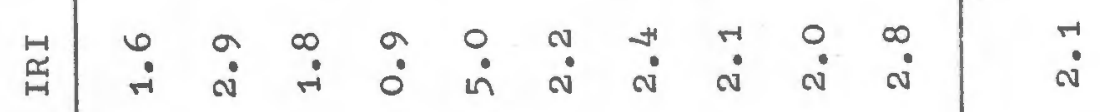

요

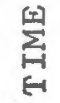

.

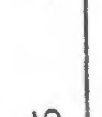

出

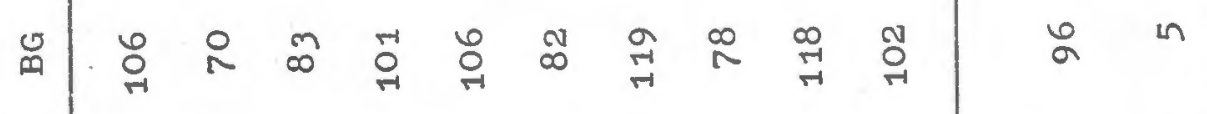

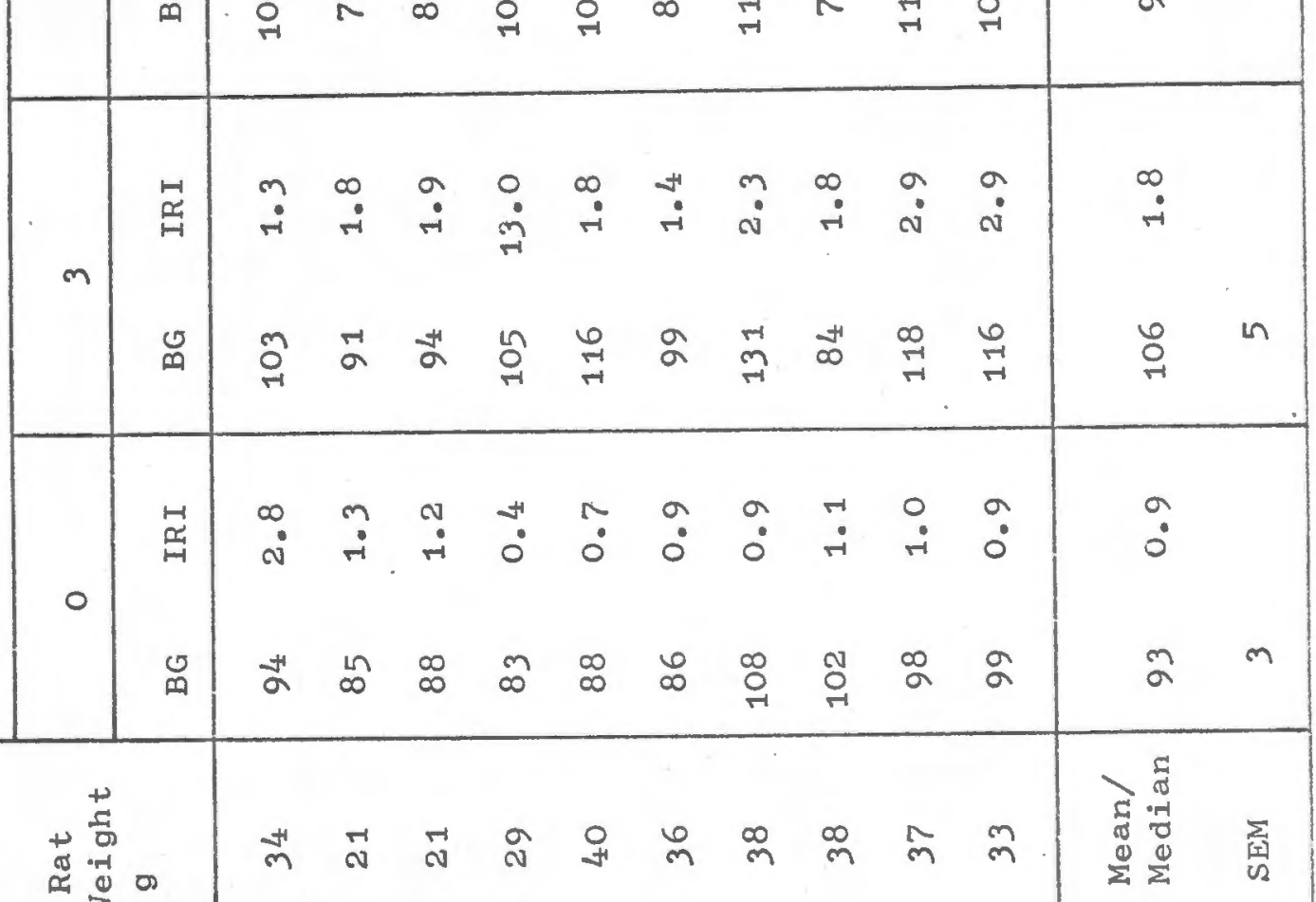


国

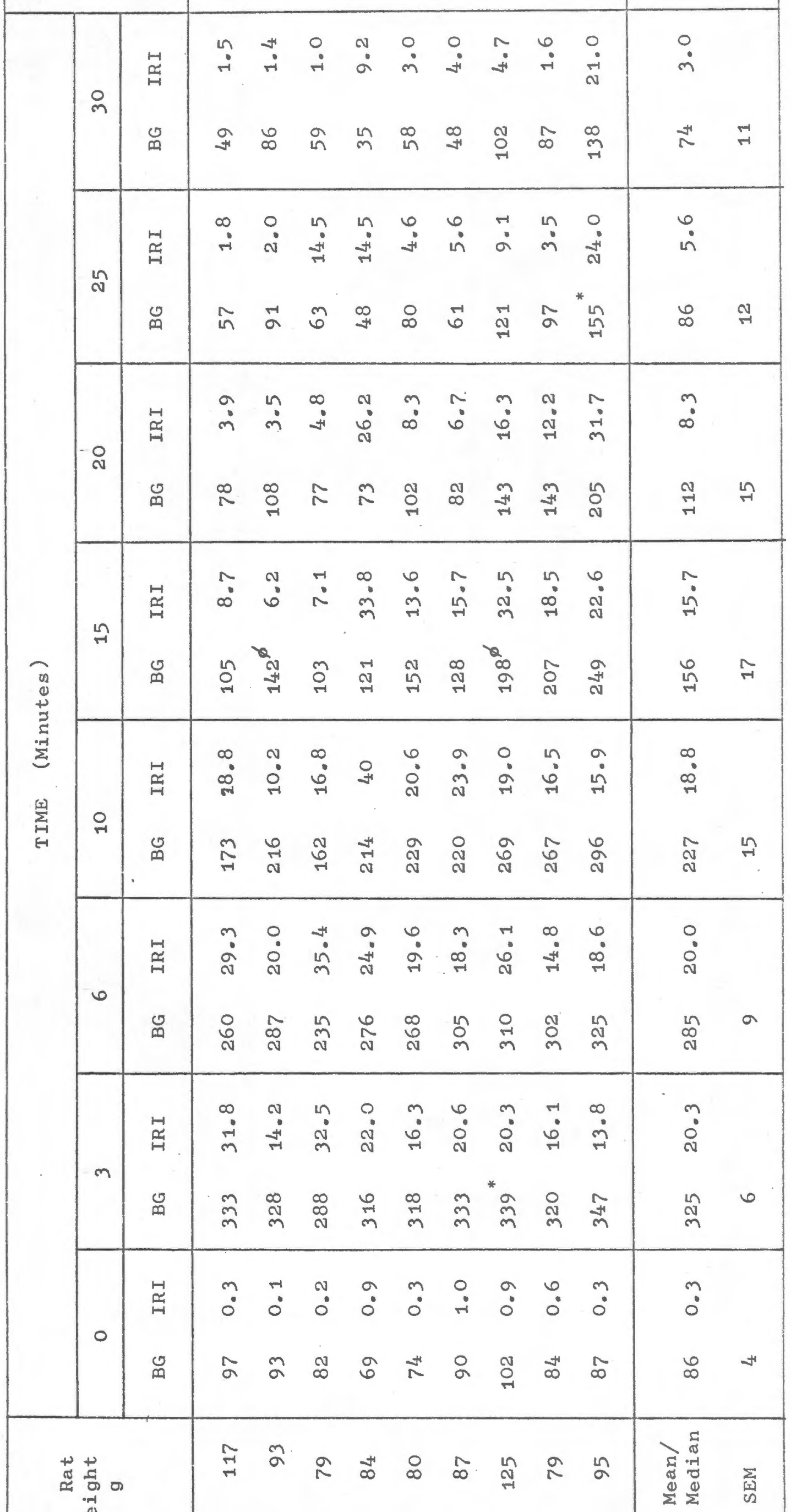




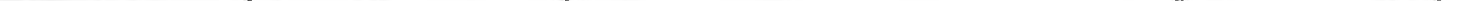




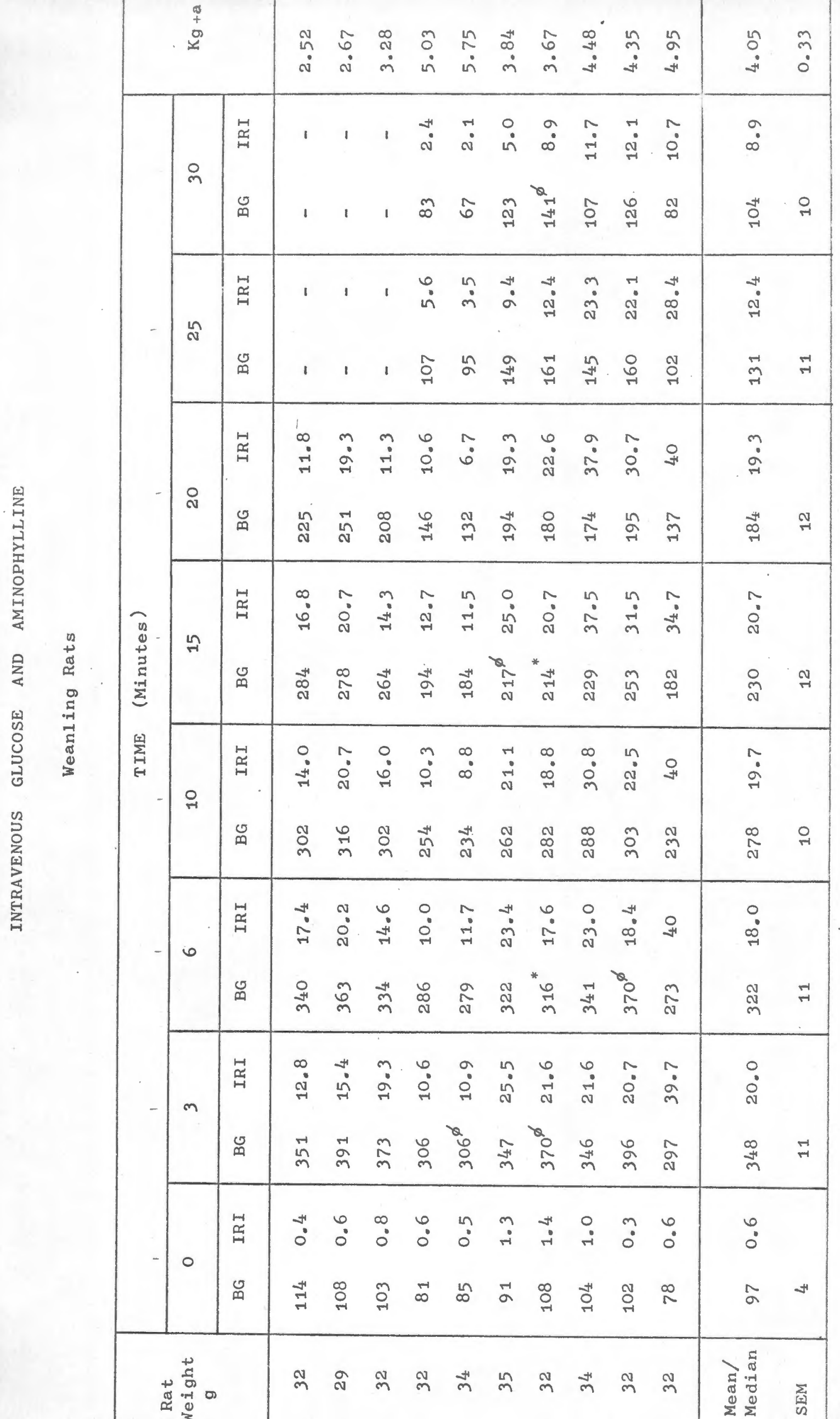




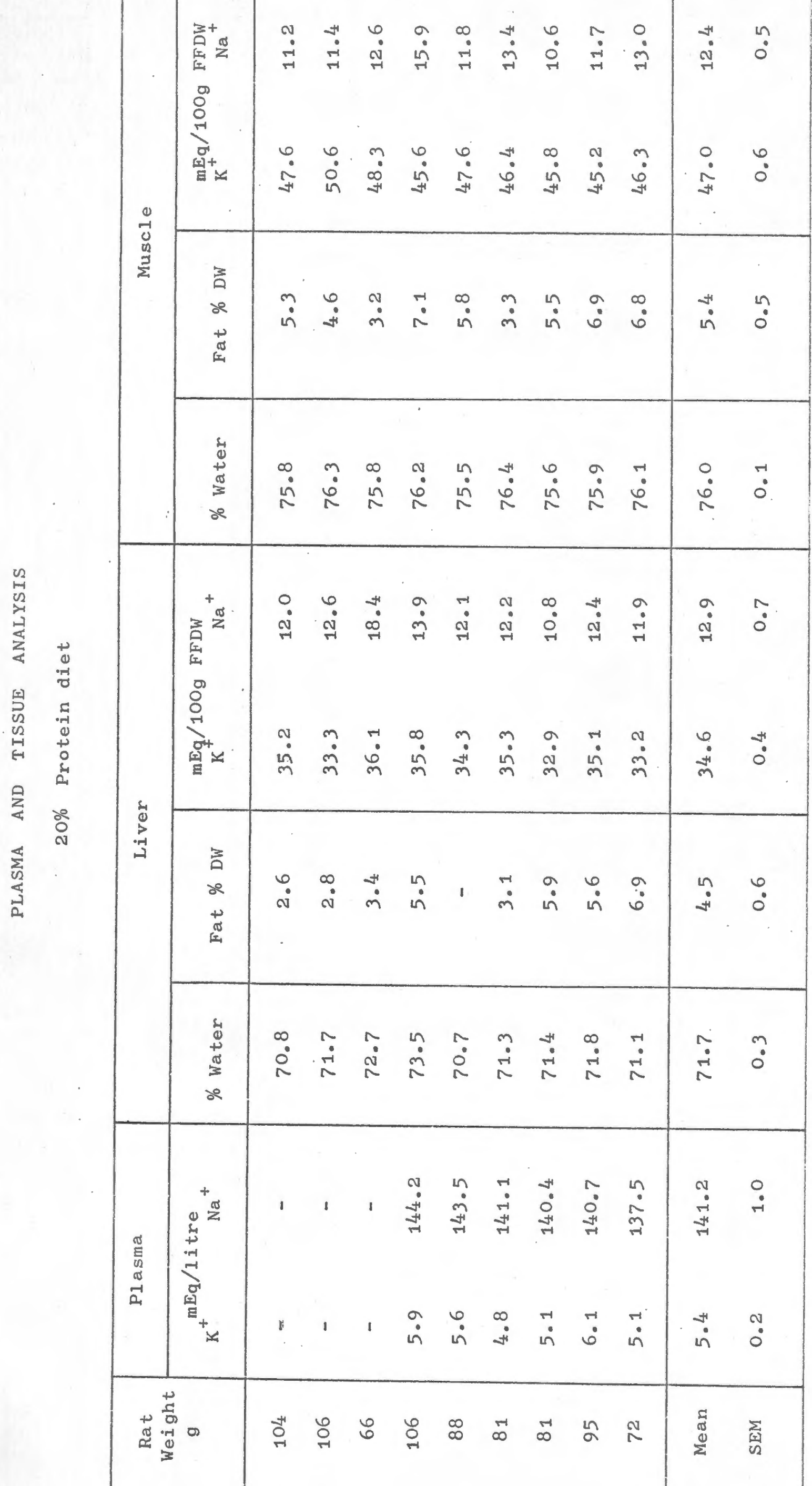




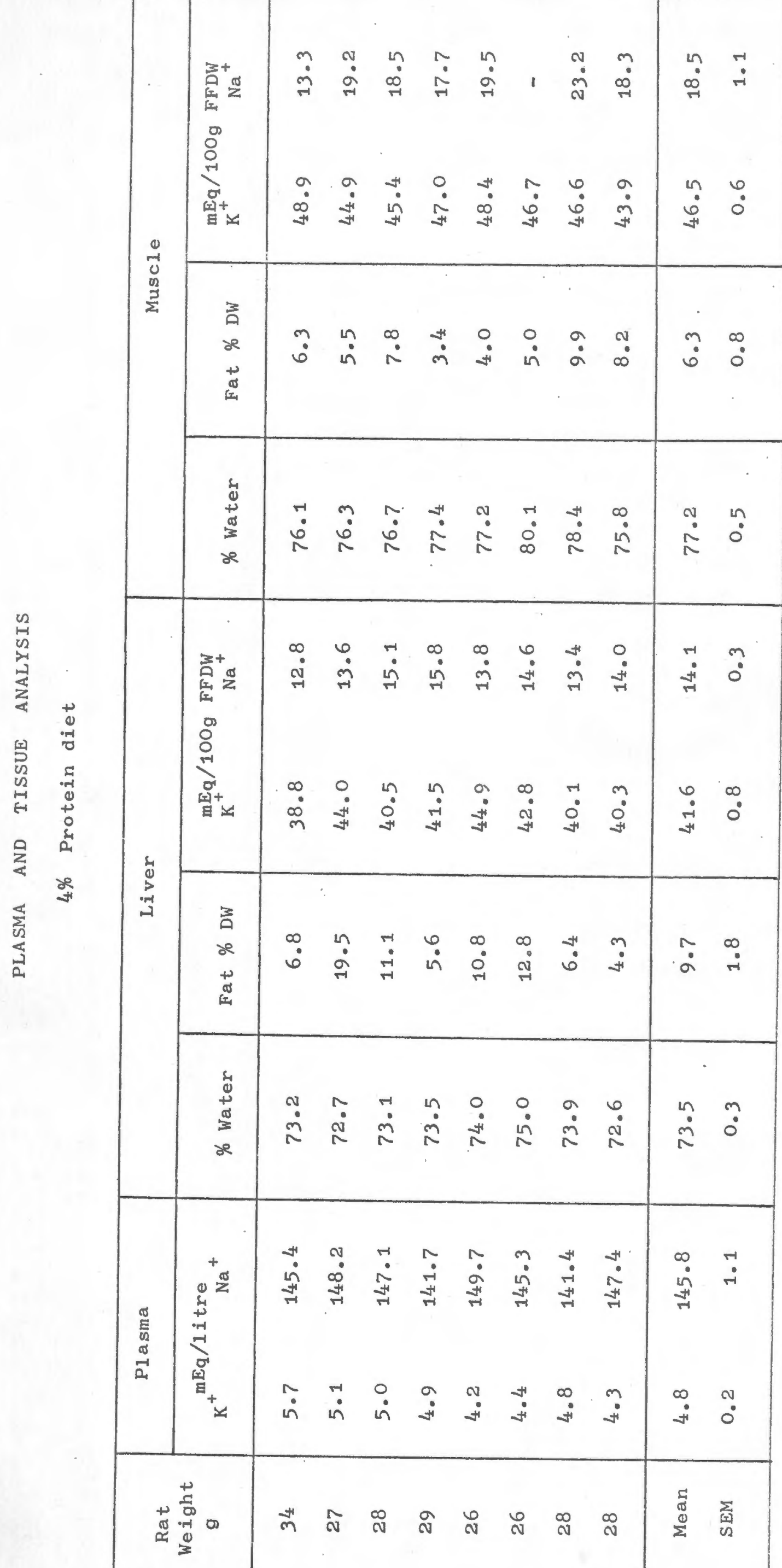




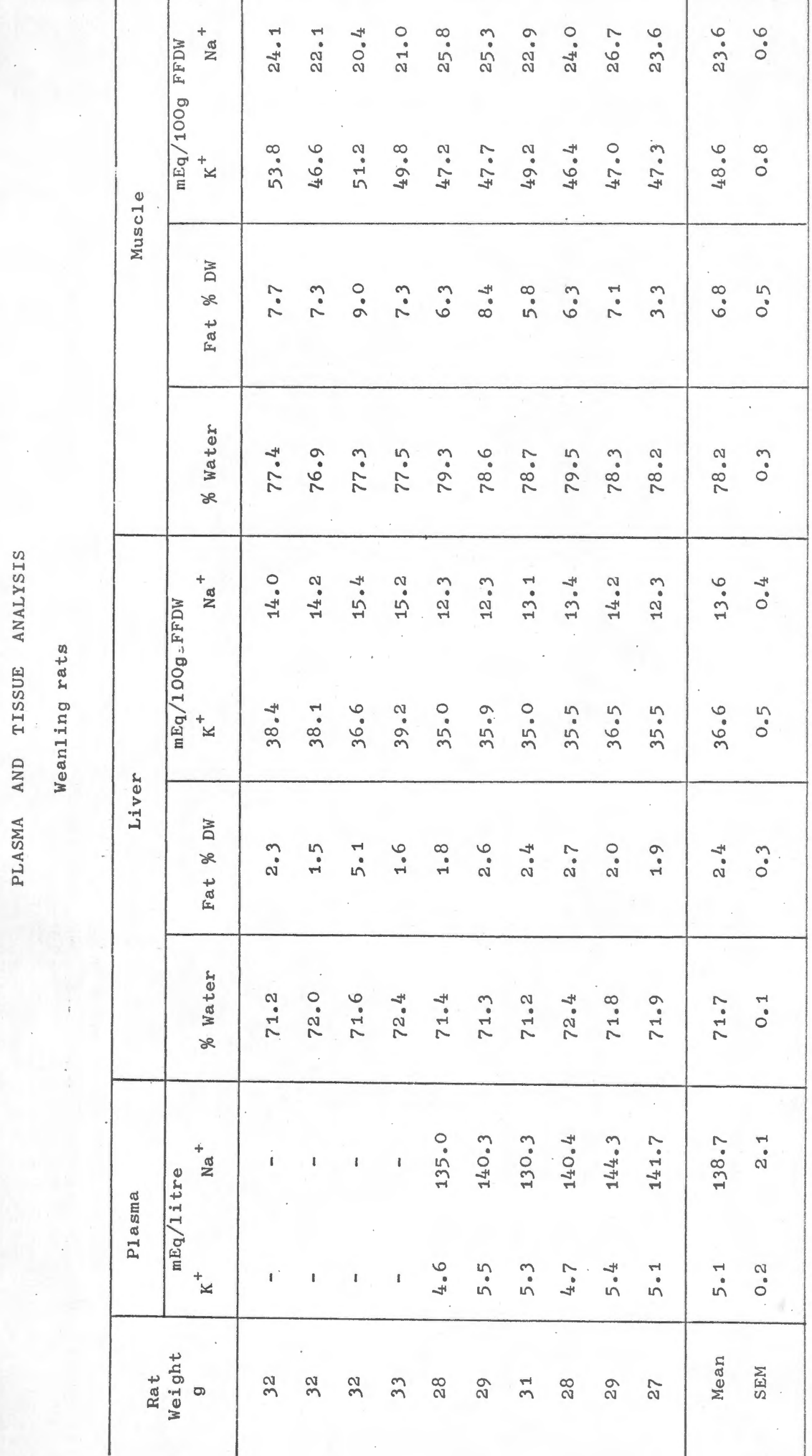




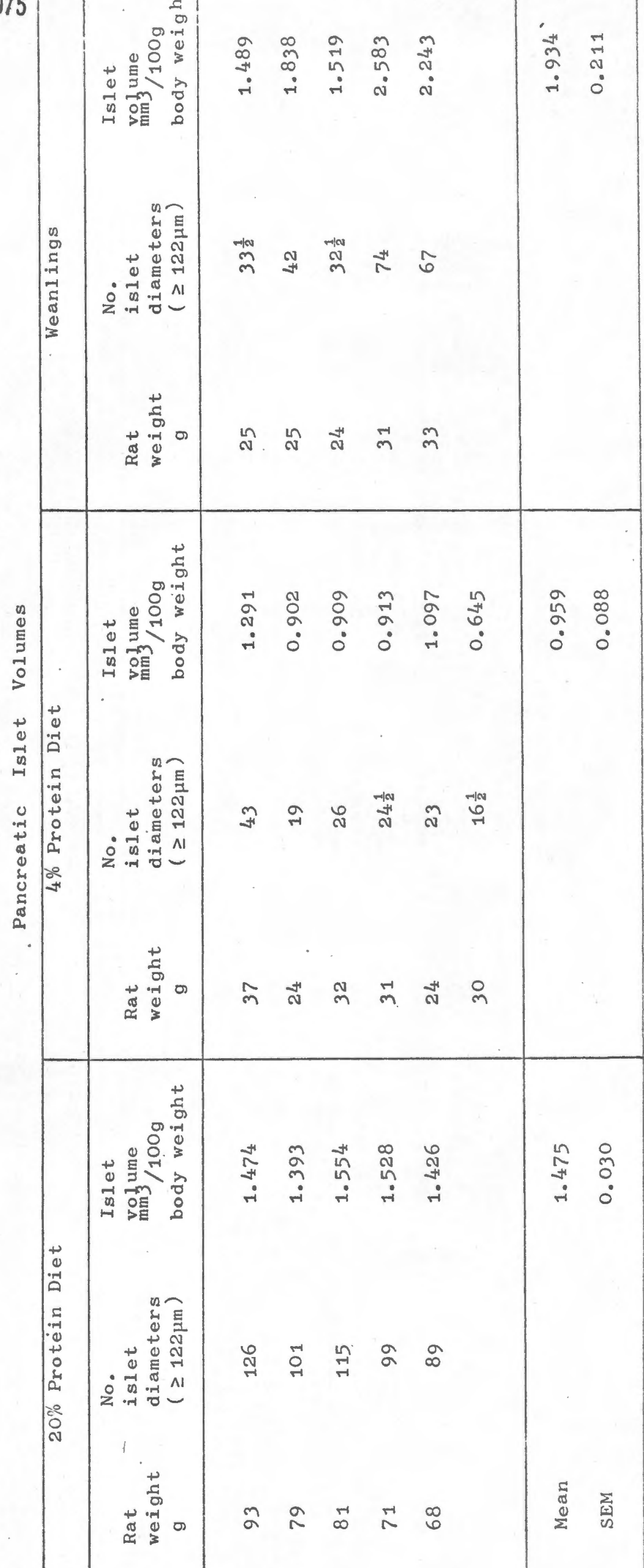




\section{A summary of the thesis}

Despite advances in modern technology and scientific knowledge, malnutrition (undernutrition) remains one of the major causes of death in the world. Those who survive the infective complications might still suffer permanent alsability as a result of infantile malnutrition.

An Impalrment of carbohydrate metabolism has long been recognised as an accompaniment of undernutrition in the child and has been regarded by some as the cause of diabetes mellitus in the adult. clinical investigators have ascribed the glucose intolerance of infantile proteincalorie malnutrition to diminished insulin release, or insulin resistance, or both. Regional genetic factors and local dietary habits, complicated by the presence of infection (which in itself causes glucose intolerance) have led to some conflicting reports.

To eliminate some of these variables, glucose tolerance and insulin release were investigated in rats fed a protein-calorie deficient diet. Weanling rats were allowed free access to a $4 \%$ protein diet supplemented with methionine, vitamins and minerals for 3 weeks.' They failed to gain weight and at the time of the investigation had developed hypoalbuminaemia and fatty infiltration of the liver. When compared to controls maintained on an isocaloric $20 \%$ protein diet, they showed the following 
abnormalities.

1) Markedly impaired intravenous glucose tolerance.

1i) Mildly impaired oral glucose tolerance.

111) Low fasting plasma insulin concentrations.

1v) Diminished insulin release following intravenous glucose, oral glucosè, intravenous tolbutamide and intravenous glucose + aminophylline.

v) Inability to correct.insulin induced hypoglycaemia.

vi) A decreased total pancreatic islet volume.

vi1) A reduction in the ratio of dense to pale beta granules in the islets of Langerhans.

Malnourished rats had a normal fasting blood sugar concentration and showed normal insulin sensitivity as assessed by the rate of fall of blood glucose concentration following the administration of exogenous Insulın.

It appeared that the glucose intolerance in the malnourished rat could be adequately explained by an impalred early insulin release. A reduction in the total pancreatic islet volume as well as abnormalities of the beta granule may partly account for this diminished Insulin release.

Two other possible causes of impaired insulin release were considered and later excluded.

A. Functional Immaturity of the pancreas was suggested by the fact that weanling rats were also shown to have 
intravenous glucose intolerance with diminished insulin release following intravenous glucose and intravenous tolbutamide. Weanling rats however showed a normal insulin response to oral glucose and to intravenous glucose + aminophylline.

B. Potassium depletion which is found commonly in malnourished children has been regarded as a cause of thetr glucose intolerance and impaired insulin release. The malnourished rats showed no evidence of potassium deftciency as assessed by their serum and muscle potassium concentrations.

The anomaly of mild oral glucose intolerance with marked intravenous glucose intolerance in the face of a poor Insulin response to both stimuli was investigated In the malnourished rats. Others have attributed normal oral glucose tolerance in malnourished animals to an impalrment of glucose absorption. In fact the malnourlshed rats were shown to have a greater rate of glucose absorption than the $20 \%$ protein fed rats, but this was not accompanied by a higher rise in portal glucose concentrations after an oral glucose load. From this, and from the experimental work of others, it would appear that malnutrition caused an increase in the rate of glucose utllisation by the gut wall. This would account for the comparatively mild oral glucose intolerance despite the diminished insulin release in malnourished rats. From these studies it has not been possible to determine 
whether malnutrition leads to a permanent impairment of insulin release, since protein refeeding was not attempted. Nevertheless a proteir-calorie deficient diet in rats produced some of the pathological changes described in human protein-calorie malnutrition and led to glucose intolerance and diminished insulin release in the absence of infection and potassium deficiency. 